\title{
Molecularly Imprinted Solid Phase Extraction - Pulsed Elution and Capillary Electrophoresis for Rapid Screening of Metformin in Human Plasma
}

\author{
by
}

\section{Sherry Yu Feng, B.Eng.}

A Thesis submitted to the Faculty of Graduate Studies and Research in Partial Fulfillment of the Requirement for the Degree of Master of Science

\author{
Department of Chemistry \\ Carleton University \\ Ottawa, Ontario
}

\author{
May 2004 \\ (C) Copyright \\ Sherry Yu Feng
}




$\begin{array}{ll}\begin{array}{l}\text { Library and } \\ \text { Archives Canada }\end{array} & \begin{array}{l}\text { Bibliothèque et } \\ \text { Archives Canada }\end{array} \\ \begin{array}{l}\text { Published Heritage } \\ \text { Branch }\end{array} & \begin{array}{l}\text { Direction du } \\ \text { Patrimoine de l'édition }\end{array} \\ \begin{array}{l}\text { 395 Wellington Street } \\ \text { Ottawa ON K1A ON4 }\end{array} & \begin{array}{l}\text { 395, rue Wellington } \\ \text { Ottawa ON K1A ON4 } \\ \text { Canada }\end{array}\end{array}$

Your file Votre référence

ISBN: 0-494-00778-8

Ourfile Notre référence

ISBN: 0-494-00778-8

NOTICE:

The author has granted a nonexclusive license allowing Library and Archives Canada to reproduce, publish, archive, preserve, conserve, communicate to the public by telecommunication or on the Internet, loan, distribute and sell theses worldwide, for commercial or noncommercial purposes, in microform, paper, electronic and/or any other formats.

The author retains copyright ownership and moral rights in this thesis. Neither the thesis nor substantial extracts from it may be printed or otherwise reproduced without the author's permission.
AVIS:

L'auteur a accordé une licence non exclusive permettant à la Bibliothèque et Archives Canada de reproduire, publier, archiver, sauvegarder, conserver, transmettre au public par télécommunication ou par l'Internet, prêter, distribuer et vendre des thèses partout dans le monde, à des fins commerciales ou autres, sur support microforme, papier, électronique et/ou autres formats.

L'auteur conserve la propriété du droit d'auteur et des droits moraux qui protège cette thèse. $\mathrm{Ni}$ la thèse ni des extraits substantiels de celle-ci ne doivent être imprimés ou autrement reproduits sans son autorisation.
In compliance with the Canadian

Privacy Act some supporting forms may have been removed from this thesis.

While these forms may be included in the document page count, their removal does not represent any loss of content from the thesis.
Conformément à la loi canadienne sur la protection de la vie privée, quelques formulaires secondaires ont été enlevés de cette thèse.

Bien que ces formulaires aient inclus dans la pagination, il n'y aura aucun contenu manquant.

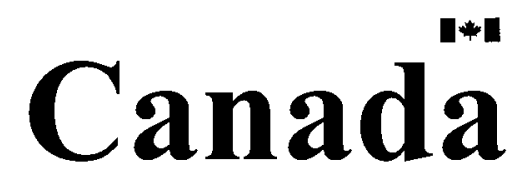




\section{ABSTRACT}

A new molecularly imprinted polymer (MIP) was specifically synthesized as a smart material for the recognition of metformin in solid-phase extraction. Particles of this MIP were packed into a stainless-steel tube $(50 \mathrm{~mm} \times 0.8 \mathrm{~mm}$ i.d.) equipped with an exit frit. This micro-column was employed in the development of a molecularly imprinted solidphase extraction (MISPE) method for metformin determination. The MISPE instrumentation consisted of a micrometer pump, an injector valve equipped with a $20-\mu \mathrm{l}$ sample loop, a UV detector, and an integrator. With $\mathrm{CH}_{3} \mathrm{CN}$ as the mobile phase flowing at $0.5 \mathrm{ml} / \mathrm{min}$, a total binding capacity of $1600 \mathrm{ng}$ metformin was determined for the $20 \mathrm{mg}$ of MIP particles. A $95 \pm 2 \%$ binding could be achieved for $1200 \mathrm{ng}$ of metformin from one injection of a phosphate-buffered sample solution ( $\mathrm{pH} 2.5)$. Methanol $+3 \%$ trifluoroacetic acid was good for quantitative pulsed elution (PE) of the bound metformin. The MISPE-PE method, with UV detection at $240 \mathrm{~nm}$, afforded a detection limit of $16 \mathrm{ng}$ (or $0.8 \mu \mathrm{g} / \mathrm{ml}$ ) for metformin. However, the micro-column interacted indiscriminately with phenformin, a structural analogue, to attain $49 \pm 2 \%$ binding. A systematic investigation of binding selectivity was conducted with respect to sample solvent, matrix, $\mathrm{pH}$, surfactant effects and buffer compositions. An intermediate step of differential pulsed elution used acetonitrile with $5 \%$ picric acid to remove phenformin and other structural analogues. A final pulsed elution of metformin for direct UV detection was achieved using 3\% trifluoroacetic acid in methanol. Each MISPE-DPE-FPE analysis required less than $5 \mathrm{~min}$ to complete. Application of this MISPE-DPE-FPE method, is demonstrated for accurate determination 
of metformin in human plasma over a linear range of $0.1 \mu \mathrm{g} / \mathrm{mL}$ to $10 \mu \mathrm{g} / \mathrm{mL}$, which represented the typical therapeutic range of metformin in patients.

In addition, a SPE-CE method was developed for the determination of metformin and phenformin in human plasma. Coupled at line to capillary electrophoresis (CE), solid phase extraction (SPE) using a C18 cartridge was employed to remove most of the water and proteins from the plasma sample. Analyte detectability was increased due to trace enrichment during the SPE process. Elution of metformin and phenformin was achieved with methanol $+3 \%$ acetic acid. CE analysis was performed using a non-aqueous buffer, acetonitrile $+20 \mathrm{mM}$ ammonium acetate $+5 \%$ acetic acid, which afforded rapid separation of metformin from phenformin within $3 \mathrm{~min}$. The present SPE-CE method, with an electrokinetic injection time of $6 \mathrm{~s}$ and UV detection at $240 \mathrm{~nm}$, was useful for monitoring down to $1 \mu \mathrm{g} / \mathrm{mL}$ of metformin and phenformin in human plasma. When the electrokinetic injection time was increased to $36 \mathrm{~s}$, the detection limits were improved to 12 $\mathrm{ng} / \mathrm{mL}$ for metformin and $6 \mathrm{ng} / \mathrm{mL}$ for phenformin. 


\section{ACKNOWLEDGEMENTS}

I would like to express my gratitude to all those who gave me the possibility to complete this thesis. First of all, my thesis supervisor, Dr. Edward P.C. Lai really does deserve the greatest of thanks, since he has provided me with incredible support, encouragement, guidance and caring from my first day at Carleton University. His overly enthusiasm and integral view on research, has made a deep impression on me. He could not even realize how much I have learned from him, in both the writing of this thesis and the work which preceded it.

I am especially grateful to Dr. Ewa Dabek from Environment Canada for her expert suggestion and active cooperation during this study. My special thanks to Dr. Susan Sadeghi, who is a visiting professor in our lab, for having shared her extended experience and knowledge with me in the selection of organic acid, without which this thesis could not be produced in the present form. To our group and my friends, thanks for providing a positive, high-spirited and enjoyable environment, sharing me their knowledge in different background.

A special thank you goes to my family for their endless love, continued support and encouragement. Thank you everyone. 


\section{Table of Contents}

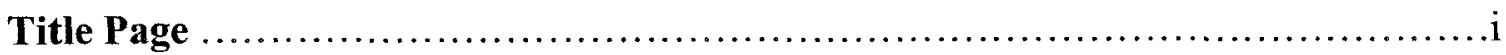

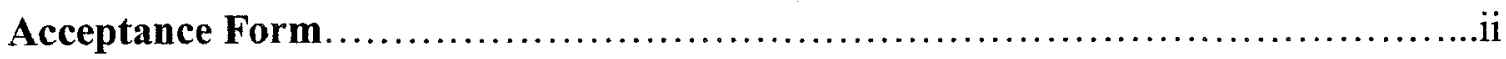

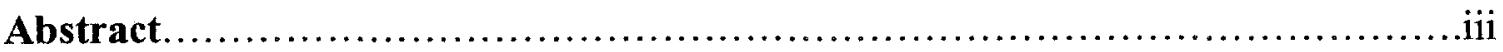

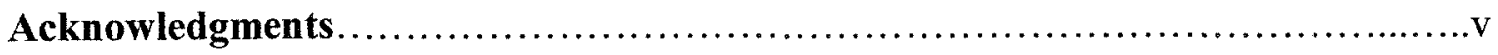

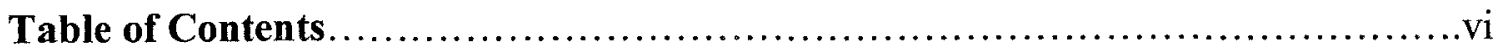

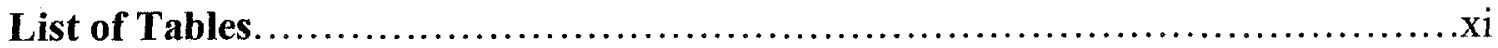

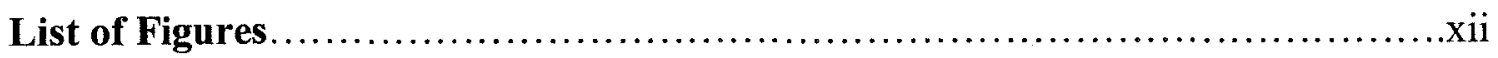

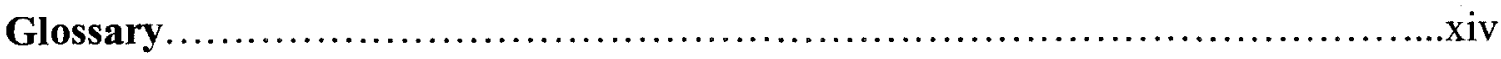

\section{Chapter I Introduction}

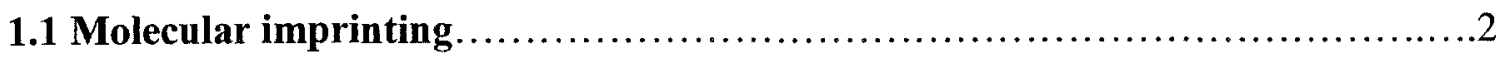

1.1.1 Historical development of molecular imprinting $\ldots \ldots \ldots \ldots \ldots \ldots \ldots \ldots \ldots . .2$

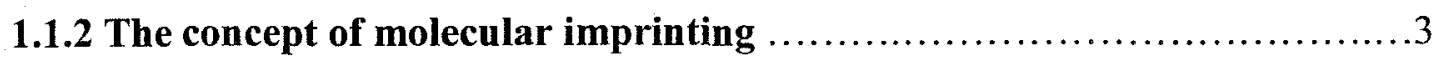

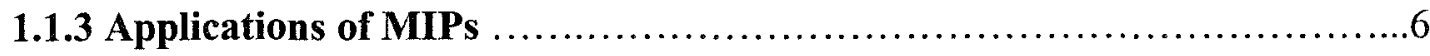

1.1.4 Molecularly imprinted solid phase extraction (MISPE) $\ldots \ldots \ldots \ldots \ldots \ldots \ldots 7$

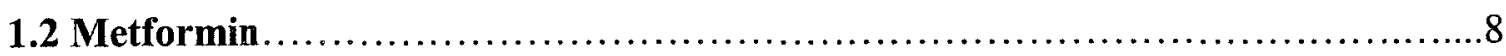

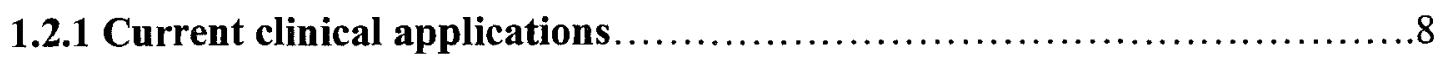

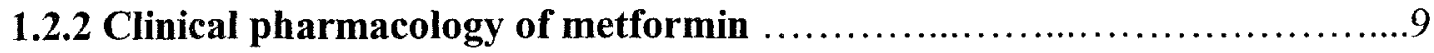

1.2.3 Adverse effects and toxicity of metformin ........................... 10

1.2.4 Current analytical methods for metformin $\ldots \ldots \ldots \ldots \ldots \ldots \ldots \ldots \ldots \ldots \ldots$ 


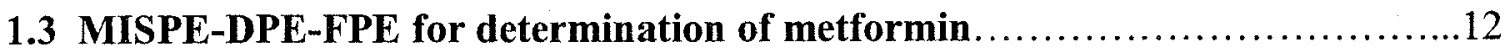

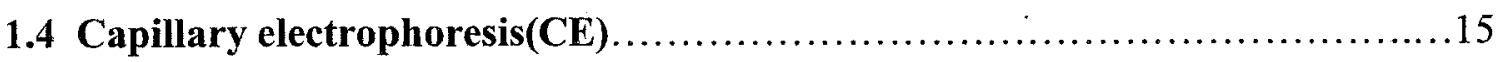

1.4.1 General introduction of CE.................................... 15

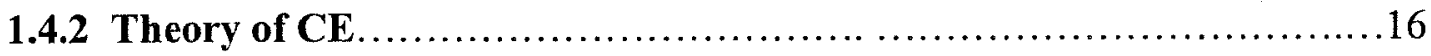

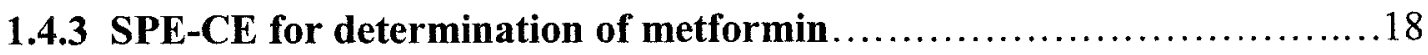

1.5 Objectives.............................................................

\section{Chapter II Experimental}

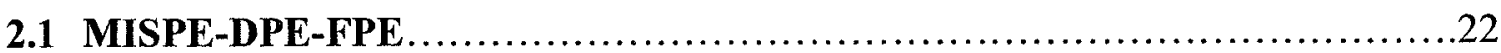

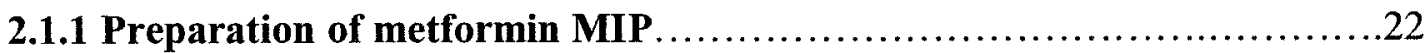

2.1.1.1 Reagents and materials ......................................22

2.1.1.2 Metformin MIP synthesis ..................................23

2.1.1.3 MIP micro-column packing ...............................23

2.1.1.4 Removal of template molecule from metformin MIP............24

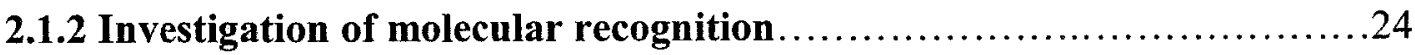

2.1.2.1 MISPE-PE instrumentation .................................24

2.1.2.2 \% Binding measurements...................................25

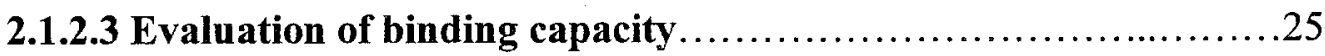

2.1.2.4 Effect of sample solvent on $\%$ binding ......................25

2.1.2.5 Effect of buffer $\mathbf{p H}$ in sample solution on \% binding .............26

2.1.2.6 Effect of phosphate buffer on $\%$ binding....................26

2.1.2.7 Effect of metformin concentration on \% binding...............26

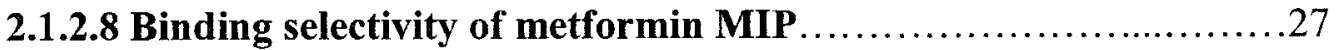




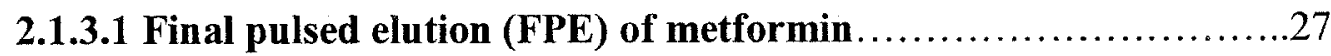

2.1.3.2 Differential pulsed elution (DPE) of phenformin ................28

2.1.3.3 Evaluation of organic acids for DPE effectiveness....................28

2.1.3.4 DPE with trifluoroacetic acid (TFA) ..................................28

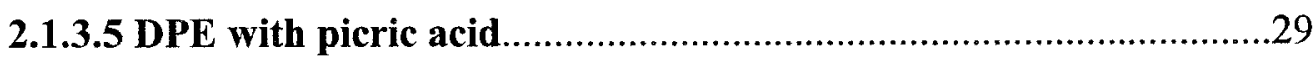

2.1.3.6 Standard calibration curve for MISPE-PE determination of metformin..................................................29

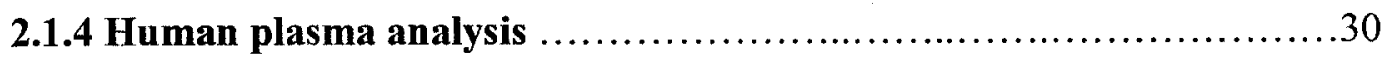

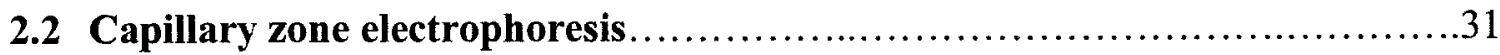

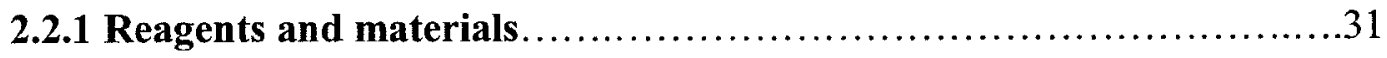

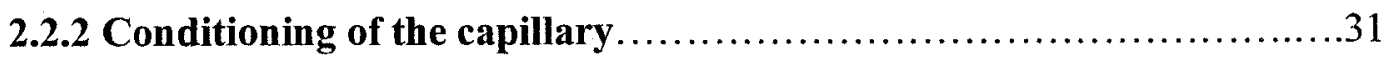

2.2.3 Capillary zone electrophoresis.................................. 31

2.2.4 Effect on buffer composition..................................32

2.2.5 Sample Matrix Effect on CE-UV Peak Area........................32

2.2.6 Human plasma analysis .................................... 33

\section{Chapter III Results and Discussion}

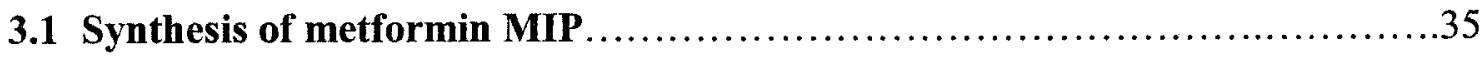

3.1.1 Preparation of metformin MIP .................................. 35

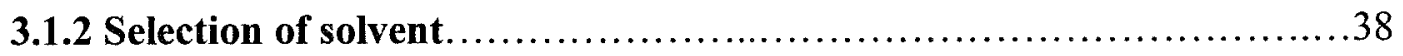

3.1.3 Choice of cross-linker.......................................... 39

3.1.4 Removal of template molecule from metformin MIP.................40 
3.2 Investigation of molecular recognition.

3.2.1\% Binding measurements........................................41

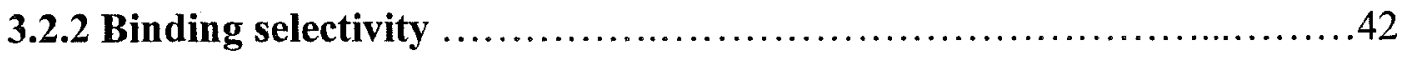

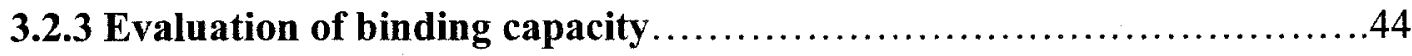

3.2.4 Effect of metformin concentration on $\%$ binding .....................47

3.2.5 Effect of sample solvent on $\%$ binding.............................48

3.2.6 Effect of buffer $\mathrm{pH}$ in sample solution on \% binding..................49

3.3 Molecularly imprinted solid phase extraction.............................54

3.3.1 Molecularly imprinted solid-phase extraction ........................54

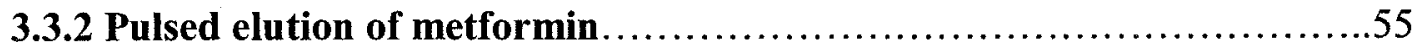

3.3.3 Standard calibration curve for MISPE-PE determination

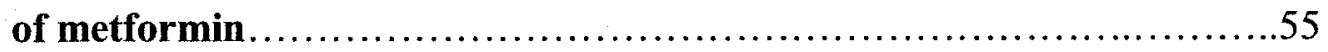

3.3.4 Elimination of non-specific binding for phenformin $\ldots \ldots \ldots \ldots \ldots \ldots \ldots . .57$

3.3.4.1 Effectiveness of surfactants...............................57

3.3.4.2 Differential pulsed elution (DPE) with organic acids.............61

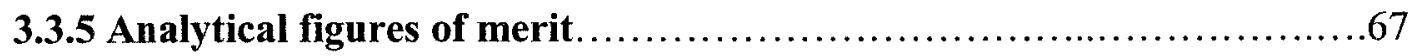

3.3.6 Human plasma analysis.......................................67

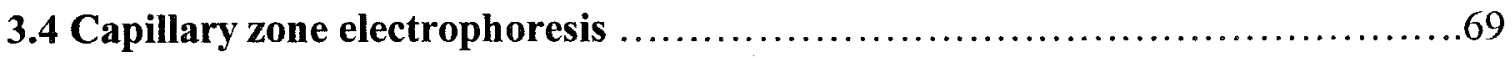

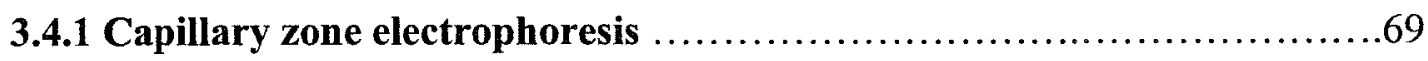

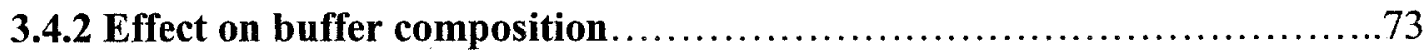

3.4.3 Sample Matrix Effects on CE-UV Peak Areas......................... 73

3.4.4 Human plasma analysis........................................ 77

3.4.5 Linear dynamic range and detection limit..........................79

3.4.6 Internal standard method ................................................. 81 


\section{Chapter IV Conclusion}

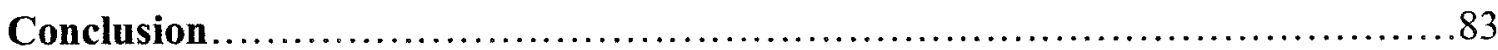

\section{References}

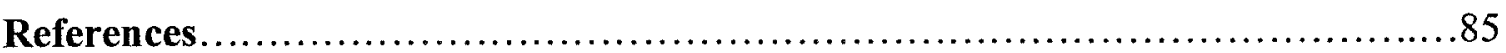




\section{LIST OF TABLES}

Table

Page

1 Comparison of binding capacity and binding constant values

2 Distances between $=\mathrm{CO}$ oxygen $\left(\right.$ or $-\mathrm{NH}_{2}$ nitrogen $)$ and

-OH hydrogen calculated for the MIP and different buffer acids and base

3 Effectiveness of using surfactant solutions for DPE after loading $60 \mu \mathrm{g} / \mathrm{ml}$ phenformin in $\mathrm{CH}_{3} \mathrm{CN}-50 \mathrm{mM}$ phosphate buffer $(\mathrm{pH}$ 7.0) $(9: 1 \mathrm{v} / \mathrm{v})$

4 Effectiveness of adding surfactants into sample solution of $60 \mu \mathrm{g} / \mathrm{ml}$ phenformin in $\mathrm{CH}_{3} \mathrm{CN}-50 \mathrm{mM}$ phosphate buffer (pH 7) (9:1)

5 Effect of HMB, DTAB, TTAB and DDAB on \% binding of metformin and phenformin.

6 Evaluation of organic acids for DPE effectiveness

7 Summary of DPE solvents for various drug compounds bound onto five different MIP micro-columns 


\section{LIST OF FIGURES}

\section{Figure}

1 Scheme of the molecular imprinting process

2 Molecular structures of metformin, phenformin and glyburide

3 Schematic diagram of MISPE-DPE-FPE-UV system for on-line determination of metformin

Molecular structures of metformin, phenformin, TFMAA, TRIM, AIBN and TFA

Comparison of \% bindings for $60 \mu \mathrm{g} / \mathrm{mL}$ metformin and phenformin in acetonitrile, 9:1 acetonitrile/phosphate buffer ( $\mathrm{pH} 2.5,50 \mathrm{mM})$, and 9:1 acetonitrile/ phosphate buffer $(\mathrm{pH} 7.0,50 \mathrm{mM})$

Comparison of $\%$ bindings for $60 \mu \mathrm{g} / \mathrm{mL}$ metformin, phenformin, caffeine and glyburide in 9:1 acetonitrile/phosphate buffer $(\mathrm{pH} 2.5$, $50 \mathrm{mM}$ ), separately.

Effect of buffer $\mathrm{pH}$ (at constant buffer concentration of $50 \mathrm{mM}$ ) in sample solution on $\%$ binding for $60 \mu \mathrm{g} / \mathrm{ml}$ metformin 
13 Effect of sodium taurodeoxycholate concentration in sample solution on \% binding of metformin and phenformin 60

$14 \quad$ Structure of picric acid 63

$15 \%$ Metformin or phenformin remaining on MIP micro-column after DPE with varying \% of picric acid in acetonitrile 64

16 Standard calibration curve of MISPE-FPE-DPE for plasma analysis $\begin{array}{ll}\text { of metformin } & 68\end{array}$

17 Separation of metformin from phenformin, $60 \mu \mathrm{g} / \mathrm{mL}$ each in aqueous sample. $50 \mathrm{mM}$ phosphate buffer $(\mathrm{pH} 2.5)$ in water as the running buffer 70

18 Separation of metformin from phenformin, $60 \mu \mathrm{g} / \mathrm{mL}$ each in aqueous sample. $20 \mathrm{mM} \mathrm{NH}_{4} \mathrm{OAc}+5 \%$ HOAc in acetonitrile as the running buffer 71

19 Separation of metformin from phenformin, $60 \mu \mathrm{g} / \mathrm{mL}$ each in aqueous sample. $20 \mathrm{mM} \mathrm{NH}_{4} \mathrm{OAc}+5 \% \mathrm{HOAc}$ in water as the running buffer

20 Effect of sample matrix on CE-UV peak area for $60 \mu \mathrm{g} / \mathrm{mL}$ metformin and $60 \mu \mathrm{g} / \mathrm{mL}$ of phenformin. $20 \mathrm{mM}$ ammonium acetate and $5 \%$ acetic acid in acetonitrile as running buffer

21 Dependence of CE-UV peak areas for $60 \mu \mathrm{g} / \mathrm{mL}$ metformin and $60 \mu \mathrm{g} / \mathrm{mL}$ of phenformin on sample conductivity. $20 \mathrm{mM}$ ammonium acetate and $5 \%$ acetic acid in acetonitrile as running buffe

22 CE analysis of metformin and phenformin from the spiked human plasma 


\section{GLOSSARY}

\begin{tabular}{|c|c|}
\hline AIBN & 2,2'-Azobisisobutyronitrile \\
\hline $\mathrm{CE}$ & Capillary Electrophoresis \\
\hline DDAB & Didodecyldimethylammoniym bromide \\
\hline DPE & Differential pulsed elution \\
\hline DTAB & Dodecyltrimethylammonium bromide \\
\hline FIA & Flow injection analysis \\
\hline FPE & Final pulsed elution \\
\hline HMB & Hexamethonium bromide \\
\hline LOD & Limit of detection \\
\hline LOQ & Limit of quantification \\
\hline MAA & Methylacrylic acid \\
\hline MIP & Molecularly imprinting polymer \\
\hline MISPE & Molecularly imprinted solid Phase extraction \\
\hline NIDDM & Non-Insulin Dependent Diabetes Mellitus \\
\hline $\mathrm{PE}$ & Pulsed elution \\
\hline RSD & Relative standard deviation \\
\hline SPE & Solid phase extraction \\
\hline TFA & Trifluoroacetic acid \\
\hline TFMAA & 2-(Trifluoromethyl)acrylic acid \\
\hline TRIM & trimethylolpropane trimethacrylate \\
\hline TTAB & Myristyltrimethylammonium bromide \\
\hline UV & Ultra-violet \\
\hline
\end{tabular}




\section{CHAPTER I}

\section{INTRODUCTION}




\subsection{Molecular Imprinting}

\subsubsection{Historical development of molecular imprinting}

Molecularly imprinted polymers (MIPs) represent a new class of materials that have artificially created receptor structures ${ }^{\mathrm{i}, \mathrm{ii}, \mathrm{iii}}$. Molecular imprinting has gained increasing research interest during the past few years. However, although interest in the technique is new, the concept itself has a long history. The lock-and-key principle formulated by Emil Fischer as early as the end of the 19th century has still not lost any of its significance for the life sciences. The idea of molecular specificity that could be tailored in sorbents has been around for a long time. In 1931, Polyakov ${ }^{\text {iv }}$ demonstrated that molecular specificity could be imprinted into silica gel by pre-treating silicic acid with organic adsorbates before polycondensation. Later, Dickey ${ }^{\mathrm{v}, ~ v i}$ performed more extensive investigations. Modern molecular imprinting technology appeared in the 1970 s, when Klotz ${ }^{\text {vii }}$ and Wulff reported that chemical memories could be prepared in synthetic polymers. The latter report showed enantiomer recognition. The group of Wulff then presented a series of papers dealing with what is called the covalent approach to molecular imprinting, since reversible covalent interactions are the basis for molecular recognition in these systems. In the early 1980s the Mosbach group developed the noncovalent approach to molecular imprinting ${ }^{\text {viii }}$. This approach, in which the molecular recognition is based on non-covalent interaction (such as hydrogen bonding, ionic interactions, hydrophobic interactions, etc.) has been used as a more general approach to molecular imprinting, since the number of compound classes that could be imprinted was dramatically increased. A third approach, which is based on metal-ion chelation between the template and the polymer, has also been reported ${ }^{\text {ix }}$. From that time, an increasing 
interest has been seen in the potential application of highly selective molecularly imprinted polymers. MIPs are adeptable to several analytical techniques, including liquid chromatography ${ }^{\mathrm{x}, \mathrm{xi}}$, solid phase extraction ${ }^{\mathrm{xii}}$, immunoassay ${ }^{\mathrm{xiii}}$, capillary electrophoresis and capillary electrochromatography ${ }^{\text {xiv }}$.

\subsubsection{The concept of molecular imprinting}

Molecularly imprinted polymers may be prepared according to a number of approaches that are different in the way the template is linked to the functional monomer and subsequently to the polymeric binding sites. Currently, the most widely applied technique to generate molecularly imprinted binding sites is represented by the noncovalent approach which is more common and flexible concerning the choice of functional monomers, possible template and application of the imprinted materials. This is based on non-covalent self-assembly of the template with functional monomers prior to polymerization, free radical polymerization with a cross-linking monomer, and then template extraction followed by rebinding via non-covalent interactions. Although the preparation of a MIP by this method is technically straightforward, it relies on the successful stabilization of the individually weak non-covalent interactions between the template and the functional monomers. This stabilization will in turn result in the incorporation of the functional binding groups to the templated cavities.

A typical imprinting system consists of a template molecule, at least one type of functional monomer, a cross-linking monomer, and a porogenic solvent. To induce radical polymerization, an appropriate initiator is added to the mixture. Formation of the initial template-functional monomer complex (imprinting), as well as of the template- 
MIP complex (re-binding) may be driven by non-covalent interactions or reversible covalent bonds. In the process of molecular imprinting, a molecular template (print molecule) is used to direct the arrangement of the functional monomers around the template, which are then chemically fixed by co-polymerization with a cross-linking monomer. This results in a rigid polymer matrix embedding the template. The resulting bulk polymer is ground and sieved to prepare particles of appropriate size. Afterwards, the print molecule can be removed from the polymer by simple solvent extraction. This creates recognition sites specific to the template based on the position of the functional groups and the shape of the cavity (Figure 1). The MIP particles can be evaluated for the presence of selective recognition sites by using them either in batch experiments or as the stationary phase in a chromatographic column. 


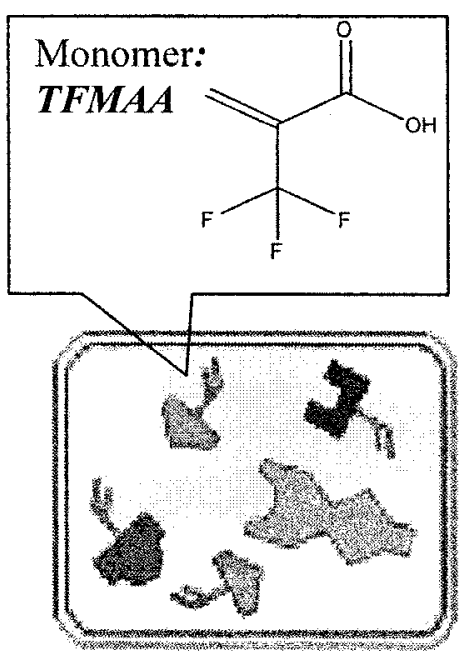

Equilibration

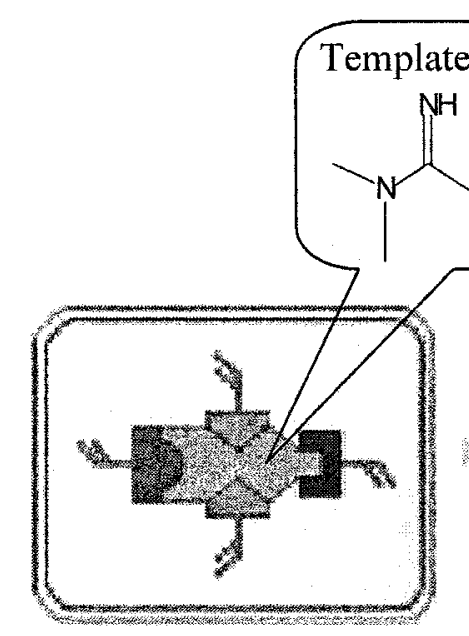

Self-Assembly

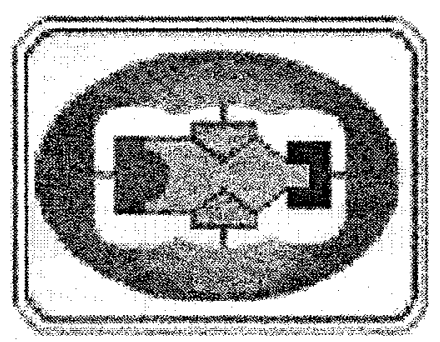

Polymerization

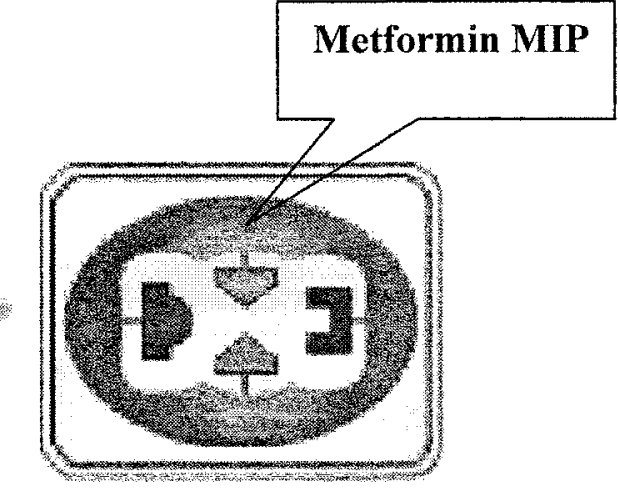

Extraction

\section{Figure 1. Scheme of the molecular imprinting process}

1. The selected template molecule is mixed with functional monomers in a solvent. 2 . The template molecule assembles with the functional monomers to form a complex. 3. Polymerization of the resulting complex with an excess of cross-linking monomer to form a rigid MIP. 4. Extraction of the template molecule to create binding cavities. 


\subsubsection{Applications of MIPs}

As antibody and receptor binding mimics, MIPs have displayed very attractive features that have made MIPs the goal of intensive investigation: (1) their high affinity and selectivity for many target molecules, which are similar to those of natural receptors; (2) their unique stability which is superior to that demonstrated by natural biomolecules; and (3) the simplicity of their preparation and the ease of adaptation to different practical applications. The favorable physical and chemical robustness of MIPs allow these artificial antibodies to be used under harsher conditions such as organic solvents, $\mathrm{pH}$ extremes, high pressures and elevated temperatures, where biomolecules are often denatured.

The technique of molecular imprinting has been applied with success to the preparation of materials with high affinity for separations ${ }^{15,16}$, binding assays ${ }^{17}$, sensor science $^{18,19,20}$, and catalysis ${ }^{21}$, wherever a highly specific interaction of the target molecule (analyte) with the MIP is demanded. A wide variety of MIPs have been screened to meet the present demand of higher selectivity in various fields, such as environmental control, drug development, health protection, forensics, and biotechnology $22,23,24,25$

Non-covalent molecular imprinting relies on multiple non-covalent interactions between the print molecule and the monomers. The association/dissociation kinetics of non-covalent MIPs is in general faster than that observed on MIPs prepared by the covalent approach. For this reason, the former polymers are more attractive for use as the stationary phase in chromatography. 


\subsubsection{Molecularly imprinted solid phase extraction (MISPE)}

The first reported study on molecularly imprinted polymer based solid phase extraction (MISPE) by Sellergren ${ }^{26}$ employed a pentamidine-selective MIP for demonstration of on-line sample enrichment of a spiked urine sample. Since then, molecular imprinting has been brought to the forefront of selective chromatographic sorbents with potential applications in widely different fields such as selective sorbents in SPE for trace analysis, sorbents for scavenging purposes, and polymeric selectors for preparative chiral separations. The selectivity of a MIP can be pre-determined by the choice of template and functional monomers employed for its preparation. One major benefit of MISPE relates to the high efficiency of sample clean up. Different modes of MISPE have been tried, including various modes of on-line SPE ${ }^{26,27}$, conventional SPE where the MIP is packed into columns or cartridges ${ }^{28,29,30}$, and batch mode SPE where the MIP is incubated with the sample ${ }^{31}$.

MISPE with pulsed elution (PE) was first developed by Mullett and Lai ${ }^{27}$ for the analysis of theophylline in serum sample. The method made use of a MIP column for the on-line enrichment of theophylline, followed by injection of a small volume of methanol to produce a rapid pulsed desorption of the analyte. The sample was applied in chloroform since in this solvent a complete retention of the analyte was observed. The matrix constituents, and other potential interferences that were not recognized by the binding sites, were rapidly eluted with chloroform. Then a rapid and quantitative recovery of theophylline was accomplished in a pulsed format through injection of $20 \mu \mathrm{L}$ of methanol. In this way, the eluted analyte could be detected directly by UV for quantification. Further improvement to the MISPE-PE method was achieved by a novel 
differential pulsed elution (DPE) to eliminate the nonspecific adsorption of interfering drugs, without sacrificing the selective binding of theophylline ${ }^{32}$.

\subsection{Metformin}

\subsubsection{Current clinical applications}

Compounds containing the guanidine group play an important role in biochemistry. Metformin (1,1-dimethylbiguanide) and phenformin (phenylethylbiguanide) are biguanide agents used as oral antihyperglycemic agents in the treatment of type 2 (non-insulin-dependent) diabetes mellitus (Figure 2). However, phenformin was withdrawn in 1977 because of its association with a high incidence of lactic acidosis. In 2002, metformin ranked 38th of the top 200 drugs in prescriptions worldwide. It is fairly widely marketed and used in the treatment of NIDDM [NonInsulin Dependent Diabetes Mellitus] $]^{33}$. Metformin has clinically been used, in combination with a high protein-low carbohydrate diet, to restore normal menstrual cycles in teenage females with polycystic ovary syndrome (PCOS) ${ }^{34}$. Metformin is also included in HIV clinical trials to assess its efficacy in the treatment of the metabolic disturbances (fat redistribution, insulin resistance, and hyperinsulinemia) associated with HIV lipodystrophy syndrome ${ }^{35}$.

Glyburide, which is an oral blood-glucose-lowering drug of the sulfonylurea class, is usually combined with metformin hydrochloride. Under the brand name of Glucovance, these two antihyperglycemic agents (with complementary mechanisms of action) could improve glycemic control in patients with type II diabetes ${ }^{36}$. 
<smiles>CN(C)C(=N)NC(=N)N</smiles>

Metformin<smiles>N=C(N)NC(=N)NCCc1ccccc1</smiles>

Phenformin<smiles>COc1ccc(Cl)cc1C(=O)NCCc1ccc(S(=O)(=O)NC(=O)NC2CCCCC2)cc1</smiles>

\section{Glyburide}

Figure 2. Molecular structures of metformin, phenformin and glyburide.

\subsubsection{Clinical pharmacology of metformin}

Metformin $\mathrm{HCl}$ (N,N-dimethylimidodicarbonimidic diamide hydrochloride) has been the only clinically available drug that can significantly improve insulin sensitivity ${ }^{37}$. This drug improves glucose tolerance in patients with type II diabetes, lowering both 
basal and postprandial plasma glucose. It decreases hepatic glucose production, decreases intestinal absorption of glucose, and improves insulin sensitivity by increasing peripheral glucose uptake and utilization ${ }^{36}$. Metformin acts principally by improving the sensitivity of peripheral tissue (chiefly skeletal muscle) and the liver, to insulin, thus opposing the insulin resistance. Metformin does not increase pancreatic insulin secretion and does not induce hypoglycemia.

Metformin has an absolute oral bioavailability of $40 \%$ to $60 \%$, and gastrointestinal absorption is apparently complete within 6 hours of ingestion. Metformin is rapidly distributed following absorption and negligibly bound to plasma proteins. Following administration at usual doses, peak plasma drug concentrations are usually attained within 2 to 4 hours and steady-state plasma concentrations (generally $<1 \mu \mathrm{g} / \mathrm{mL}$ ) are reached within 24 to 48 hours. Therapeutic level may be 0.5 to $1.0 \mu \mathrm{g} / \mathrm{mL}$ in the fasting state and 1-2 $\mu \mathrm{g} / \mathrm{mL}$ after a meal. During controlled clinical trials, maximum metformin plasma levels did not exceed $5 \mu \mathrm{g} / \mathrm{mL}$. Metformin is excreted unchanged in the urine and does not undergo hepatic metabolism or biliary excretion.

\subsubsection{Adverse effects and toxicity of metformin}

Lactic acidosis is a rare, but serious, metabolic complication that can occur as a result of metformin accumulation. In general, lactic acidosis is fatal in approximately 50 percent of cases. While the reported incidence of this condition in patients taking metformin is very low, the risk of metformin accumulation and lactic acidosis increases with the degree of renal function impairment and the patient's age. Concerns about lactic 
acidosis are particularly relevant in patients with HIV infection, given the potential for increased lactate levels ${ }^{38}$.

Gastrointestinal adverse effects (including diarrhea, abnormal stools, nausea, vomiting, abdominal bloating or cramping, flatulence, and taste disorder) were severe enough to require drug discontinuation in about 4 percent of study participants ${ }^{38}$. Additionally, the following adverse reactions were reported by study patients: hypoglycemia, myalgia, lightheadedness, headache, dyspnea, nail disorder, rash, increased sweating, chest discomfort, chills, flu syndrome, flushing, and palpitation ${ }^{39}$.

\subsubsection{Current analytical methods for metformin}

Monitoring of metformin plasma concentration usually has little clinical value, except when lactic acidosis is suspected or diagnosed. Metformin accumulation can induce serious metabolic complications such as lactic acidosis when the metformin concentration in plasma becomes too high ${ }^{35}$. For this reason, the determination of plasma metformin should always be done during treatment. Indeed, when lactic acidosis occurs in metformin-treated patients, early determination of the metformin plasma concentration appears to be the best criterion for assessing this acute condition. Determination of metformin has previously been reported in human plasma, urine, breast milk and pharmaceutical preparations by high-performance liquid chromatography (HPLC) with spectrophotometric detection $39,40,41,42,43,44$, capillary electrophoresis (CE) using fieldamplified sample stacking technique ${ }^{45}$, voltammetry on a glassy carbon electrode ${ }^{46}$, potentiometry, and spectrofluorimetry ${ }^{47}$. One challenge with measuring very low metformin concentrations in human plasma (in pharmacokinetic studies) is due to the high polarity of this compound. It is difficult to extract the drug directly from biological 
fluids by solvent extraction. A method based on the extraction of metformin with bromothymol blue (as an ion-pair) into chloroform had previously been described, using phenformin as internal standard ${ }^{45}$.

Its direct determination by chromatographic analytical techniques is rather difficult because of its strong base properties $\left(\mathrm{pK}_{\mathrm{a}}=13.1 \pm 0.5\right)$ and high polarity ${ }^{48}$. Gas chromatographic methods require a pre-derivatization of the analyte with acetic anhydride ${ }^{49}$. In the analysis of biological fluids such as human plasma and urine, liquid chromatographic methods require a pre-extraction with solid phase sorbents to clean up

the matrix complexity ${ }^{50},{ }^{51}$. Recently, an ion-pair HPLC method was developed for the determination of metformin in human plasma. The sample preparation involved protein precipitation and no evaporation step was required ${ }^{53}$. These sample pretreatment procedures are potentially sources of supplementary errors to the analysis.

\subsection{MISPE-DPE-FPE for determination of metformin}

Generally, analytical methods comprise a sample-pretreatment step followed by either separation and detection steps that can discriminate to a variable degree between the analyte and the matrix components, or quantification in a competitive binding assay. The general idea is that all elements of a method should contribute to its required sensitivity and selectivity. In many instances, however, bioanalytical sample pretreatment is required as a step to get rid of water, salts and bulk amounts of proteins present in the samples. In trace analysis, many other compounds, some of which may have very similar structures to the analyte of interest, are also present as interferences. These compounds can also interfere with analyses. Highly selective phases that can discriminate and isolate the target analyte from the multitude of other compounds in the 
sample are desirable. Therefore, MISPE has become widely evaluated for analyte preconcentration and sample matrix cleanup. To date MISPE methods are available for the rapid screening of many drugs (including aminopyridine, bupivacaine, cephalexin, darifenacin, 7-hydroxycoumarin, nicotine, pentamidin, propranolol, sameridine, tamoxifen, and theophylline) $)^{32}$. Metformin is more basic than all of these drugs previously reported, and was chosen as a challenging molecule (with a high $\mathrm{pKa}$ of 13.1 \pm 0.5 and a large number of functional groups for binding interactions) to re-establish generic rules that would enable speedy development of MISPE-DPE-FPE methods.

In the present study, a new MIP was synthesized by using metformin as the print molecule and trifluoromethacrylic acid (TFMAA, $\mathrm{pKa}=2.1 \pm 0.2$ ) as the functional monomer. A micro-column packed with these MIP particles was evaluated for its ability to bind metformin selectively in acetonitrile. Molecularly imprinted solid phase extraction followed by pulsed elution (MISPE-PE) was demonstrated to be a useful procedure for matrix clean up and analyte pre-concentration. A differential pulsed elution (DPE) step was added to eliminate potential interferences due to the binding of structural analogues. A schematic diagram of MISPE-DPE-FPE-UV system for on-line determination of metformin was shown in Figure 3. 


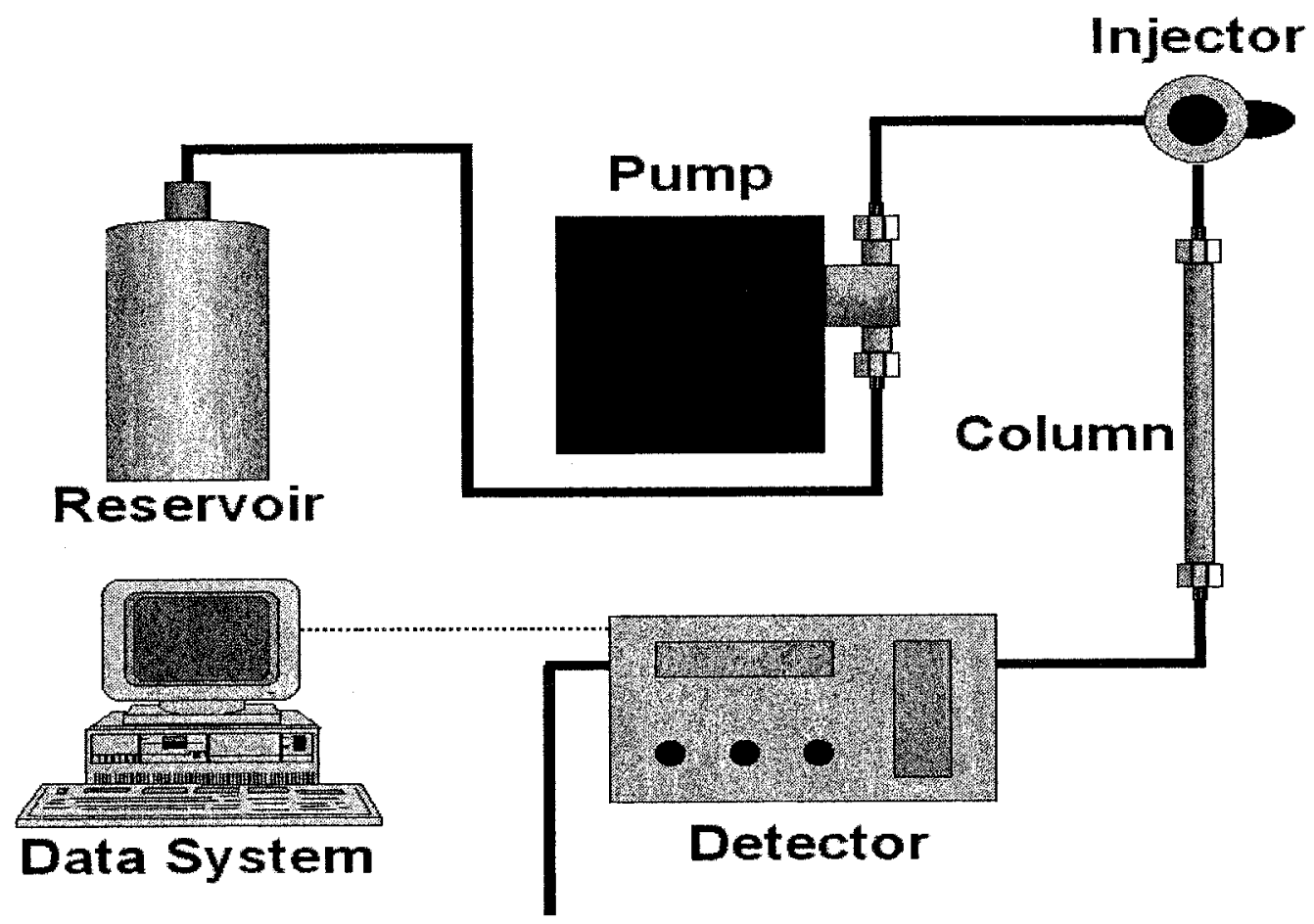

Figure 3. Schematic diagram of MISPE-DPE-FPE-UV system for on-line determination of metformin 


\subsection{Capillary Electrophoresis (CE)}

\subsubsection{General introduction of $\mathrm{CE}$}

Capillary electrophoresis (CE) is a relatively new separation technology that combines both aspects of gel electrophoresis and HPLC. The main advantages of CE over HPLC are the much higher separation efficiency, lower solvent (or buffer) consumption, and shorter analysis time. Like gel electrophoresis, the separation depends upon differential migration in an electrical field. Since its first description in the late $1960 \mathrm{~s}^{54}$, several capillary electrophoretic techniques have been demonstrated: zone electrophoresis, displacement electrophoresis, isoelectric focusing, and sieving separations. $\mathrm{CE}$ is characterized by high resolving power, and commercial $\mathrm{CE}$ instruments became available since 1980s. Narrow-bore capillaries with excellent heat dissipation properties enable the use of very high field strengths, which decrease analysis time and minimize band diffusion. When separations are performed in the presence of electroosmotic flow (EOF), the plug-flow characteristics of EOF also contribute to high efficiency.

Because of its many advantages, CE shows great promise in the analysis of hydrophilic molecules and highly charged solutes. These techniques have led to the rapid separation and quantitation of: basic pharmaceuticals ${ }^{55}$, proteins $^{56}$, glycoproteins, peptides $^{57}$, carbohydrates, chiral isomers ${ }^{58}$, inorganic ions, and organic ions 59,60 . Especially, CE has been applied to the analysis of various pharmaceuticals and their mixtures $^{61}$. 


\subsubsection{Theory of capillary electrophoresis}

As the name implies, capillary electrophoresis (CE) is performed by a narrowbore fused-silica capillary filled with a buffer electrolyte. A schematic of CE system is presented in Figure 4.

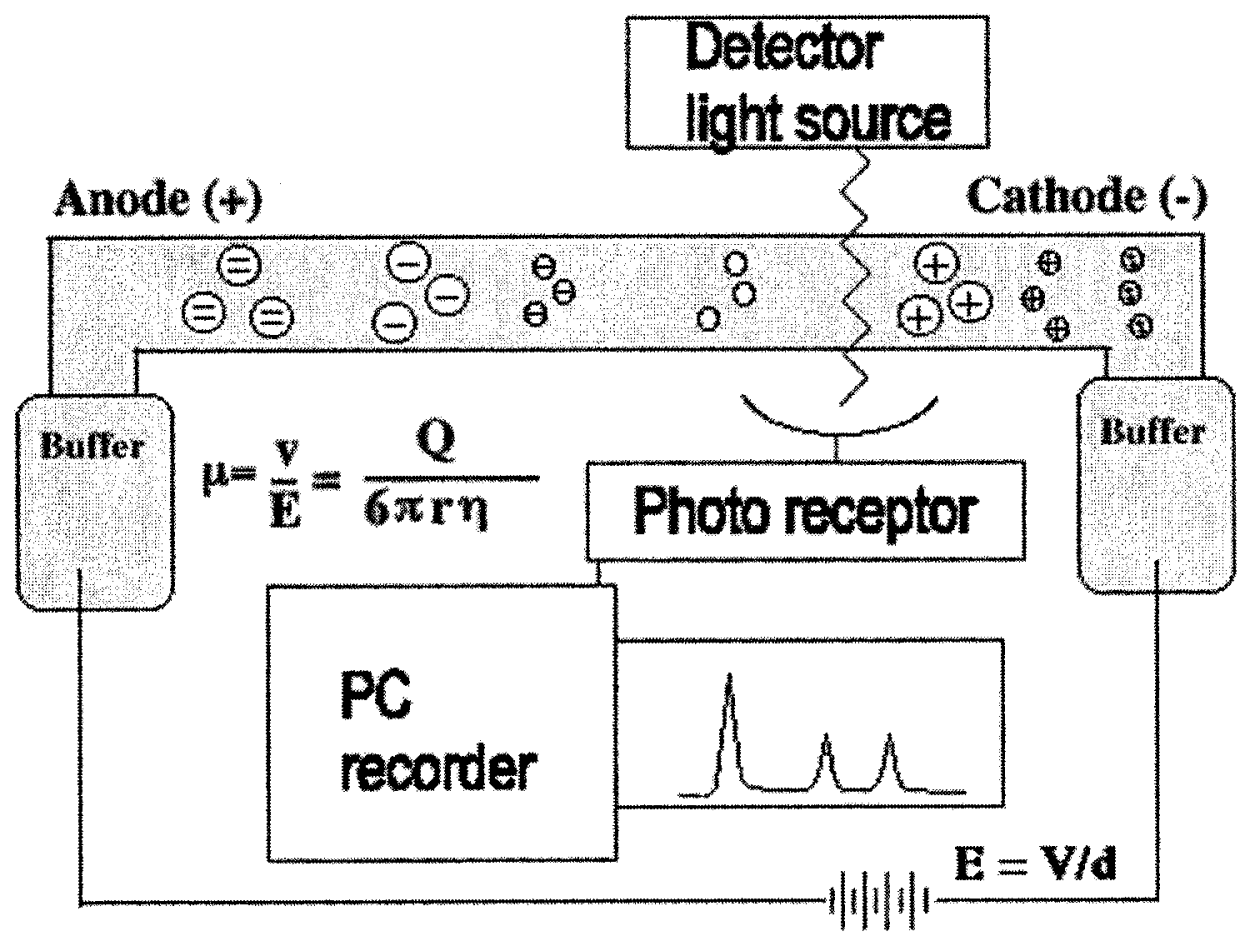

Figure 4. Schematic diagram of capillary electrophoresis (CE) system.

The magnified view depicts the capillary interior with molecules of different size and charge separating. As illustrated, in capillary electrophoresis, the positive molecules migrate toward the negative electrode while the electroosmotic flow carries the neutral and negatively charged molecules in the same direction. 
Capillary zone electrophoresis $(\mathrm{CZE})$ is the simplest form of $\mathrm{CE}$. High voltages are used to separate molecules based on the charge-to-size ratio of the analytes. The choice of the running buffer $\mathrm{pH}$ plays a crucial role because it influences the charge of the analytes. Injection into the capillary is accomplished by immersing the end of the capillary into a sample vial and applying pressure, vacuum or voltage. As soon as the high voltage power supply of the instrument is switched on, an electric field $\mathrm{E}$ along the capillary with length $\mathrm{L}$ will be generated:

$$
\mathrm{V}=\mathrm{E} \times \mathrm{L}
$$

where $\mathrm{V}$ is the total applied voltage. Without consideration of the electroendosmotic flow, the sample ions are moving with the speed $v_{\mathrm{EP}}$, the velocity of migration, which is given by:

$$
v_{\mathrm{EP}}=\mu_{\mathrm{EP}} \times \mathrm{V} / \mathrm{L}
$$

where $\mu_{\mathrm{EP}}$ is the electrophoretic mobility, $\mathrm{V}$ is the applied voltage, and $\mathrm{L}$ is the capillary length. Generally, the capillary surface is charge carrier (negative in the case of fused silica capillaries because of the dissociated silanol groups). An electric double layer at the solid-liquid interface is formed, due to preferential adsorption of ions. Cations or partial positive charges in the medium are electrostatically attracted to the capillary wall, thus forming the electric double layer that is responsible for the electroosmotic flow. The velocity of electroosmotic flow, $v_{E O}$, is described by:

$$
v_{\mathrm{EO}}=\mu_{\mathrm{EO}} \times \mathrm{V} / \mathrm{L}
$$

where $\mu_{\mathrm{EO}}$ is the coefficient of electroosmotic flow. The total migration time, $t$, is thus calculated as follows:

$$
t=L /\left(v_{E P}+v_{E O}\right)=V L^{2} /\left(\mu_{E P}+\mu_{E O}\right)
$$


During the migration time, diffusion continues to occur. If an initially infinitely thin zone is allowed to diffuse for a time t, the spatial variance $\sigma^{2}{ }_{L}$ of the zone will be:

$$
\sigma_{L}^{2}=2 \mathrm{D}=2 \mathrm{DL}^{2} \mathrm{~V} /\left(\mu_{\mathrm{EP}}+\mu_{\mathrm{EO}}\right)
$$

where $\mathrm{D}$ is the diffusion coefficient of the analyte. The number of plates, $\mathrm{N}$, can be calculated according to $\mathrm{N}=\mathrm{L} / \mathrm{H}$, where $\mathrm{H}$ is the height per theoretical plate:

$$
\mathrm{N}=\left(\mu_{\mathrm{EP}}+\mu_{\mathrm{EO}}\right) \times \mathrm{V} / 2 \mathrm{D}
$$

From the last equation it follows that, in CE separations, high voltages result in high separation efficiencies. This can be achieved by narrow bore capillaries with efficient heat dissipation.

\subsubsection{SPE-CE for determination of metformin}

The availability of fast, precise and reliable analytical methods for the determination of drug levels is essential in clinical chemistry. Over the past two decades, different techniques have been developed for drug monitoring in body fluids and biological tissue specimens, with clinical relevance such as dosage adjustments,

compliance control, and determination of efficient drug levels or overdoses ${ }^{62}$. With its distinct advantages, modern $\mathrm{CE}$ is an attractive tool for fast and quantitative monitoring of drugs.

One challenge with measuring very low metformin concentrations in human plasma is due to the high polarity of this compound. It is difficult to extract the drug directly from biological fluids by solvent extraction. In the present work, a new solid phase extraction (SPE) method was developed for the pre-treatment of human plasma 
samples. Then, non-aqueous CE was employed for the rapid separation of metformin from phenformin, glyburide and other drugs.

Several advantages should be mentioned: (1) minute quantities of buffer (milliliter) are required for replicate analyses; (2) only microliters of a patient sample are needed for analysis; (3) the capillary can be rinsed and regenerated for subsequent runs in minutes; and (4) the potential to implement fully automatic procedures. As a net result, the SPE-CE method provides rapid, highly efficient and reproducible separation for metformin in low-volume plasma samples.

\subsection{Objectives}

The main objective of this research was to choose metformin as a challenging molecule for advancing our understanding of molecular imprinting, and re-establishing generic rules that would enable speedy development of MISPE-DPE-FPE methods. In the present work, a new MIP was specifically synthesized (by non-covalent imprinting) as a smart material for the recognition of metformin. The molecular recognition properties of the MIP were investigated and optimized. In order to eliminate potential interference due to the binding of structural analogues and sample matrix components, a differential pulsed elution (DPE) technique was investigated and developed.

The second objective involved the method development of solid phase extraction (SPE) and capillary electrophoresis (CE) for the determination of metformin and other antidiabetic drugs in human plasma samples. Separations performed in a non-aqueous buffer system were explored and studied. Furthermore, the MISPE-DPE-FPE method and SPE-CE method for metformin determination were validated for pharmaceutical and biomedical analyses. 


\section{CHAPTER II}

\section{EXPERIMENTAL}




\subsection{MISPE-DPE-FPE}

\subsubsection{Preparation of metformin-MIP}

\subsubsection{Reagents and materials}

Metformin, phenformin, glyburide and caffeine were obtained from Sigma (St. Louis, MO). Stock solutions of $1 \mathrm{mg} / \mathrm{mL}$ each was prepared in distilled deionized water. They were stable when stored at $4^{\circ} \mathrm{C}$ for several months. Standard solutions of $60 \mu \mathrm{g} / \mathrm{mL}$ each were prepared afresh by dilution with acetonitrile for daily use.

Acetonitrile $\left(\mathrm{CH}_{3} \mathrm{CN}\right)$ and methanol $\left(\mathrm{CH}_{3} \mathrm{OH}\right)$ were HPLC-grade solvents obtained from Caledon (Georgetown, ON). Acetic acid (HAc) was purchased from Anachemia (Toronto, ON). Trifluoroacetic acid (TFA), 2-trifluoromethacrylic acid (TFMAA), picric acid, benzoic acid and pentafluorobenzoic acid were obtained from Aldrich (Milwaukee, WI). Trimethylolpropane trimethacrylate (TRIM) and 2,2'-azobis2-methylproprionitrile (AIBN) were purchased from Sigma (St. Louis, MO) and Caledon (Georgetown, $\mathrm{ON}$ ).

All 50-mM aqueous buffers (glycine for $\mathrm{pH} 1.7$, phosphate for $\mathrm{pH} 2.5$, acetate for $\mathrm{pH}$ 4.5, MES for $\mathrm{pH}$ 6.0, phosphate for $\mathrm{pH} 7.0$ and Tris for $\mathrm{pH} 8.0$ ) were obtained from Beckman Coulter (Fullerton, $\mathrm{CA})$. Ammonium acetate $\left(\mathrm{NH}_{4} \mathrm{OAc}\right)$ and glacial acetic acid (HAc) were obtained from Anachemia (Toronto, ON).

Didodecyldimethylammonium bromide (DDAB), dodecyltrimethyl-ammonium bromide (DTAB), hexamethonium bromide (HMB) hydrate, and myristyl-trimethylammonium bromide (TTAB) were obtained from Aldrich (Milwaukee, WI, USA). 
Human plasma and serum samples were supplied by the Biochemistry Laboratory, Ottawa General Hospital.

\subsubsection{Metformin MIP synthesis}

The MIP was synthesized in a $10-\mathrm{mL}$ pyrex vial containing $16 \mathrm{mg}$ of metformin $\mathrm{HCl}(0.10 \mathrm{mmol}$, print molecule), $101 \mathrm{mg}$ of TFMAA (0.72 mmol, functional monomer) and $3.0 \mathrm{~mL}$ of acetonitrile (porogenic solvent). $\quad 0.23 \mathrm{~mL}$ of TRIM $(0.72 \mathrm{mmol}$, crosslinker) and $12 \mathrm{mg}$ of AIBN (0.07 mmol, initiator) were added. The mixture was purged with nitrogen and sonicated in a water bath for $5 \mathrm{~min}$. Polymerization was then initiated by UV light and left overnight at $60^{\circ} \mathrm{C}$. A colorless translucent bulk of solid MIP was obtained. The bulk MIP was broken down and ground in a mortar with a pestle. The ground MIP particles were sieved to a size range of $38-63 \mu \mathrm{m}$ in diameter. A control polymer was also synthesized in the same conditions as described above, without the addition of metformin $\mathrm{HCl}$.

\subsubsection{MIP micro-column packing}

An adequate amount of the sieved MIP particles was suspended in methanol. After sonication in a water bath for $10 \mathrm{~min}$, the slurry of suspended MIP particles was poured into a stainless-steel HPLC tubing (35 mm length, $0.8 \mathrm{~mm}$ i.d.) equipped with an exit frit. A zero-volume union was put on each end of the newly packed column before acetonitrile was pumped through for 2-3 hours to achieve uniformly tight packing. Approximately $20 \mathrm{mg}$ of MIP particles were contained in the micro-column. 


\subsubsection{Removal of template molecule from metformin MIP}

The packed MIP micro-column was installed by connecting with an Eldex Duro Series CC-30s micrometer pump (San Carlos, CA). A Valco Cheminert VIGI C2XL injector valve (Houston, TX) equipped with a $20-\mu \mathrm{L}$ sample loop was used for sample injection. A Bischoff Lambda 1010 UV detector (Leonberg, Germany) was used to monitor the removal of metformin template. The retention times and peak areas were recorded by a Dionex 4270 integrator (Sunnyvale, CA).

Removal of the metformin template was achieved by performing an on-line flushing using methanol $+3 \% \mathrm{TFA}$ at a flow rate of $0.5 \mathrm{~mL} / \mathrm{min}$, until a stable baseline was attained for UV absorbance at $240 \mathrm{~nm}$. This was followed by flushing with $100 \% \mathrm{CH}_{3} \mathrm{CN}$ for 2 hours.

\subsubsection{Investigation of molecular recognition}

\subsubsection{MISPE-PE instrumentation}

The MISPE-PE instrumentation was set up with an Eldex Duro Series CC-30s micrometer pump (San Carlos, CA), a Valco Cheminert VIGI C2XL injector valve (Houston, TX) equipped with a $20-\mu \mathrm{L}$ sample loop, a Bischoff Lambda 1010 UV detector (Leonberg, Germany), and a Dionex 4270 integrator (Sunnyvale, CA). Acetonitrile was driven as the mobile phase through the MIP micro-column at a flow rate of $0.5 \mathrm{~mL} / \mathrm{min}$. A previous work had studied the effects of flow rate on the recovery and PE efficiency for a cephalexin MIP micro-column with an identical i.d. ${ }^{63}$. A slower flow rate than 0.5 $\mathrm{mL} / \mathrm{min}$ was not adopted mainly for the sake of a rapid analysis time (under $5 \mathrm{~min}$ ). 


\subsubsection{2 \% Binding measurements}

With acetonitrile as the mobile phase at a flow rate of $0.5 \mathrm{~mL} / \mathrm{min}, 20 \mu \mathrm{L}$ of a $60-$ $\mu \mathrm{g} / \mathrm{mL}$ metformin solution was tested for binding on the MIP micro-column. The breakthrough peak of metformin was recorded and the remaining analyte bound to the MIP micro-column was removed with a $20 \mu \mathrm{L}$ pulsed elution (PE) with 3\% TFA in methanol. The breakthrough and PE peaks were detected at an optimal wavelength of $240 \mathrm{~nm}$. These peak areas were blank-subtracted before their ratio was calculated to determine the \% binding for metformin. A similar binding test and calculation was done for phenformin.

\subsubsection{Evaluation of binding capacity}

Binding capacity of metformin MIP micro-column was investigated by multiple injections of a $7.5-\mu \mathrm{g} / \mathrm{mL}$ metformin solution in $9: 1 \mathrm{CH}_{3} \mathrm{CN} / 50 \mathrm{mM}$ phosphate buffer (pH 2.5) onto the metformin MIP micro-column, with acetonitrile as the mobile phase at a flow rate of $0.5 \mathrm{~mL} / \mathrm{min}$. Binding saturation was finally observed when the breakthrough peak area of each injection became identical to the flow injection analysis (FIA) peak area. A similar binding capacity evaluation was done for phenformin.

\subsubsection{Effect of sample solvent on \% binding}

The hydrodynamic ability of the metformin MIP micro-column to bind and retain metformin was evaluated for various aqueous and acetonitrile standard solutions. The effect of sample solvent in the molecular recognition process of MISPE-PE was 
investigated by injection of $60-\mu \mathrm{g} / \mathrm{mL}$ metformin solutions with various ratios of acetonitrile to water. Acetonitrile was employed as the mobile phase in all subsequent investigations for the benefit of minimal non-specific binding during MISPE-PE. Breakthrough and PE peak areas were measured in separate $20-\mu \mathrm{L}$ loading injections at $240 \mathrm{~nm}$ by UV absorbance detection.

\subsubsection{Effect of buffer $\mathrm{pH}$ in sample solution on \% binding}

Binding of metformin onto the MIP micro-column was examined over a $\mathrm{pH}$ range from 1.5 to 8.0. Different types of aqueous buffers were added to the $60-\mu \mathrm{g} / \mathrm{mL}$ metformin solutions in acetonitrile, in a constant $\mathrm{v} / \mathrm{v}$ ratio of 1:9. The breakthrough and PE peaks were detected at an optimal wavelength of $240 \mathrm{~nm}$. These peak areas were blank-subtracted before their ratio was calculated to determine the $\%$ binding for metformin.

\subsubsection{Effect of phosphate buffer on \% binding}

To test the effect of phosphate buffer on $\%$ binding for metformin, the sample solutions were phosphate-buffered (at $\mathrm{pH} 2.5$ or 7.0 ). The $\%$ binding of $60-\mu \mathrm{g} / \mathrm{mL}$ metformin in $\mathrm{CH}_{3} \mathrm{CN}$, in 9:1 $\mathrm{CH}_{3} \mathrm{CN} / 50 \mathrm{mM}$ phosphate buffer (pH 2.5), and in 9:1 $\mathrm{CH}_{3} \mathrm{CN} / 50 \mathrm{mM}$ phosphate buffer ( $\mathrm{pH} 7.0$ ) were compared by single loading injections.

\subsubsection{Effect of metformin concentration on \% binding}

For further investigation of the relation between metformin concentration and $\%$ binding, metformin standard solutions of different concentrations over the range of 7.5- 
$60 \mu \mathrm{g} / \mathrm{mL}$ in 9:1 $\mathrm{CH}_{3} \mathrm{CN} / 50 \mathrm{mM}$ phosphate buffer $(\mathrm{pH} 2.5)$ were tested. $\mathrm{CH}_{3} \mathrm{CN}$ was used as the mobile phase at a flow rate $0.5 \mathrm{~mL} / \mathrm{min}$. MISPE was performed by single injection of individual metformin standard solution, followed by PE with $3 \%$ TFA + $\mathrm{CH}_{3} \mathrm{OH}$. The breakthrough peak area after injection of each individual metformin concentration was measured to determine the $\%$ binding achieved.

\subsubsection{Binding selectivity of metformin MIP}

To investigate the binding selectivity of metformin MIP micro-column, the \% binding of metformin (imprinting template), phenformin (structural analogue), caffeine (most common interference in human plasma samples) and glyburide (sulfonylurea antidiabetic drug) were measured separately under the same MISPE condition. $20-\mu \mathrm{L}$ aliquots of metformin, phenformin, caffeine and glyburide solutions (60 $\mu \mathrm{g} / \mathrm{mL}$ in $9: 1$ $\mathrm{CH}_{3} \mathrm{CN} / 50 \mathrm{mM}$ pH 7 phosphate buffer) were loaded separately on the metformin MIP micro-column, followed by $\mathrm{PE}$ with $3 \% \mathrm{TFA}$ in $\mathrm{CH}_{3} \mathrm{OH}$. Acetonitrile was employed as the mobile phase at a flow rate of $0.5 \mathrm{~mL} / \mathrm{min}$. The breakthrough and PE peaks were detected at optimal wavelengths of $230-260 \mathrm{~nm}$, and their ratio was calculated to determine the $\%$ binding.

\subsubsection{MISPE-DPE-FPE}

\subsubsection{Final pulsed elution (FPE) of metformin}

Acetonitrile was used as the mobile phase at a flow rate of $0.5 \mathrm{~mL} / \mathrm{min}$. TFA is a strong organic acid with a pKa value ranging from -0.23 to 0.0 as reported in the literature. In the present MISPE method development, various concentrations of TFA 
over the range from $0.025 \%$ to $3 \%$ in methanol were tested to remove bound metformin from the MIP micro-column for UV detection at $240 \mathrm{~nm}$. Finally, 3\% TFA in methanol was chosen as the optimal FPE solvent.

\subsubsection{Differential pulsed elution (DPE) of phenformin}

Acetonitrile was used as the mobile phase at a flow rate of $0.5 \mathrm{~mL} / \mathrm{min}$. An intermediate wash step, differential pulsed elution (DPE), was added to eliminate potential interference due to the binding of structural analogues. Phenformin is a guanidine derivative that is structurally analogous to metformin. As a strong base with a pKa value of $12.7 \pm 0.5$, phenformin was used as a model interferent molecule to challenge the selectivity of this MISPE method. DPE was studied as a means to eliminate phenformin quantitatively while leaving behind an adequate amount of metformin for UV detection. A final pulsed elution (FPE) of metformin for direct UV detection was achieved using 3\% TFA in methanol.

\subsubsection{Evaluation of organic acids for DPE effectiveness}

Acetonitrile was used as the mobile phase at a flow rate of $0.5 \mathrm{~mL} / \mathrm{min}$. Several organic acids: benzoic acid, pentafluorobenzoic acid, acetic acid, trifluoroacetic acid (TFA), trifluoromethacrylic acid (TFMAA) and picric acid in acetonitrile or methanol were evaluated for their DPE effectiveness. After DPE with each organic acid, 3\% TFA $+\mathrm{CH}_{3} \mathrm{OH}$ was used in FPE to elute all of the remaining phenformin.

\subsubsection{DPE with trifluoroacetic acid (TFA)}


Acetonitrile was used as the mobile phase at a flow rate of $0.5 \mathrm{~mL} / \mathrm{min}$. After single injection of $20-\mu \mathrm{L}$ of phenformin solution $\left(60-\mu \mathrm{g} / \mathrm{mL}\right.$ in $9: 1 \mathrm{CH}_{3} \mathrm{CN} / 50 \mathrm{mM} \mathrm{pH} 7$ phosphate buffer) onto the metformin MIP micro-column, different concentrations of TFA ranging from $0.025 \%$ to $2 \%$ in methanol were tested for DPE individually. After each DPE, $3 \%$ TFA $+\mathrm{CH}_{3} \mathrm{OH}$ was used in FPE to elute all of the remaining phenformin.

\subsubsection{DPE with picric acid}

Acetonitrile was used as the mobile phase at a flow rate of $0.5 \mathrm{~mL} / \mathrm{min}$. Picric acid ( $\mathrm{pKa}=0.3$ to 0.53 as reported in the literature) was strategically selected from among the strongest organic acids that were commercially available. After a single 20$\mu \mathrm{L}$ injection of phenformin solution $\left(60 \mu \mathrm{g} / \mathrm{mL}\right.$ in $9: 1 \mathrm{CH}_{3} \mathrm{CN} / 50 \mathrm{mM} \mathrm{pH} 7$ phosphate buffer) onto the metformin MIP micro-column, different concentrations of picric acid over the range from $1.7 \%$ to $22 \%$ in acetonitrile were evaluated for the best DPE result. After DPE with each picric acid solution, $3 \%$ TFA (pKa $=-0.23$ to 0.0$)$ in methanol was used in FPE to elute all of the remaining phenformin. The $\triangle$ FPE peak area was determined and plotted versus the concentration of picric acid. Metformin standard solution, with concentrations ranging from 7.5 to $50 \mu \mathrm{g} / \mathrm{mL}$ in $9: 1 \mathrm{CH}_{3} \mathrm{CN} / 50 \mathrm{mM}$ phosphate buffer ( $\mathrm{pH} 7.0)$, were tested.

\subsubsection{Standard calibration curve for MISPE-PE determination of metformin}

Under isocratic mobile phase conditions of $100 \%$ acetonitrile, a standard calibration curve was performed for MISPE-PE determination of metformin in 


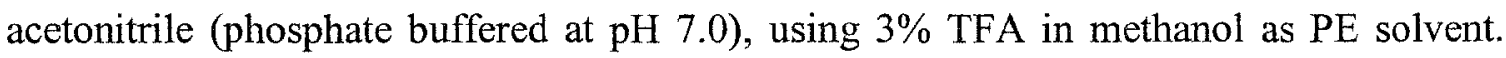
The concentration of metformin standards was over the range from 3.75 to $60 \mu \mathrm{g} / \mathrm{mL}$ in 9:1 $\mathrm{CH}_{3} \mathrm{CN} / 50 \mathrm{mM}$ phosphate buffer $(\mathrm{pH} 7.0)$. The MISPE-PE peak area was plotted vs. the mass of metformin loaded on the MIP micro-column.

The detection limit was determined for metformin, based on 3 standard deviations of the blank.

\subsubsection{Human plasma analysis}

Human plasma samples were obtained from the Ottawa General Hospital (Ottawa, Ontario, Canada). Several $0.2-\mathrm{mL}$ aliquots of a plasma sample were spiked with $20-\mu \mathrm{g} / \mathrm{mL}$ metformin and $300-\mu \mathrm{g} / \mathrm{mL}$ phenformin to provide a series of working solutions over the concentration range from 0.1 to $10 \mu \mathrm{g} / \mathrm{mL}$ metformin and $60 \mu \mathrm{g} / \mathrm{mL}$ phenformin. $1 \mathrm{~mL}$ of 9:1 acetonitrile / $50 \mathrm{mM}$ phosphate buffer ( $\mathrm{pH} \mathrm{7.0)}$ was added to

precipitate the proteins ${ }^{64}$. The mixture was thoroughly vortexed and then centrifuged at $5000 \mathrm{rpm}$ for $20 \mathrm{~min}$. The supernatant was filtered through SuporAcrodisc $®$ syringe filter (Gelman Sciences, pore size $0.45 \mu \mathrm{m}$ ). A $20-\mu \mathrm{L}$ of filtered supernatant was injected onto the MIP micro-column for MISPE-DPE-FPE analysis.

$\mathrm{CH}_{3} \mathrm{CN}$ was used as the mobile phase at a flow rate of $0.5 \mathrm{~mL} / \mathrm{min}$. A standard calibration curve for MISPE-DPE-FPE was constructed by triplicate $20-\mu \mathrm{L}$ injections of the above standard solutions onto the metformin MIP micro-column. This was followed by DPE with $5 \%$ picric acid in $\mathrm{CH}_{3} \mathrm{CN}$ and $\mathrm{FPE}$ with $3 \%$ TFA in $\mathrm{CH}_{3} \mathrm{OH}$. The $\%$ recovery of metformin was determined by analyzing a plasma sample $(0.2 \mathrm{~mL})$ that had been spiked with $3-\mu \mathrm{g} / \mathrm{mL}$ metformin and $60-\mu \mathrm{g} / \mathrm{mL}$ phenformin. 


\subsection{Capillary zone electrophoresis}

\subsubsection{Reagents and materials}

Ammonium acetate $\left(\mathrm{NH}_{4} \mathrm{OAc}\right)$ was obtained from Anachemia (Toronto, $\mathrm{ON}$ ).

\subsubsection{Conditioning of the capillary}

CE separation was performed on a fused silica capillary (65 $\mu \mathrm{m}$ i.d., $360 \mu \mathrm{m}$ o.d., $30 \mathrm{~cm}$ total length, $22.5 \mathrm{~cm}$ effective length to detector) obtained from Polymicro Technologies (Phoenix, AZ). The new fused silica capillary was flushed with $1 \mathrm{M}$ $\mathrm{NaOH}$, rinsed with deionized distilled water and cleaned with the running buffer. Before use, the capillary was conditioned with the running buffer at an applied voltage of $15 \mathrm{kV}$ for $30 \mathrm{~min}$. One blank run (no sample injection) was allowed before the first analysis.

\subsubsection{Capillary zone electrophoresis}

CE analyses were performed on a laboratory-built system that included a Spellman CZE1000R high voltage power supply. The electrolyte was composed of acetonitrile, and different concentrations of buffer, ammonium acetate $\left(\mathrm{NH}_{4} \mathrm{OAc}\right)$ and acetic acid (HOAc). The optimal non-aqueous buffer ( $\mathrm{pH} 5.1$ ) for $\mathrm{CE}$ was composed of $20 \mathrm{mM} \mathrm{NH}_{4} \mathrm{OAc}$ and 5\% HOAc in $\mathrm{CH}_{3} \mathrm{CN}$. When the buffer was run under an applied voltage of $15 \mathrm{kV}$, the capillary was equilibrated with the ambient temperature of $22-25^{\circ} \mathrm{C}$. The samples were degassed by sonication, and electrokinetic injections were made by applying $15 \mathrm{kV}$ for $6 \mathrm{~s}$ typically.

A Bischoff Lambda 1010 (Leonberg, Germany) UV detector was employed to monitor the elution of analytes at a wavelength of $240-280 \mathrm{~nm}$. The detector output 
signal was acquired by both a Dionex 4270 integrator (Sunnyvale, CA) and a personal computer running the Peak Simple Chromatography Data System (SRI model 203, Torrance, CA). After each run, the capillary was conditioned by running the buffer at 15 $\mathrm{kV}$ for $1 \mathrm{~min}$ before the next analysis.

\subsubsection{Effect on buffer composition}

A non-aqueous CE buffer was previously reported by Siren et al ${ }^{65}$ to provide separation of polar drugs. In the present work, a non-aqueous separation medium, which was acetonitrile modified by $\mathrm{NH}_{4} \mathrm{OAc}$ and glacial $\mathrm{HOAc}$, was employed. In the $\mathrm{CE}$ technique, after laboratory optimization, the final buffer solution was chosen to be 20 $\mathrm{mM} \mathrm{NH} 4 \mathrm{OAc}_{4}$ and $5 \%$ HOAc in acetonitrile ( $\left.\mathrm{pH} 5.1\right)$.

To investigate the effect of the concentration of electrolytes, buffer solutions were prepared by varying the $\mathrm{NH}_{4} \mathrm{OAc}$ from 1 to $20 \mathrm{mM}$ and the $\mathrm{HOAc}$ from $1 \%$ to $5 \%$ in acetonitrile. The prepared buffers were degassed by ultrasonication before use. The sample solutions, which contained $60 \mu \mathrm{g} / \mathrm{mL}$ of metformin and phenformin in acetonitrile, were electrokinetically injected at $15 \mathrm{kV}$ for $6 \mathrm{~s}$. The analyte peaks were detected by UV detector at $240 \mathrm{~nm}$. Finally, $20 \mathrm{mM} \mathrm{NH} \mathrm{N}_{4} \mathrm{OAc}$ and $5 \% \mathrm{HOAc}$ in acetonitrile was chosen as the non-aqueous media that gave the best separation for the analytes.

\subsubsection{Sample Matrix Effect on CE-UV Peak Area}


Various standard mixtures which contained $60-\mu \mathrm{g} / \mathrm{mL}$ of metformin and 60 $\mu \mathrm{g} / \mathrm{mL}$ of phenformin were prepared in $\mathrm{H}_{2} \mathrm{O}, 20 \mathrm{mM} \mathrm{NH} \mathrm{NHAc}_{4}+5 \% \mathrm{HOAc}, \mathrm{CH}_{3} \mathrm{OH}+$ $3 \% \mathrm{HOAc}$, and $\mathrm{CH}_{3} \mathrm{OH}+3 \% \mathrm{TFA}$, respectively. These sample solutions were analyzed by $\mathrm{CE}$ to investigate the sample matrix effects on CE-UV peak areas.

\subsubsection{Human plasma analysis}

Each 0.5 -mL human plasma sample was spiked with metformin, phenformin (as an internal standard ${ }^{66}$ ) and glyburide (as potential interference) from aqueous standard solutions. After dilution to $2 \mathrm{~mL}$ with deionized water, extraction treatment was carried out on a C18 SPE cartridge (T. Baker, 7020-03). The cartridge was dried by helium gas, before the extracted metformin, phenformin and glyburide were eluted with $2 \mathrm{~mL}$ of methanol $+3 \%$ acetic acid. The eluate was collected and electrokinetically injected (at $15 \mathrm{kV}$ for 6-36 s) to the capillary for CE analysis using a running buffer of $20 \mathrm{mM}$ $\mathrm{NH}_{4} \mathrm{OAc}+5 \%$ HOAc in acetonitrile. A standard calibration curve was constructed by performing SPE-CE-UV analysis of human plasma samples that were spiked with metformin and phenformin in the concentration ranges from $1 \mu \mathrm{g} / \mathrm{mL}$ to $30 \mu \mathrm{g} / \mathrm{mL}$. 


\section{CHAPTER III}

\section{RESULTS AND DISCUSSION}




\subsection{Synthesis of metformin-MIP}

\subsubsection{Preparation of metformin-MIP}

In non-covalent molecular imprinting, functional monomers are chosen to allow hydrogen bonds, ionic interactions, $\pi-\pi$ interactions and/or hydrophobic interactions with the imprint molecules. The strength and positioning of the monomer-template interactions are of importance to obtain a MIP with good molecular recognition properties. The broad applicability of MAA as a functional monomer is related to the fact that the carboxylic acid group serves as a hydrogen bond and proton donor, as well as a hydrogen bond acceptor ${ }^{67}$. In aprotic solvents such as acetonitrile, carboxylic acids and amine bases form hydrogen-bonded assemblies where the association strength for a given functional monomer acid increases with the basicity of the print molecule ${ }^{68}$. Often, a large excess of MAA in the synthesis step is required for recognition to be observed and then only in solvents of low to medium polarity and hydrogen bond capacity ${ }^{69}$. Moreover, the excess of functional monomer results in a portion not containing imprinted cavities. These cavities interact non-selectively with solutes with affinity for carboxylic acids (from the functional monomer) and limit the degree of separation that can be achieved. Hence, MAA, although broadly applicable, is not a universal monomer for the generation of high affinity sites. Instead, trifluoromethyl acrylic acid (TFMAA) can enhance selectivity in a terpolymer with $\mathrm{MAA}^{70}$.

Therefore, in this study, 2-(trifluoromethyl)acrylic acid (TFMAA) was selected as the functional monomer for its ability to interact by non-covalent bond with metformin, the print molecule. Compared with methacrylic acid (MAA), TFMAA has a higher acidity and would afford stronger ionic interaction with metformin. Before 
polymerization, the monomers and the print molecules were self-assembled elaborately by dissolving them in an appropriate solvent. Cross-linker (TRIM) is added and the polymerization was initiated. The print molecules were subsequently extracted from the highly cross-linked polymeric network obtained.

The molecular structure of metformin has characteristics that make it suitable for successful molecular imprinting (Figure 5). It was not difficult to foresee a priori how the formation of hydrogen bonding interactions with multiple TFMAA in the polymerization mixture would be possible because of the primary, secondary and ternary amine groups on metformin. Multiple $\mathrm{N}-\mathrm{H} \cdots \mathrm{O}=$ interactions between metformin and oxygen lone pairs had previously been reported by Kataky et al. ${ }^{71}$. Only one kind of functional monomer was deemed necessary for the present MIP preparation. The molar ratio of TFMAA to the print molecule was varied by adjusting the amount of print molecule added to an otherwise constant pre-polymerization mixture. A molar ratio of 1:7 (metformin : TFMAA) was found to be optimal in ensuring specific binding and reducing non-specific binding. 
<smiles>C=C(C)NC(=N)C(C)C</smiles>

Metformin<smiles>C=C(C)N[C](C(=C)C)C(=C)CCc1ccccc1</smiles>

Phenformin<smiles>C=C(C=O)C(=O)O</smiles>

TFMAA<smiles>C=C(C)C(=C)CCC(CC)(CCC(=O)C(=C)C)CCC(C)C(C)C(C)C</smiles>

TRIM

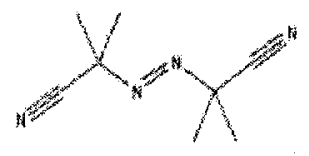

AIBN

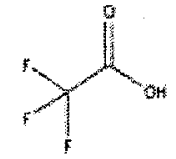

TFA

Figure 5. Molecular structures of metformin, phenformin, TFMAA, TRIM, AIBN and TFA. 


\subsubsection{Selection of solvent}

MIPs often display good recognition in organic solvents, whereas significant nonspecific binding is seen in aqueous solutions ${ }^{72}$. Generally, in most successful noncovalent imprinting systems, an aprotic solvent of low to medium polarity (e.g. $\mathrm{CH}_{2} \mathrm{Cl}_{2}$, toluene, $\mathrm{CH}_{3} \mathrm{CN}$ ) was used as diluent or porogen. Similarly, the rebinding to MIPs is strongly dependent on the medium. The properties of MIPs are often correlated with the solvent conditions employed during polymerization and thus optimum recognition is frequently observed using this same solvent ${ }^{73,74,75}$. Previously, when the same solvent was used in the rebinding as in the polymerization step, the strength and selectivity of the template rebinding increased with decreasing polarity and hydrogen bond capacity of the solvent. For instance, a MIP using chloroform as the diluent exhibited higher affinity for the template in a chloroform medium than that of a polymer prepared using acetonitrile as diluent and evaluated in an acetonitrile medium ${ }^{76}$. Interestingly when evaluating the latter polymer in the less polar chloroform medium, a much lower affinity was observed. Likewise, the polymer prepared in chloroform showed a lower rebinding affinity in acetonitrile. Similar solvent dependence has been observed in a number of other systems. This indicates that the binding sites are complementary to the template, including part of the solvation shell, in the solvent used as diluent, and/or that the polymer chains need to be solvated by the same solvent used in the synthesis in order to adopt a conformation for optimum rebinding of the template. 
In a study of the influence of the diluent properties in the recognition properties of MIPs, a series of L-PA (L-phenylalanine anilide) MIPs were prepared in the presence of various solvents (diluents) with different polarity and hydrogen bond capacities ${ }^{77}$. Acetonitrile or benzene resulted in mesoporous low-swelling polymers while non-porous swellable polymers were obtained by using chloroform or dichloromethane as diluents. In present study, acetonitrile was eventually chosen as a suitable solvent since it is classified as poor in hydrogen bonding and thus has little ability to compete for the hydrogen bonding sites of the template or the MIP binding sites ${ }^{77}$. Furthermore, it solvates the methacrylate polymer backbone well ${ }^{78}$ and is polar enough to dissolve a large number of compounds, including the polar metformin and phenformin.

\subsubsection{Choice of cross-linker}

EDMA is the most commonly used cross-linker for the methacrylate-based systems, primarily because it yields polymers with mechanical and thermal stability, good wetability in most rebinding media and rapid mass transfer with good recognition properties ${ }^{79}$. Comparing with EDMA, as a trimethacrylate monomer, TRIM could provides similar recognition properties for a large variety of target molecules. MIPs that were prepared by TRIM possessed a higher sample load capacity and better performance than similar MIPs prepared using EDMA as cross-linker ${ }^{80}$. Therefore, TRIM was used as cross-linker in this present study. 


\subsubsection{Removal of template molecule from metformin MIP}

Before the MIP can be used in any application, the template molecules have to be removed to leave behind cavities (or recognition sites) with affinity for the target analyte. In addition, the aim is to reduce template bleeding to levels that would allow the use of the MIP as affinity phases for extraction of the target analyte from samples at low concentrations. Otherwise, the remaining template can constitute a problem as it might bleed from the polymer during the elution step of solid-phase extraction (SPE), giving erroneous results and/or an increased limit of quantification (LOQ). Therefore, it was of prime concern to search for methods capable of removing the metformin template from the MIP.

Careful and effective wash procedure was needed to remove the metformin template from the MIP. Continuous extraction using a Soxhlet apparatus typically results in the removal of up to $99 \%$ of the template. Several studies, however, have shown that a small portion of the template remains unextracted even after extensive washing using various organic solvents containing acid or base additives ${ }^{81,82,83,84}$.

To remove the metformin template, methanol was combined with trifluoroacetic acid (TFA) in order to disrupt the binding interactions between metformin and the MIP. TFA is by far the strongest organic acid, which has a pKa value of -0.25 . In the present experiment, the metformin MIP particles were packed into a stainless steel HPLC tubing equipped with an exit frit, and treated by extensive on-line washing with methanol containing $3 \% \mathrm{TFA}$ at $0.5 \mathrm{~mL} / \mathrm{min}$. The baseline was monitored by $\mathrm{UV}$ detection at 240 $\mathrm{nm}$. Bleeding was gradually reduced until a flat baseline was observed. Comparing with Soxhlet extraction, this on-line washing procedure was very simple and straightforward 
in terms of operation and efficiency. After optimization, 3\% TFA in methanol was proven to be effective in eluting the template metformin molecules entrapped in the MIP particles. No further eluted metformin was detected when the MIP micro-column was flushed with acetonitrile for 2 hours. This indicated that, within the time interval, bleeding of the template molecules was significantly reduced to levels acceptable for trace level analysis.

\subsection{Investigation of molecular recognition}

\subsection{1 \% Binding measurements}

$\%$ Binding is a criterion for evaluating the molecular recognition ability of the MIP particles for metformin and its structural analogues. It was calculated by subtracting the breakthrough peak area from the flow injection analysis (FIA) peak area (with the sample solution bypassing the metformin MIP micro-column) and dividing by the latter:

$\%$ Binding $=\frac{\text { FIA peak area }- \text { Breakthrough peak area }}{\text { FIA peak area }} \times 100 \%$

When $\mathrm{CH}_{3} \mathrm{CN}$ was used as the mobile phase for MISPE, 53\% binding of metformin could be achieved on this metformin MIP micro-column at the $60-\mu \mathrm{g} / \mathrm{ml}$ concentration level. 


\subsubsection{Binding selectivity}

Phenformin is a guanidine derivative that is structurally analogous to metformin. As a strong base with a pKa value of $12.7 \pm 0.5^{92}$, phenformin was used as a model interferent molecule to challenge the selectivity of this MISPE method. Fig. 6 compares the $\%$ bindings obtained for metformin and phenformin at the $60-\mu \mathrm{g} / \mathrm{ml}$ concentration level when $\mathrm{CH}_{3} \mathrm{CN}$ was used as the mobile phase for MISPE. Clearly, the MIP exhibited much stronger binding with metformin than phenformin in all of the three sample solvents. The MISPE selectivity $(=\%$ binding for metformin $/ \%$ binding for phenformin) was calculated to be 2.3 in acetonitrile, 1.9 in $9: 1$ acetonitrile/phosphate buffer $(\mathrm{pH} 2.5,50 \mathrm{mM})$, and 1.8 in 9:1 acetonitrile/phosphate buffer (pH 7.0, $50 \mathrm{mM})$, respectively.

To further test the binding selectivity, phenformin (structural analogue), caffeine (common diet ingredient) and glyburide (sulfonylurea anti-diabetic drug) were chosen as potential interferences. \% Binding was tested by using $60 \mu \mathrm{g} / \mathrm{mL}$ of metformin, phenformin, caffeine and glyburide in 9:1 $\mathrm{CH}_{3} \mathrm{CN} / 50 \mathrm{mM}$ phosphate buffer $(\mathrm{pH} 2.5)$, separately. Caffeine is a common organic molecule found in many beverages such as coffee, tea, and cola. Glyburide is a sulfonylurea anti-diabetic agent which is usually combined with metformin, to improve glycemic control in patients with type 2 diabetes. As expected, this metformin MIP micro-column has very good binding selectivity for metformin (Figure 7). 


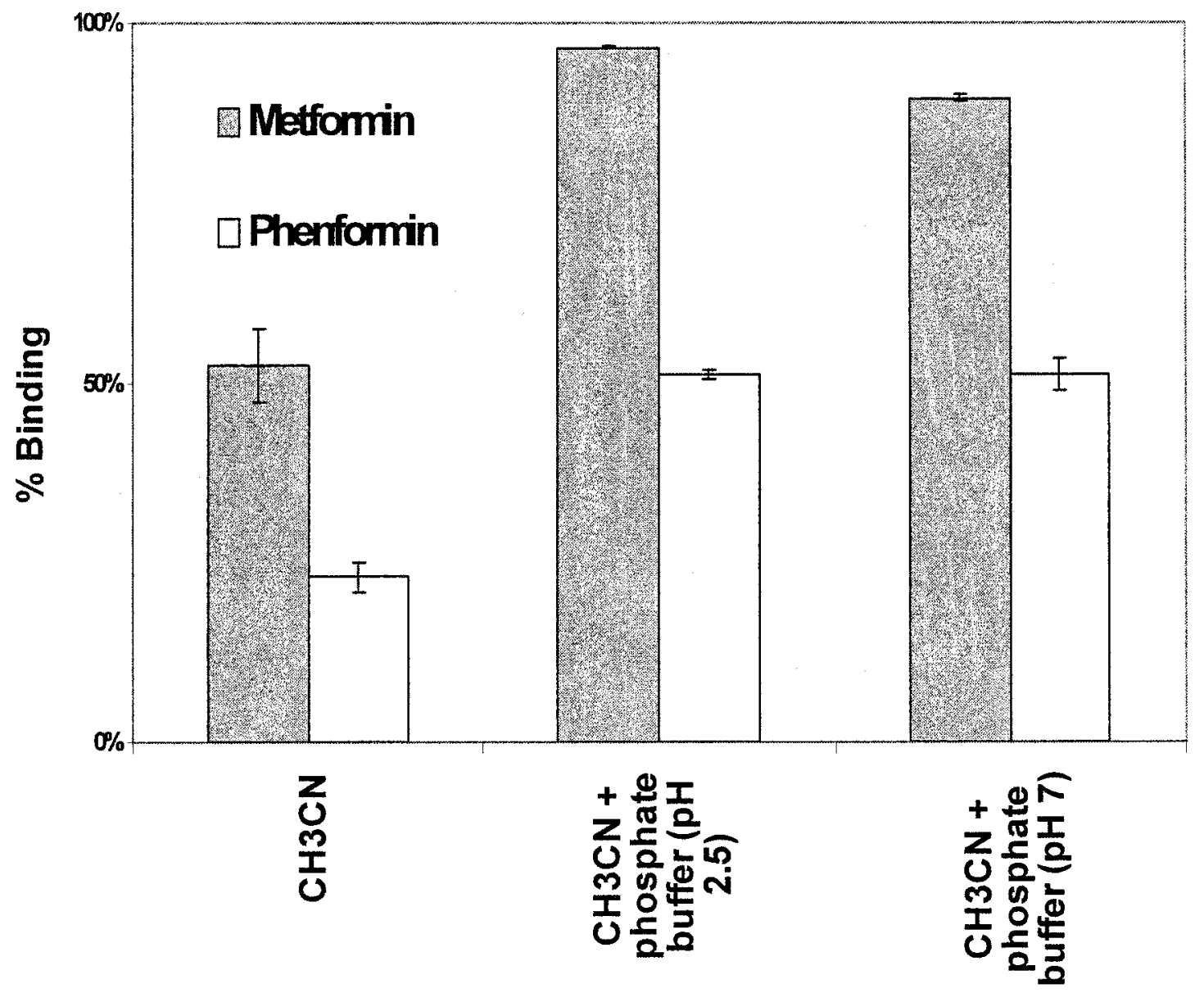

Figure 6 Comparison of \% bindings for $60 \mu \mathrm{g} / \mathrm{mL}$ metformin and $60 \mu \mathrm{g} / \mathrm{mL}$ phenformin in acetonitrile, 9:1 acetonitrile/phosphate buffer (pH 2.5, $50 \mathrm{mM}$ ), and 9:1 acetonitrile/ phosphate buffer (pH 7.0,50 mM). 


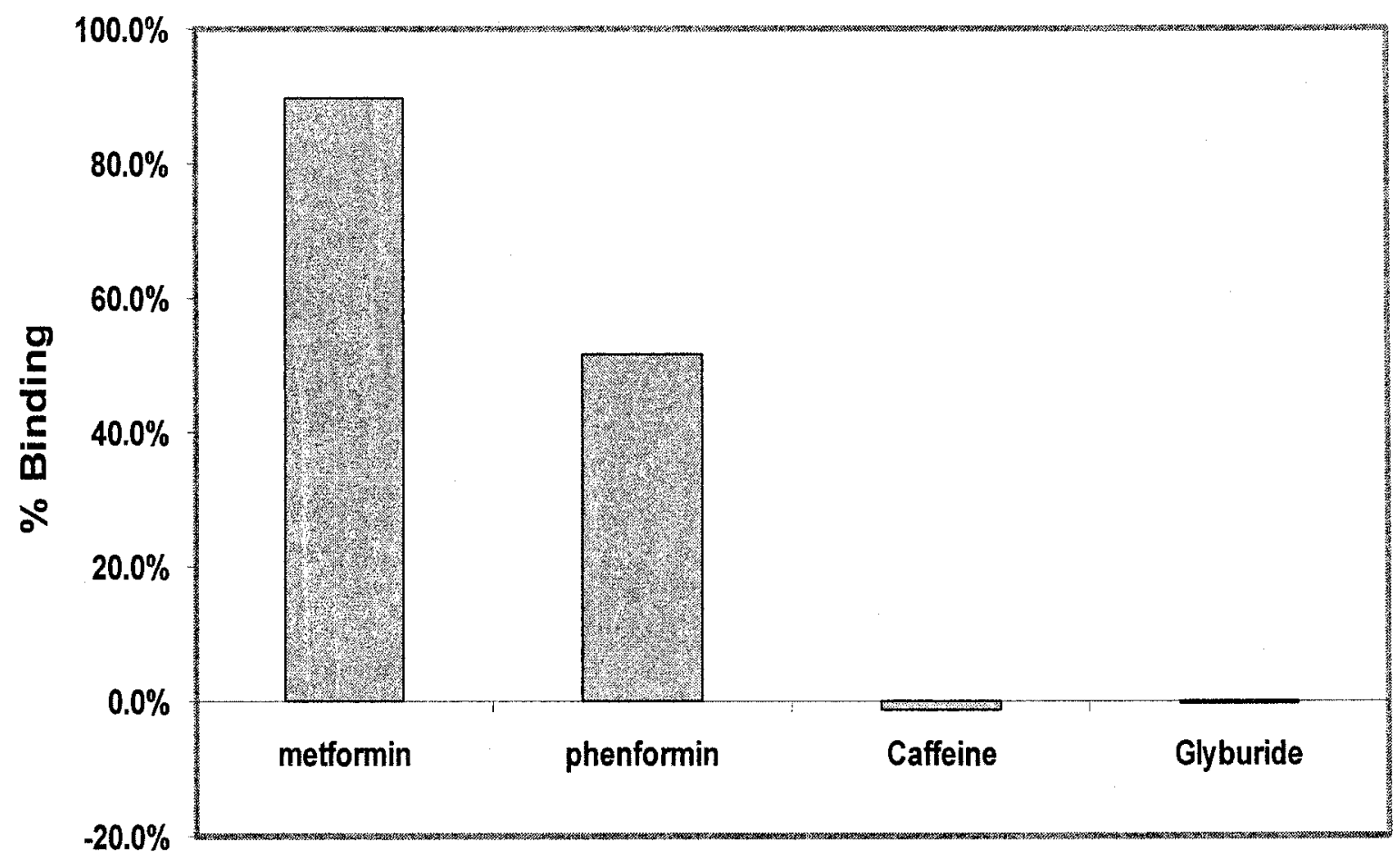

Figure 7. Comparison of \% bindings for $60 \mu \mathrm{g} / \mathrm{mL}$ metformin, phenformin, caffeine and glyburide in 9:1 acetonitrile/phosphate buffer (pH 2.5, $50 \mathrm{mM}$ ), separately.

\subsubsection{Evaluation of binding capacity}

Binding capacity and binding constant, as determined by the method of multiple loading injections ${ }^{85}$, are important indices for evaluating the molecular recognition 
ability of a MIP. Metformin binding onto the MIP micro-column was evaluated by multiple $20-\mu \mathrm{L}$ loading injections of a $7.5-\mu \mathrm{g} / \mathrm{mL}$ metformin standard in $9: 1 \mathrm{CH}_{3} \mathrm{CN} / 50$ $\mathrm{mM}$ phosphate buffer $(\mathrm{pH} 2.5)$, with acetonitrile as mobile phase at a flow rate of 0.5 $\mathrm{mL} / \mathrm{min}$ (Figure 8). As showed in Table 1, this metformin MIP micro-column showed a much higher binding recognition for metformin than for phenformin. The binding capacity and binding constant were 2 and 3 times higher for metformin than phenformin.

Table 1. Comparison of binding capacity and binding constant values, as determined for $20 \mathrm{mg}$ of MIP particles in micro-column.

\begin{tabular}{|l|c|c|}
\hline \multicolumn{1}{|c|}{ Micro-column } & Metformin & Phenformin \\
\hline Binding capacity & $1630 \mathrm{ng}$ & $780 \mathrm{ng}$ \\
\hline Binding constant $(\mathrm{Keq})$ & 13.6 & 4.4 \\
\hline
\end{tabular}




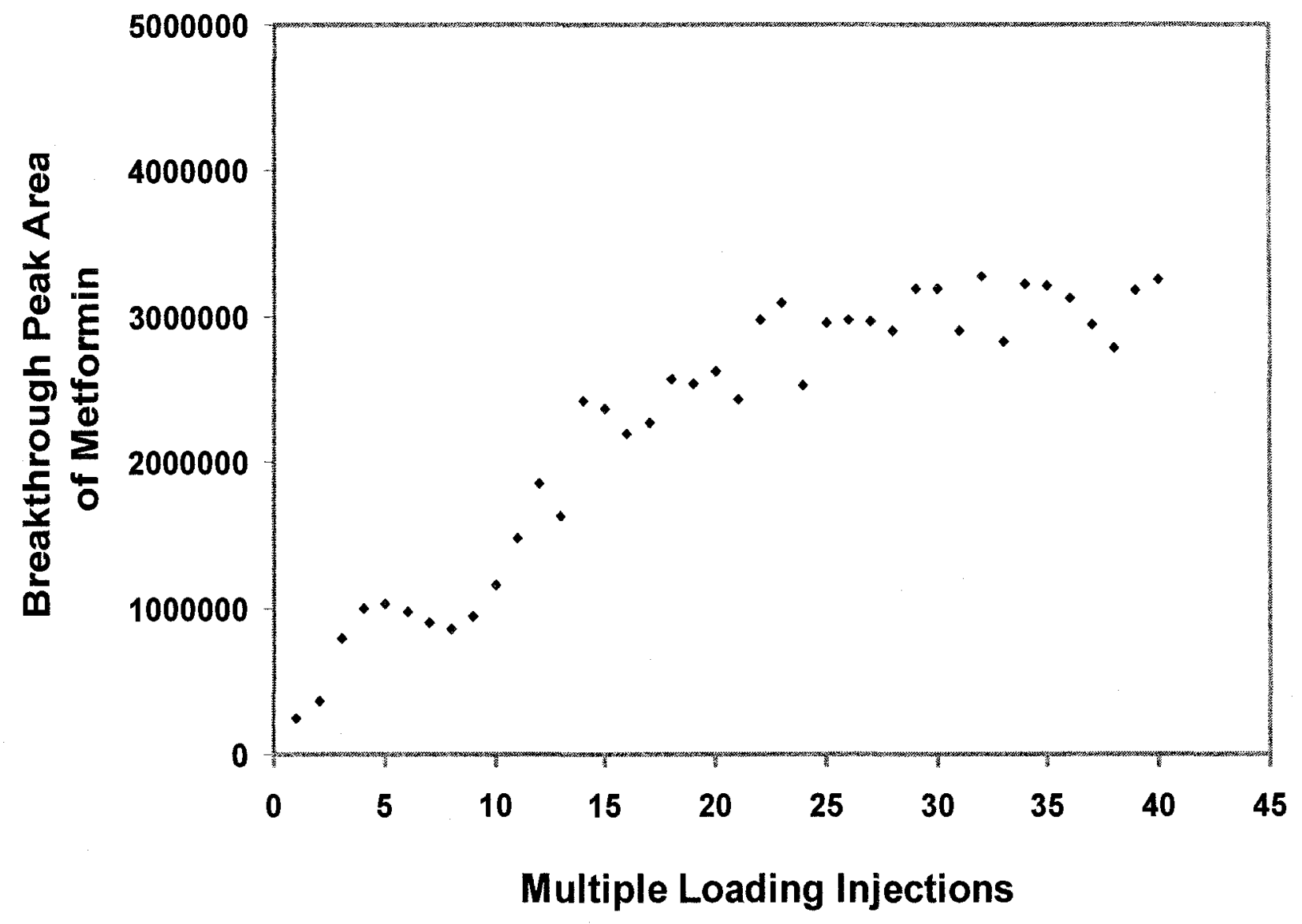

Figure 8. Metformin binding saturation test 


\subsubsection{Effect of metformin concentration on \% binding}

The effect of metformin concentration on \% binding was investigated by testing metformin standard solutions over the range of $7.5-60 \mu \mathrm{g} / \mathrm{mL}(150-1200 \mathrm{ng})$ in $9: 1$ $\mathrm{CH}_{3} \mathrm{CN} / 50 \mathrm{mM}$ phosphate buffer ( $\mathrm{pH} 2.5$ ). As shown in Figure 9, the mass of metformin loaded has no significant effect on \% binding, and 86.0-96.6 \% binding could be achieved over the tested concentration range. These results show that the metformin MIP behaves well to recognize metformin molecules at various concentration levels.

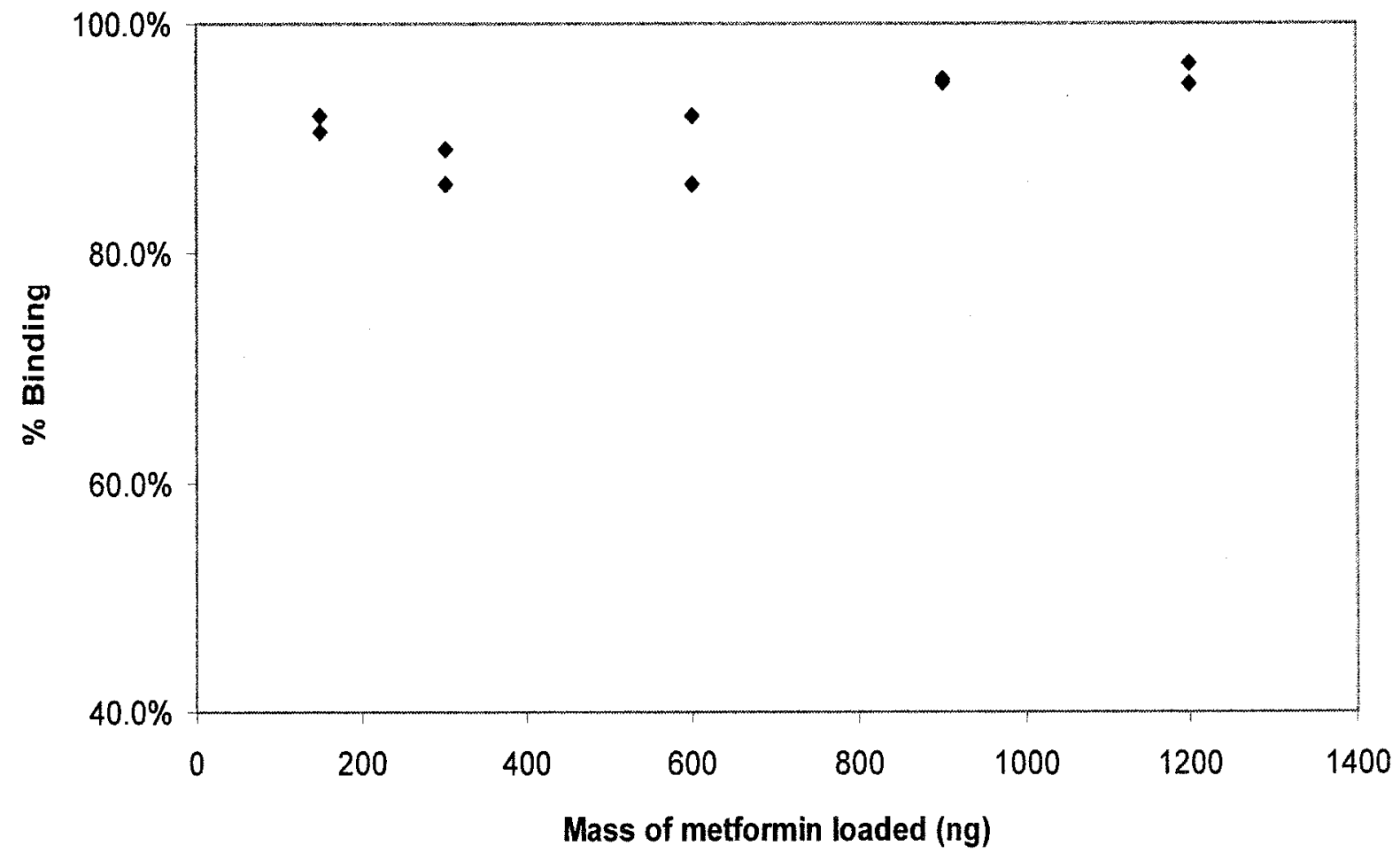

Figure 9. Relationship of \% binding and mass of metformin loaded 


\subsubsection{Effect of sample solvent on \% binding}

MIPs can be used to extract the target analytes from either organic or aqueous solutions. Swelling and shrinkage is an inherent property of even highly cross-linked MIPs ${ }^{86}$. Shrinkage can reduce the analyte binding because of collapsing cavities and diffusion hindrance in the MIP. Swelling can often be disregarded in aqueous solutions, whereas organic solutions will affect the polymer properties. Hence, it is important to investigate the performance of a new MIP in different sample media for the potential application of MISPE in various assay formats and application areas.

Acetonitrile was the mobile phase of choice in terms of minimal non-specific binding during MISPE. The hydrodynamic ability of the MIP micro-column to bind and retain metformin was evaluated for various aqueous and acetonitrile standard solutions $(60 \mu \mathrm{g} / \mathrm{mL})$. Breakthrough peak area measurements were made in separate $20-\mu \mathrm{L}$ loading injections. Acetonitrile afforded a $35 \pm 2 \%$ binding for metformin while distilled deionized water attained a $55 \pm 3 \%$. It was apparent that hydrophobic (or non-ionic) polar interactions between the MIP and metformin molecules played a determining role in the strength of binding when measured for water as a polar, protic sample solvent ${ }^{87}$. In comparison, water/acetonitrile ( $1: 9 \mathrm{v} / \mathrm{v})$ afforded a $35 \pm 3 \%$ binding for metformin. These results agree with the previous findings of Karlsson et al's that the entropy-driven hydrophobic effect would be significant in aqueous buffers and polar solvents, whereas enthalpy driven binding interactions would dominate in non-polar solvents ${ }^{88}$. Since they had observed a maximum level of MIP binding selectivity in pure acetonitrile, this organic solvent was employed as the mobile phase in all subsequent investigations. 


\subsubsection{Effect of buffer $\mathrm{pH}$ in sample solution on \% binding}

Binding of metformin onto the MIP micro-column was examined over a $\mathrm{pH}$ range from 1.5 to 8.0 . Different types of aqueous buffers were added to the $60-\mu \mathrm{g} / \mathrm{mL}$ standard solutions of metformin in acetonitrile, in a constant ratio of $1: 9 \mathrm{v} / \mathrm{v}$. Given the basic nature of metformin $(\mathrm{pKa}=13.1 \pm 0.5)$, the positively-charged protonated metformin was expected to interact strongly with the negatively-charged carboxylic groups in the MIP at $\mathrm{pH} \leq 7.0$. The results in Figure 10 show a marked effect of buffer $\mathrm{pH}$ on the MIP microcolumn binding ability. Relatively high \% bindings were achieved at $\mathrm{pH} 2.5,4.5$ and 7.0. No general trend in $\mathrm{pH}$ effect could be established because a low \% binding was observed at the intermediate $\mathrm{pH}$ of 6.0. It is interesting to note that the two phosphate buffers ( $\mathrm{pH} 2.5$ and 7.0$)$ afforded significantly higher \% bindings of metformin than the other buffers. One plausible explanation is that some buffer acids might compete with metformin for the MIP carboxylic acid functional group. Consider acetic acid for instance:

$$
\begin{gathered}
\text { Metformin }+\mathrm{CH}_{3} \mathrm{COOH}+\text { HOOC-MIP } \\
\rightleftharpoons \quad \text { Metformin }+\mathrm{CH}_{3} \mathrm{CO} \cdots \mathrm{HO} \\
\text { OH } \cdots \text { OC-MIP }
\end{gathered}
$$

where two hydrogen bonds $(=\mathrm{CO} \cdots \mathrm{HO}-)$ could exist to form a dimeric interaction between the acetic acid molecule and the MIP carboxylic acid functional group. According to this hypothetical model, a critical parameter would be the distance between the $=\mathrm{CO}$ oxygen and the $-\mathrm{OH}$ hydrogen in the buffer acid molecule. This distance should 
ideally match the distance between the $=\mathrm{CO}$ oxygen and the $-\mathrm{OH}$ hydrogen in the MIP carboxylic acid functional group. Calculations were performed at the semi-empirical molecular orbital level (AM1) using PC Spartan Plus for the buffer acids and base studied, with their molecular structures shown in Figure 11. As summarized in Table 2, the distances calculated for glycine, acetic acid, 2-(4-morpholino)ethanesulfonic acid and tris(hydroxymethyl)-methylamine are comparable to that for the MIP. Interestingly, the distance for phosphoric acid is significantly larger. This mismatch explains why the phosphate buffers (both $\mathrm{pH} 2.5$ and $\mathrm{pH}$ 7.0) did not compete favorably for the MIP carboxylic acid functional group. As a result, the \% bindings for metformin onto the MIP micro-column were significantly higher in these two phosphate buffers. 


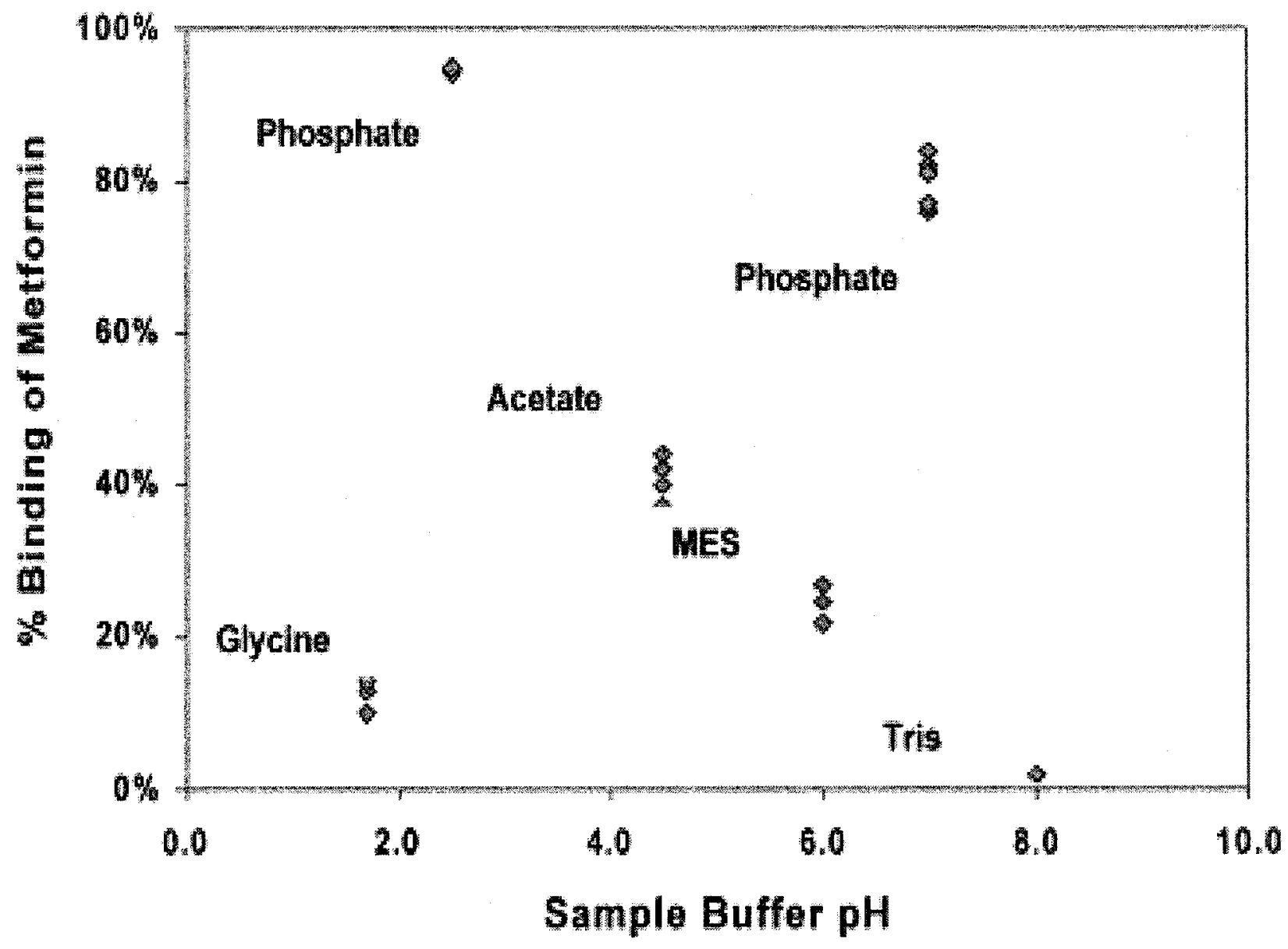

Figure 10. Effect of buffer $\mathrm{pH}$ (at constant buffer concentration of $50 \mathrm{mM}$ ) in sample solution on \% binding for $60 \mu \mathrm{g} / \mathrm{ml}$ metformin. 


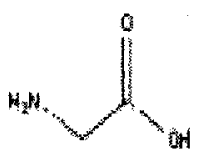

Glycine

(or Aminoacetic acid)

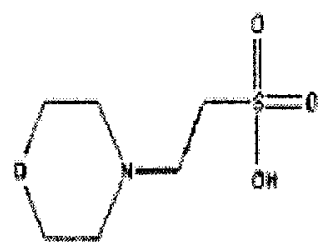

2-(4-Morpholino) ethanesulfonic acid

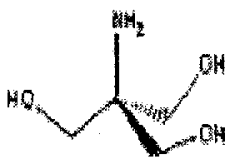

Tris(hydroxymethyl)met hylamine

Figure 11. Molecular structures of buffer acids and base studied. 
Table 2. Distances between $=\mathrm{CO}$ oxygen (or $-\mathrm{NH}_{2}$ nitrogen) and $-\mathrm{OH}$ hydrogen calculated for the MIP and different buffer acids and base. TFA is included as a useful reagent for pulsed elution of metformin from the MIP micro-column.

\begin{tabular}{|l|c|c|}
\hline \multicolumn{1}{|c|}{$\begin{array}{c}\text { Molecular structure } \\
\text { (MIP) }\end{array}$} & pH & Distance between O (or N) and H ( $)$ ) \\
\hline $\begin{array}{l}\text { 2-Trifluoromethylpropranoic acid } \\
\text { Glycine }\end{array}$ & 1.7 & 2.192 \\
\hline $\begin{array}{l}\text { Phosphoric acid } \\
\text { (pKa =2.2, 7.2 and 12.2) }\end{array}$ & 2.5 & 2.194 \\
\hline Acetic acid & 4.5 & 2.214 \\
\hline 2-(4-Morpholino)ethanesulfonic acid & 6.0 & 2.369 \\
\hline Phosphate & 7.0 & 2.136 \\
\hline Tris(hydroxymethyl)methylamine & 8.0 & 2.195 \\
\hline Trifluoroacetic acid & & \\
\hline
\end{tabular}




\subsection{Molecularly imprinted solid phase extraction}

Sorbents for SPE need to work only in "on" or "off" modes, strongly adsorbing and easily releasing an analyte, while moderate strength of retention with good resolution is required for chromatographic stationary phases. Furthermore, the column efficiency, negatively affected by peak broadening and tailing, is much less significant in SPE applications. SPE is thus regarded as an application suitable for MIPs. SPE was previously reported using a dispersion polymer for enrichment of a specific sample ${ }^{89}$. Some other examples of MIP-based SPE have also been reported ${ }^{90,91}$.

\subsubsection{Molecularly imprinted solid-phase extraction}

The new MIP was specifically synthesized as a smart material for the recognition of metformin hydrochloride. Particles of this MIP were packed into a micro-column for the development of a molecularly imprinted solid-phase extraction (MISPE) method. With $\mathrm{CH}_{3} \mathrm{CN}$ as the mobile phase flowing at $0.5 \mathrm{ml} / \mathrm{min}, 95 \pm 2 \%$ binding could be achieved for up to $1200 \mathrm{ng}$ of metformin from one $20-\mu 1$ loading injection of a $60-\mu \mathrm{g} / \mathrm{ml}$ metformin solution (phosphate buffer at $\mathrm{pH} 2.5$ or 7.0 ). However, the micro-column interacted indiscriminately with phenformin with a $49 \pm 2 \%$ binding. The molecular structures of metformin and phenformin are very similar as shown in Figure 5. When a FPE of metformin for direct UV detection was performed using 3\% TFA in methanol, the phenformin would also be detected to cause a positive interference. 


\subsubsection{Pulsed elution of metformin}

TFA is a strong organic acid with a pKa value of $0.7 \pm 0.2^{92}$. It had previously been reported that elution with $2 \%$ TFA in acetonitrile yielded approximately $80 \%$ recovery of the analytes (ropivacaine and bupivacaine) that was bound on the MIP, and that the extracts were less pure than elution with $2-10 \%$ triethylamine (TEA) ${ }^{93}$. We expected that $2 \%$ TEA in acetonitrile would transfer to the present MISPE method development because this elution solvent contained a strong base (TEA) that could effectively displace metformin from the MIP binding sites. However, TEA could not be employed for the PE of metformin because it is a strong base itself that would bind on the MIP micro-column to hamper MISPE analysis of the next sample. Fortunately, improvement to $98 \pm 1 \%$ recovery was achieved when $3 \%$ TFA in methanol (not acetonitrile) was evaluated for the PE of metformin. Increasing the TFA content up to $10 \%$ in methanol, however, only marginally improved the recovery of metformin but significantly increased the blank signal to jeopardize low-concentration metformin analysis.

\subsubsection{Standard calibration curve for MISPE-PE determination of metformin}

A standard calibration curve for MISPE-PE determination of metformin in acetonitrile (phosphate buffered at $\mathrm{pH} 2.5$ ), using 3\% TFA in methanol for PE, is shown in Figure 12. The MISPE-PE peak area was linearly related $\left(\mathrm{R}^{2}=0.9895\right)$ to the mass of metformin loaded on the MIP micro-column up to $900 \mathrm{ng}$. Deviation from linearity 
began near $1200 \mathrm{ng}$, which was approaching the micro-column binding capacity of 1600 ng for metformin. The detection limit was found to be $0.8 \mu \mathrm{g} / \mathrm{ml}$ (or $16 \mathrm{ng}$ in $20 \mu \mathrm{l}$ of sample injected) for metformin, based on 3 standard deviations of the blank.

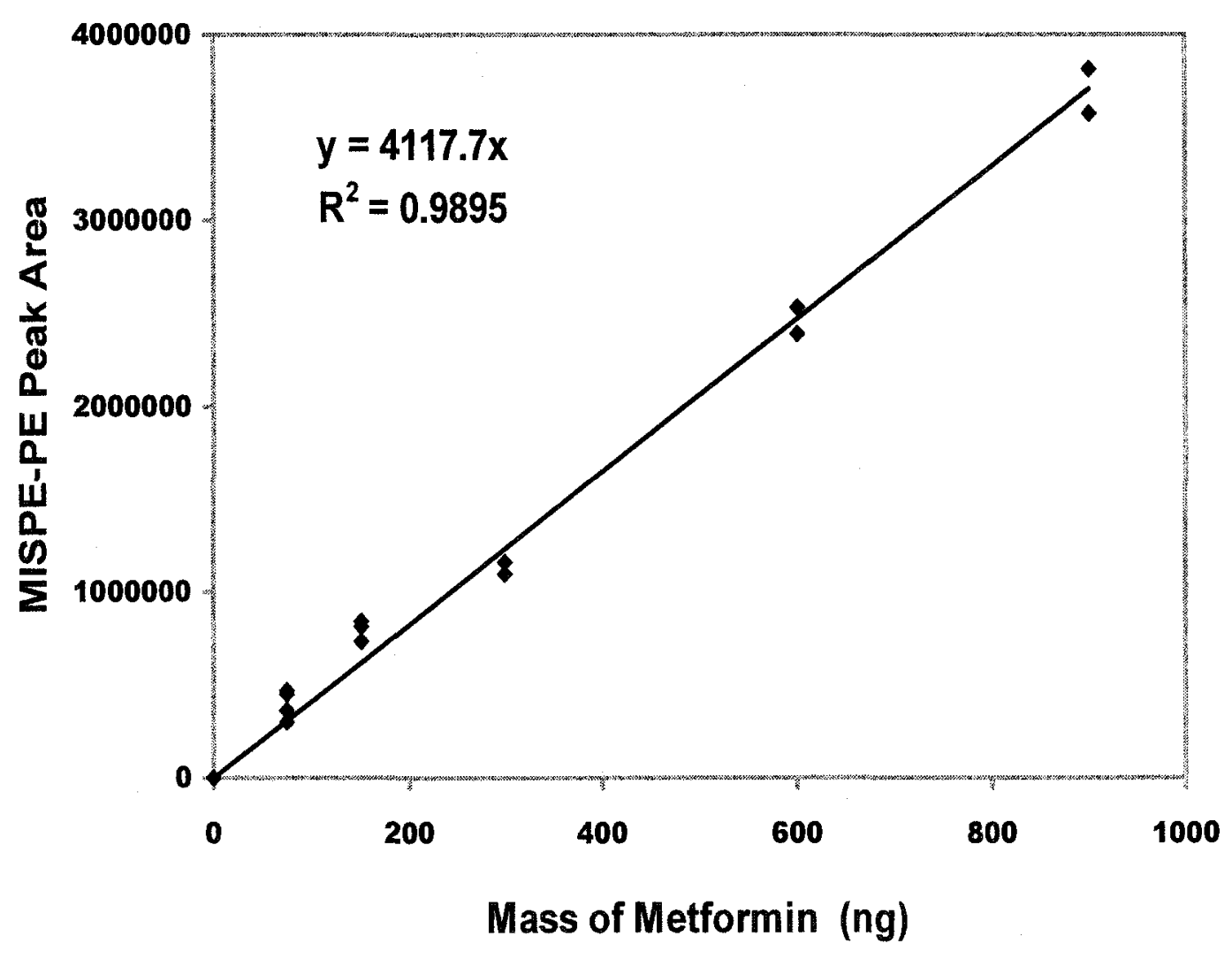

Figure 12. Standard calibration curve for MISPE-PE determination of metformin in acetonitrile (phosphate buffer at $\mathrm{pH} 2.5$ ), using $\mathrm{CH}_{3} \mathrm{OH}+3 \%$ TFA for PE. 


\subsubsection{Elimination of non-specific binding for phenformin}

\subsubsection{Effectiveness of surfactants}

Previously, Andersson et al. had investigated the influence of the type and concentration of detergent in the buffer on specific binding and non-specific binding ${ }^{94}$. They found that Triton X-100, Tween 20 and Brij $35(0.1-0.5 \%)$ were able to eliminate non-specific adsorption while analyte specific binding was left essentially unaffected. A systematic investigation of enhancing binding selectivity with detergents (or surfactants) was conducted for the purpose of eliminating phenformin interference. The three approaches were Differential pulsed elution (DPE), sample matrix addition and mobile phase composition. They all involved a variation of surfactants, differing mostly in their consumption of chemicals and simplicity of operation.

First, MISPE-DPE approach was adopted ${ }^{95,96,97,98}$. DPE was an intermediate wash step used to remove phenformin and other structural analogues from the MIP micro-column. Two nonionic (Triton X-100 and Tween 20) surfactants were tested for their DPE effectiveness. Unfortunately, phenformin could not be removed using $1 \%$ Triton $\mathrm{X}-100$ in $0.1 \mathrm{M}$ aqueous $\mathrm{NaOH}$ as the DPE solution. One reason might be that Triton X-100 could not form a charge-transfer complex with phenformin because they are both electron donors ${ }^{99}$. Table 3 shows the DPE effectiveness observed for Tween 20 at three different $\%$ in $\mathrm{CH}_{3} \mathrm{OH}$ over multiple injections. On the average, $62 \pm 4 \%$ of the phenformin remained on the MIP micro-column. With acetonitrile as the mobile phase, it seemed hard to quantitatively eliminate the non-specific binding of phenformin on the micro-column by using non-ionic surfactants in DPE. 
Second, surfactants were added as a matrix component in the sample solution to prevent non-specific binding of phenformin on the MIP micro-column. As shown in Table 4 , as much as $11 \%$ of the injected phenformin could bind with the micro-column even though the Tween 20 content was increased up to $50 \%$. A plausible explanation is that the surfactant failed to competitively occupy the binding sites because hydrophobic interactions in the non-aqueous solvent were too weak for the surfactant molecules to adsorb readily on the MIP particles. One anionic surfactant, Na taurodeoxycholate, was then added in varying concentrations to different sample solutions. As illustrated in Figure 13, the surfactant could not prevent the non-specific binding of phenformin on the MIP micro-column. 
Table 3. Effectiveness of using surfactant solutions for DPE after loading $60 \mu \mathrm{g} / \mathrm{ml}$ phenformin in $\mathrm{CH}_{3} \mathrm{CN}-50 \mathrm{mM}$ phosphate buffer (pH 7.0) $(9: 1 \mathrm{v} / \mathrm{v})$

\begin{tabular}{ll} 
Concentration of surfactant & Phenformin remaining on \\
solution for DPE & micro-column after DPE (\%) \\
\hline $1 \%$ Tween 20 in $\mathrm{CH}_{3} \mathrm{OH}(4 \times 20 \mu \mathrm{l})$ & 58 \\
$10 \%$ Tween 20 in $\mathrm{CH}_{3} \mathrm{OH}(6 \times 20 \mu \mathrm{l})$ & 58 \\
$20 \%$ Tween 20 in $\mathrm{CH}_{3} \mathrm{OH}(3 \times 20 \mu \mathrm{l})$ & 67 \\
\hline
\end{tabular}

Mobile phase: acetonitrile at $0.5 \mathrm{ml} / \mathrm{min}$; FPE solvent: $3 \%$ TFA in methanol. These $\%$ phenformin remaining results can be compared with $100 \%$ without DPE.

Table 4. Effectiveness of adding surfactants into sample solution of $60 \mu \mathrm{g} / \mathrm{ml}$ phenformin in $\mathrm{CH}_{3} \mathrm{CN}-50 \mathrm{mM}$ phosphate buffer (pH 7) (9:1)

Surfactant added

$20 \%$ Tween 20

$50 \%$ Tween 20
Binding of phenformin (\%)

19

11

Mobile phase: acetonitrile at $0.5 \mathrm{ml} / \mathrm{min}$; FPE solvent: $3 \%$ TFA in methanol. The $\%$ phenformin binding results can be compared with $49 \%$ without adding surfactant. 


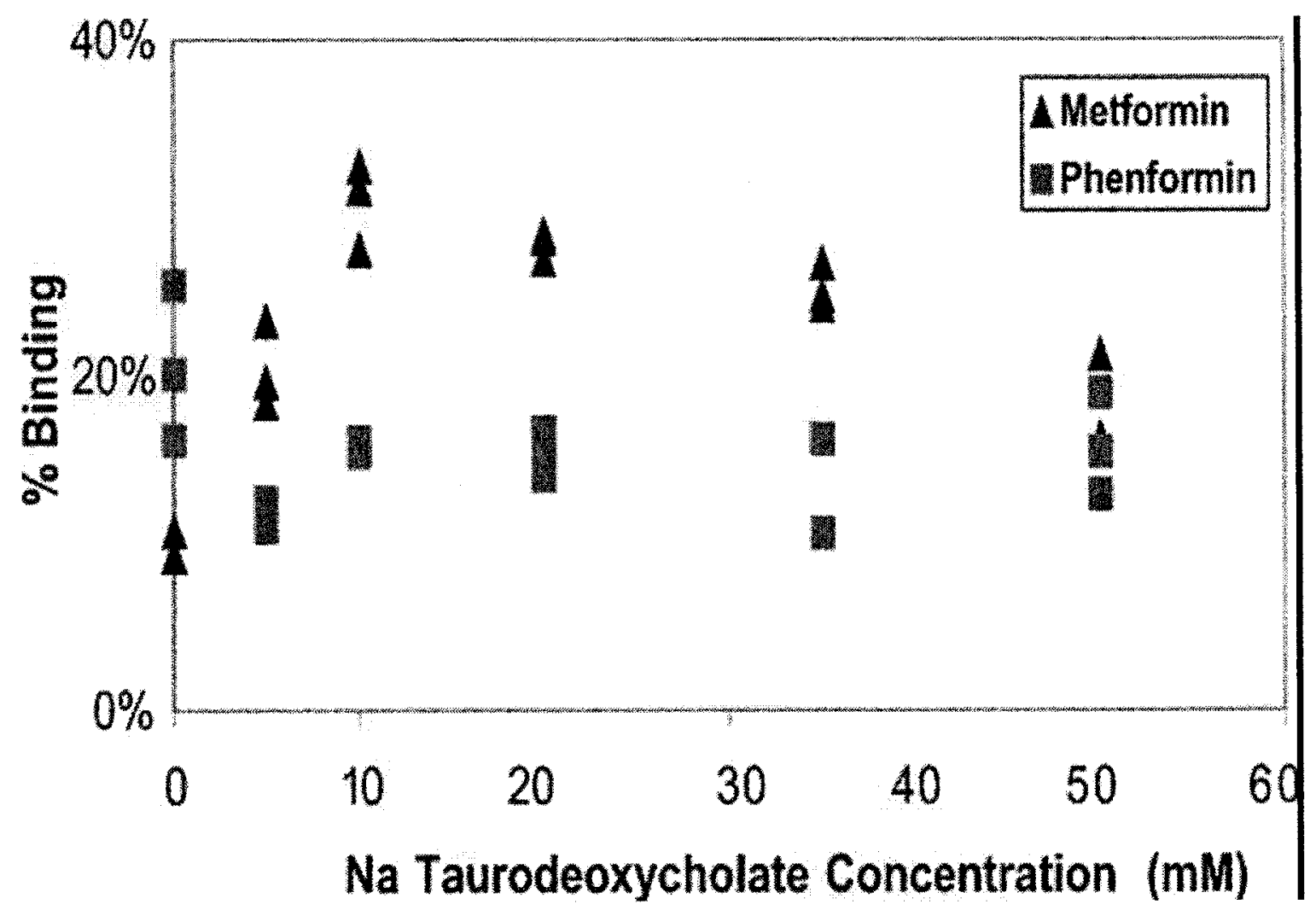

Figuree 13. Effect of sodium taurodeoxycholate concentration in sample solution on \% binding of metformin and phenformin.

Third, surfactants were added in the mobile phase to pre-occupy the binding sites on the MIP micro-column. When $0.5 \%$ Tween $20+5 \%$ ethanol in acetonitrile was employed as the mobile phase ${ }^{94}$, the $52 \pm 2 \%$ binding result for phenformin was statistically the same as before when using pure acetonitrile as the mobile phase. Several cationic surfactants (HMB, DTAB, TTAB, DDAB) were last evaluated as modifiers. 
After injection of $20-\mu \mathrm{l}$ aliquots of these solutions to pre-condition the MIP, phenformin and metformin sample solutions were loaded on the micro-column. Their \% binding results are presented in Table 5 to show no significant effects overall.

Table 5. Effect of HMB, DTAB, TTAB and DDAB on \% binding of metformin and phenformin.

\begin{tabular}{lll} 
Surfactant solution & $\begin{array}{l}\text { Binding of } \\
\text { metformin (\%) }\end{array}$ & $\begin{array}{l}\text { Binding of } \\
\text { phenformin (\%) }\end{array}$ \\
\hline 0.1M HMB in $\mathrm{CH}_{3} \mathrm{CN}$-water (8:2) & 75 & 43 \\
0.1M DTAB in $\mathrm{CH}_{3} \mathrm{CN}$-water (8:2) & 76 & 48 \\
0.1M TTAB in $\mathrm{CH}_{3} \mathrm{CN}$-water (8:2) & 75 & 47 \\
0.1M DDAB in $\mathrm{CH}_{3} \mathrm{CN}$-water (8:2) & 77 & 46 \\
\hline
\end{tabular}

\subsubsection{Differential pulsed elution (DPE) with organic acids}

DPE method was chosen for elimination of phenformin from the MIP microcolumn, while metformin was selectively retained. Several organic acids were evaluated for their DPE effectiveness. As summarized in Table $6,10 \%$ benzoic acid $(\mathrm{pKa}=4.19)$ in $\mathrm{CH}_{3} \mathrm{OH}$ was poor for the DPE removal of phenformin. $18 \%$ pentafluorobenzoic acid $(\mathrm{pKa}=1.99)$ in $\mathrm{CH}_{3} \mathrm{CN}$ left behind $20 \%$ of phenformin on the micro-column. $30 \%$ acetic acid $(\mathrm{pKa}=4.74)$ in $\mathrm{CH}_{3} \mathrm{OH}$ was fairly good for the removal of phenformin, but only $10 \%$ of metformin remained on the micro-column. $2 \%$ TFA in $\mathrm{CH}_{3} \mathrm{OH}$ was very good at 
removing phenformin, but only $5 \%$ of metformin remained. Ideally, DPE must eliminate phenformin quantitatively while leaving behind an adequate amount of metformin for UV detection. Picric acid ( $\mathrm{pKa}=0.30-0.53$ ), as shown in Figure 14 , was strategically selected from among the strongest organic acids that were commercially available 100,101,102. Different concentrations of picric acid in acetonitrile were evaluated for the best DPE result. After DPE with each picric acid, TFA $(\mathrm{pKa}=-0.23-0.0)$ was used in FPE to elute all of the remaining phenformin. As shown in Figure 15 for $60 \mu \mathrm{g} / \mathrm{ml}$ phenformin, a picric acid concentration of $5 \%$ or higher proved to be effective in the quantitative elution of phenformin. As a $\pi$-electron acceptor ${ }^{103,104}$, picric acid could form a stronger charge-transfer complex with phenformin than with metformin. Note that the functional monomer, TFMAA $(\mathrm{pKa}=1.9-2.3)$, must be able to hold a significant amount of metformin on the micro-column during DPE. When the evaluation was repeated for $60 \mu \mathrm{g} / \mathrm{ml}$ metformin, the result indicated that $37 \pm 3 \%$ of metformin remained on the micro-column after DPE with $5 \%$ picric acid. This suggested that picric acid would be an effective reagent for the quantitative DPE of phenformin in the presence of bound metformin. $5 \%$ picric acid was evaluated as the DPE solvent for mixtures of metformin $(5-50 \mu \mathrm{g} / \mathrm{ml}$ in acetonitrile $-50 \mathrm{mM} \mathrm{pH} 7$ phosphate buffer, 9:1 v/v) and phenformin $(60 \mu \mathrm{g} / \mathrm{ml})$. The results verified that, over the concentration range studied, a reasonably constant $37 \pm 2 \%$ of the bound metformin remained on the MIP micro-column while phenformin was quantitatively removed by the DPE. 
Table 6. Evaluation of organic acids for DPE effectiveness

(\% metformin remaining was not determined unless \% phenformin remaining on microcolumn was under $3 \%$.)

\begin{tabular}{lcc}
\hline DPE solution & $\begin{array}{c}\text { Phenformin remaining on } \\
\text { micro-column after DPE (\%) }\end{array}$ & $\begin{array}{c}\text { Metformin remaining on } \\
\text { micro-column after DPE (\%) }\end{array}$ \\
\hline $10 \%$ Benzoic acid in $\mathrm{CH}_{3} \mathrm{OH}$ & 87 & \\
$20 \%$ Acetic acid in $\mathrm{CH}_{3} \mathrm{OH}$ & 10 & 10 \\
$20 \%$ Acetic acid in $\mathrm{CH}_{3} \mathrm{OH}$ & 5 & \\
$30 \%$ Acetic acid in $\mathrm{CH}_{3} \mathrm{OH}$ & 3 & \\
$18 \%$ Pentafluorobenzoic acid in $\mathrm{CH}_{3} \mathrm{CN}$ & 20 & \\
$0.025 \%$ TFA in $\mathrm{CH}_{3} \mathrm{OH}$ & 68 & 5 \\
$0.05 \%$ TFA in $\mathrm{CH}_{3} \mathrm{OH}$ & 50 & 5 \\
$0.1 \%$ TFA in $\mathrm{CH}_{3} \mathrm{OH}$ & 2 & 5 \\
$0.5 \%$ TFA in $\mathrm{CH}_{3} \mathrm{OH}$ & 1 & \\
$2 \% \mathrm{TFA}$ in $\mathrm{CH}_{3} \mathrm{OH}$ & 1 & \\
\hline
\end{tabular}<smiles>O=[N+]([O-])c1cc([N+](=O)[O-])c(O)c([N+](=O)[O-])c1</smiles>

Figure 14. Structure of picric acid. 


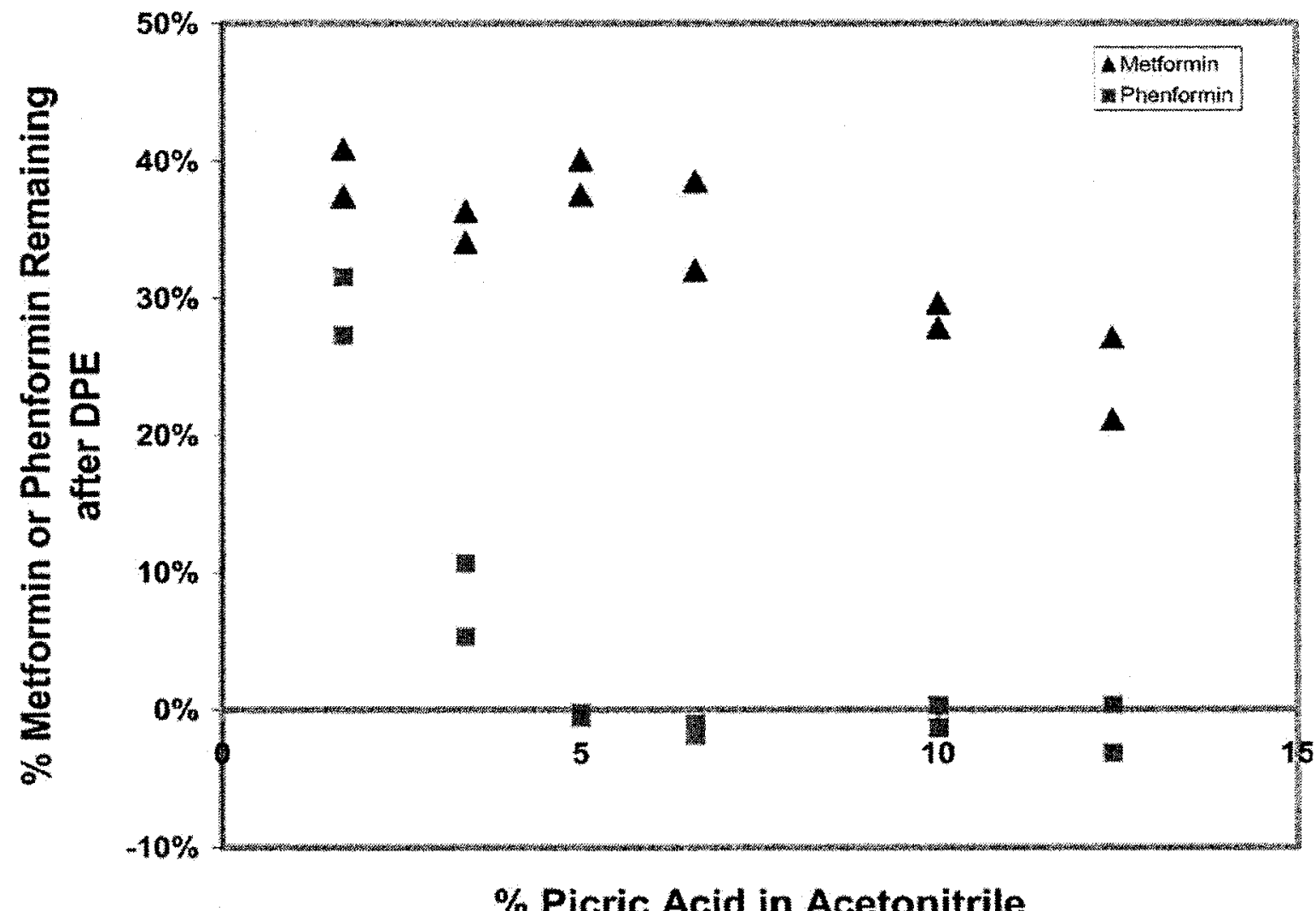

Figure 15. \% Metformin or phenformin remaining on MIP micro-column after DPE with varying \% of picric acid in acetonitrile.

Table 7 is a summary of the DPE solvents that have been reported in the literature as required for various drug compounds bound on five different MIP micro-columns. In the first three cases, different organic solvents could be effective for optimal DPE. In the fourth case, the DPE solvent was optimized by systematically increasing the $\%$ acetic acid in acetonitrile. It cannot be overemphasized how critical it was in the present work 
to find picric acid as an effective reagent for the DPE of phenformin in the presence of metformin. The final increment from 3.4 to $5 \%$ picric acid made a big difference between incurring a risk of $8 \pm 2 \%$ interference by phenformin and enjoying an interference-free determination of metformin in the FPE step. 
Table 7. Summary of DPE solvents for various drug compounds bound onto five different MIP micro-columns

\begin{tabular}{|c|c|c|c|c|c|c|}
\hline Analyte & $\begin{array}{l}\text { pKa of } \\
\text { Analyte }\end{array}$ & $\begin{array}{r}\text { Interferents } \mathrm{pK} \\
\text { inte }\end{array}$ & ferents & $\begin{array}{l}\text { Solvent for MISPE of } \\
\text { analytes and interferents }\end{array}$ & $\begin{array}{l}\text { Solvent for elution of } \\
\text { interferents by DPE }\end{array}$ & $\begin{array}{l}\text { Solvent for elution } \\
\text { of analyte }\end{array}$ \\
\hline Theophylline ${ }^{95,96}$ & 8.68 & $\begin{array}{l}\text { Dyphylline } \\
\text { Nicotinic acid }\end{array}$ & $\begin{array}{l}5.36 \\
4.80\end{array}$ & $\mathrm{CHCl}_{3}$ & $\mathrm{CH}_{3} \mathrm{CN}$ & $\mathrm{CH}_{3} \mathrm{OH}$ \\
\hline Nicotine $^{97}$ & 8.02 & Myosin & & $\mathrm{CH}_{3} \mathrm{CN}$ & $\mathrm{CH}_{3} \mathrm{OH}$ & $\mathrm{H}_{2} \mathrm{O}+1 \% \mathrm{TFA}$ \\
\hline 4-Aminopyridine ${ }^{98}$ & ${ }^{8} 9.26$ & 2-Aminopyridine & 6.67 & $\mathrm{CHCl}_{3}$ & DMSO & $\mathrm{CH}_{3} \mathrm{OH}+1 \% \mathrm{TFA}$ \\
\hline Cephalexin $^{63}$ & $5.3 \& 7.3$ & $\begin{array}{l}\text { Cefradine } \\
\text { Cefadroxil }\end{array}$ & $2.6 \& 7.3$ & $\begin{array}{l}\mathrm{CH}_{3} \mathrm{C} \\
\mathrm{CH}_{3} \mathrm{C}\end{array}$ & $\begin{array}{l}\mathrm{CH}_{3} \mathrm{CN}+10 \% \mathrm{CH}_{3} \mathrm{COOH} \\
\mathrm{CH}_{3} \mathrm{CN}+12 \% \mathrm{CH}_{3} \mathrm{COOH}\end{array}$ & $\mathrm{CH}_{3} \mathrm{OH}+1 \%$ TFA \\
\hline Metformin & 13.1 & Phenformin & 12.7 & $\mathrm{CH}_{3} \mathrm{CN}$ & $\mathrm{CH}_{3} \mathrm{CN}+5 \%$ picric acid & $\mathrm{CH}_{3} \mathrm{OH}+3 \% \mathrm{TFA}$ \\
\hline
\end{tabular}




\subsubsection{Analytical figures of merit}

At a mobile phase flow rate of $0.5 \mathrm{ml} / \mathrm{min}$, the MISPE-DPE method required an analysis time of $6 \mathrm{~min}$ and a solvent consumption of $3 \mathrm{ml}$. Over a 24-h analysis of 360 samples, the total solvent consumption would be $1.1 \mathrm{~L}$ approximately. This affords a substantial reduction in the costs of solvent purchase and waste disposal. With UV detection at $240 \mathrm{~nm}$, a standard calibration curve of $\triangle \mathrm{FPE}$ peak area versus metformin concentration showed good linearity in the range from 5 to $50 \mu \mathrm{g} / \mathrm{ml}$. The limit of detection was $20 \mathrm{ng}$ metformin, or $1 \mu \mathrm{g} / \mathrm{ml}$ with a $20-\mu 1$ loading injection of sample. Since the total binding capacity was determined to be $1600 \mathrm{ng}$ metformin for $20 \mathrm{mg}$ of MIP particles in the micro-column ${ }^{105}$, loading injection of a larger-volume sample could easily be adopted to improve the detection limit. Moreover, there is no potential risk of supplementary errors due to exogenous diet ingredients (e.g. caffeine) that might be observed in human blood to give interference peaks.

\subsubsection{Human plasma analysis}

The usefulness and applicability of the MISPE-PE-DPE method was tested on human plasma samples. Human plasma samples spiked with known quantities of metformin and phenformin were analyzed to confirm the \% recovery of the method. A mean recovery of $94( \pm 4) \%$ for metformin showed good concordance with two previous reports ${ }^{106,107}$. Good linearity $\left(\mathrm{R}^{2}=0.9919\right)$ was observed in the metformin concentration range from 0.1 to $10 \mu \mathrm{g} / \mathrm{mL}$ (Figure 16), which represented the typical therapeutic range of metformin in patients. The limit of detection (LOD) is $57 \mathrm{ng} / \mathrm{ml}$ (expressed as 
$3 \times$ standard deviation of the plasma blank) was adequate for human plasma analysis. This method would be useful for pharmacological and biomedical applications.

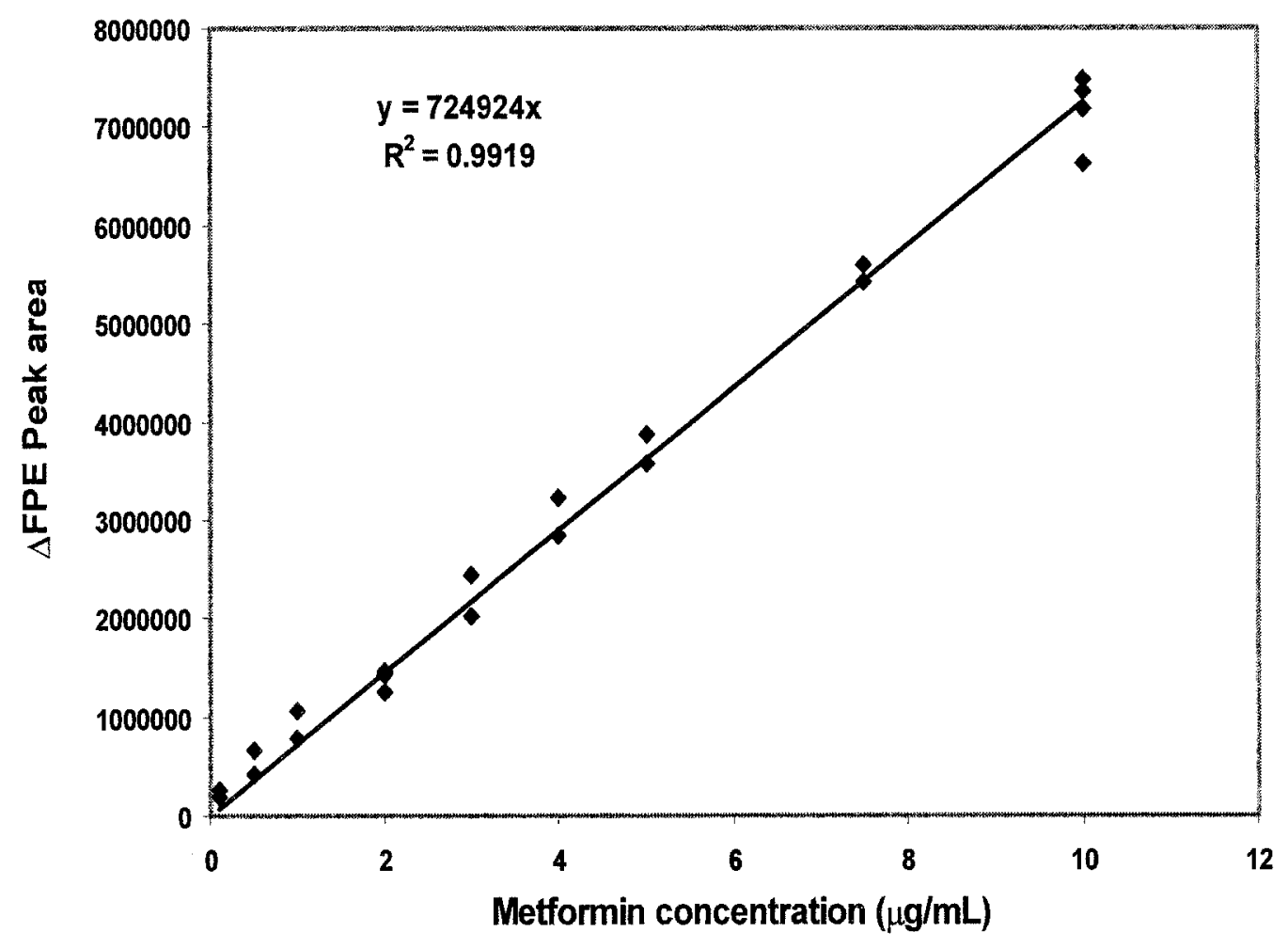

Figure 16. Standard calibration curve of MISPE-FPE-DPE for plasma analysis of metformin. 


\subsection{Capillary zone electrophoresis}

\subsubsection{Capillary zone electrophoresis}

A capillary electrophoresis (CE) method had previously been described for the determination of metformin in human plasma based on the extraction of an ion-pair with bromothymol blue into chloroform. Phenformin was used as an internal standard, and field-amplified sample stacking was employed ${ }^{108}$. When the method was adopted in our laboratory, the separation results turned out to be rather different. As shown in Figure 17. using $50 \mathrm{mM}$ phosphate buffer $(\mathrm{pH} 2.5)$ in water as the medium, separation of metformin from phenformin was attained at $4.33 \mathrm{~min}$ and $6.40 \mathrm{~min}$, respectively. These migration times were deemed to be relatively long.

Song et al had previously demonstrated a general CE method development process of starting at low $\mathrm{pH}$ for basic compounds ${ }^{108}$. Low $\mathrm{pH}(<3.0)$ would be ideal for basic compounds with cathodic $\mathrm{CE}$. At a low $\mathrm{pH}$, peak tailing interactions with the capillary would be minimized, providing the best peak shape. At mid $\mathrm{pH}(5.0-8.0)$, basic compounds might still have a positive charge but different selectivity would result. Changing the $\mathrm{pH}$ could be used to optimize selectivity in most CE method development.

In the present study, the successful $\mathrm{CE}$ method employed $20 \mathrm{mM} \mathrm{NH}_{4} \mathrm{OAc}$ and $5 \%$ HOAc in acetonitrile as the running buffer ( $\mathrm{pH} 5.1$ ), which was modified from the non-aqueous separation medium of $20 \mathrm{mM} \mathrm{NH}_{4} \mathrm{OAc}$ and $1 \mathrm{M} \mathrm{HOAc}$ in acetonitrilealcohol $(50: 49 \mathrm{v} / \mathrm{v})$ reported by Siren et al ${ }^{109}$. The CE analysis results are illustrated in Figure 18, showing good resolution, high separation efficiency and short migration times for metformin $(2.48 \mathrm{~min})$ and phenformin $(3.47 \mathrm{~min})$. When the $\mathrm{CE}$ analysis was repeated by employing $20 \mathrm{mM} \mathrm{NH} \mathrm{NAc}_{4} \mathrm{OAnd} 5 \% \mathrm{HOAc}$ in water as the running buffer 
(pH 3.0), the results exhibited peak tailing, low separation efficiency and increased migration times as shown in Figure 19. This comparison demonstrates that acetonitrile, a dipolar-aprotic solvent, was really contributing to the good separation of metformin and phenformin shown in Figure 18.

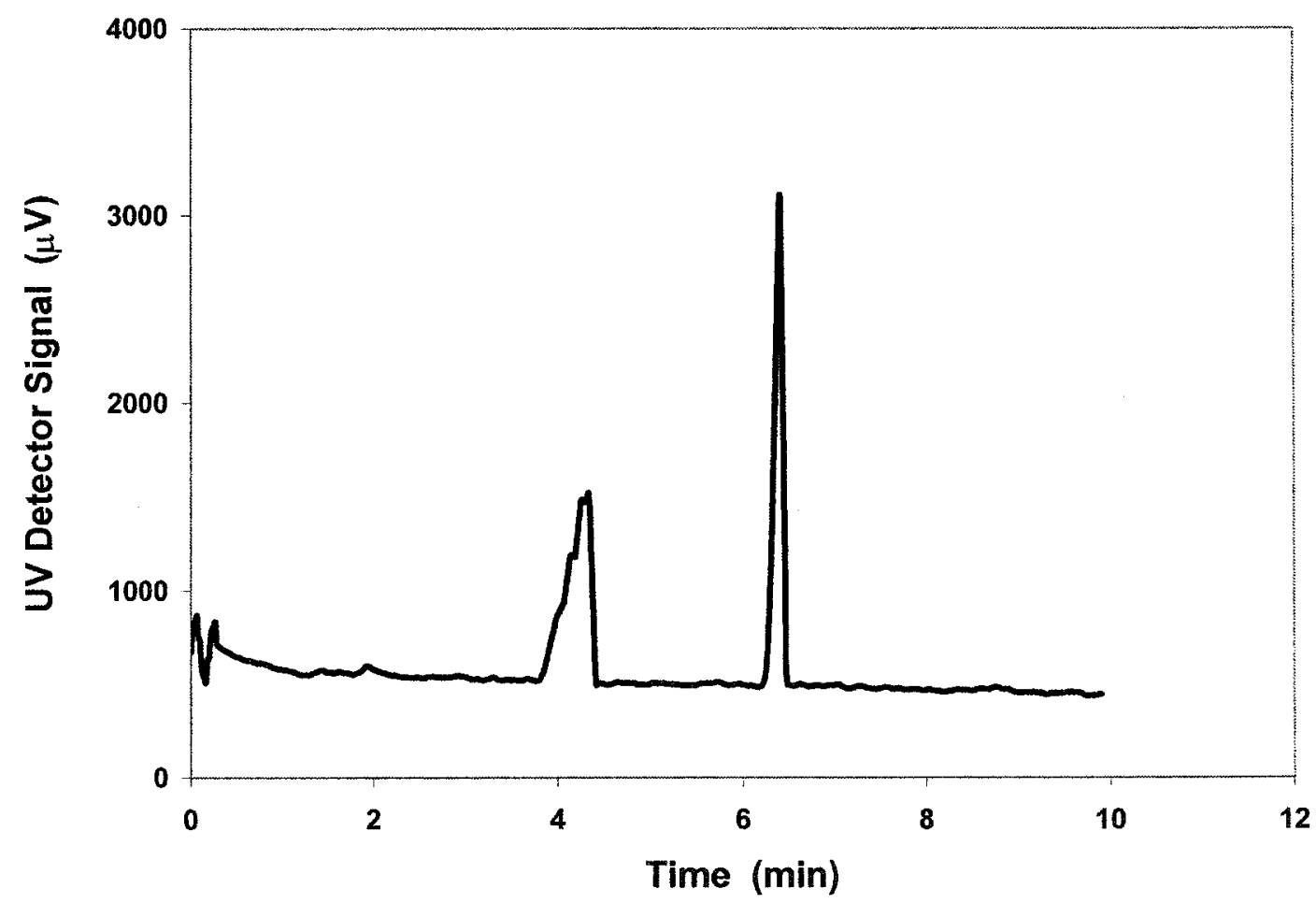

Figure 17 Separation of metformin (at $4.33 \mathrm{~min}$ ) from phenformin (at $6.40 \mathrm{~min}$ ), $60 \mu \mathrm{g} / \mathrm{mL}$ each in aqueous sample. $50 \mathrm{mM}$ phosphate buffer (pH 2.5) in water as the running buffer; $\mathrm{CE}$ under $15 \mathrm{kV}$; room temperature $=$ $22^{\circ} \mathrm{C}$; electrokinetic injection at $15 \mathrm{kV}$ for $6 \mathrm{~s}$; UV detection at $240 \mathrm{~nm}$. 


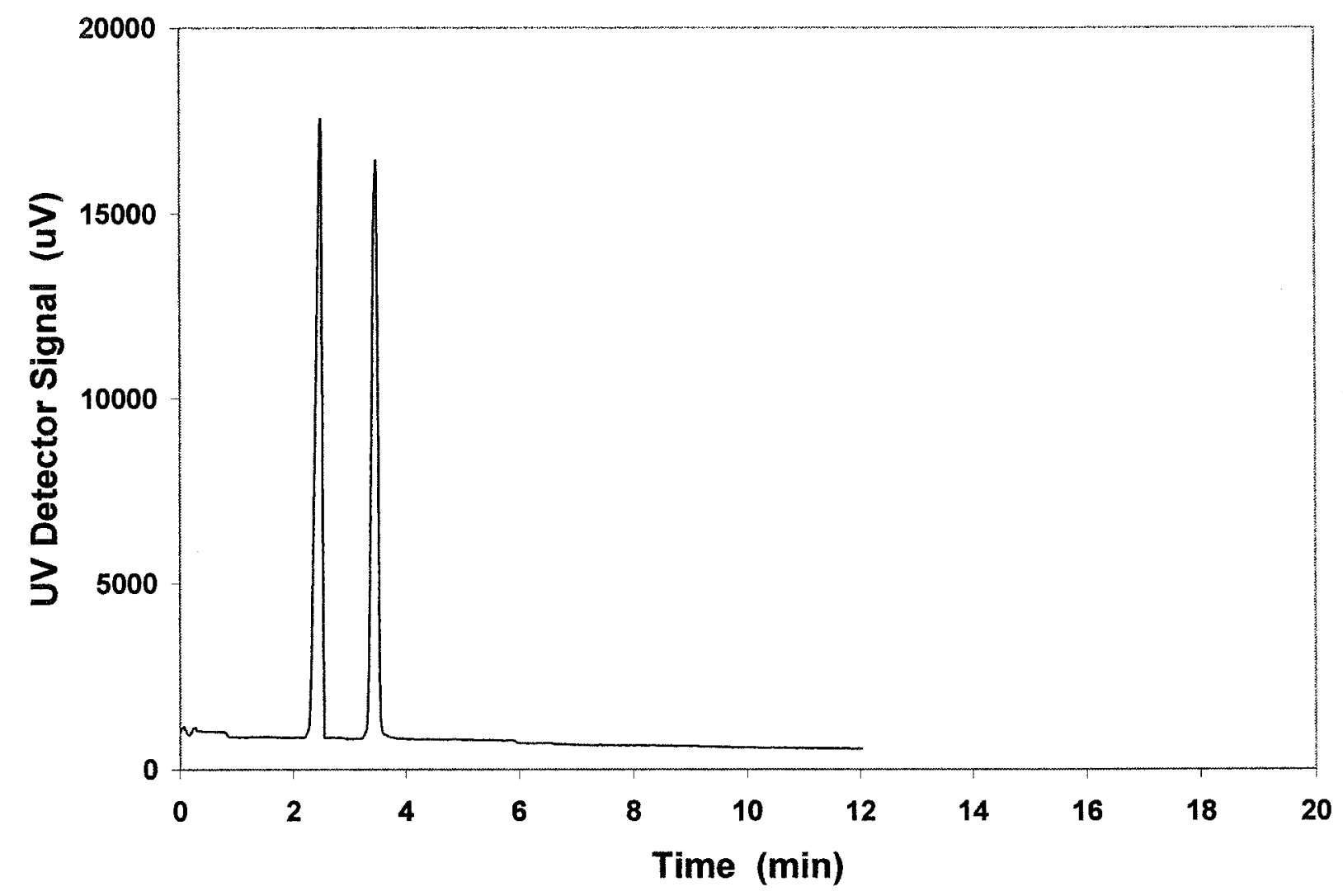

Figure 18 Separation of metformin (at $2.48 \mathrm{~min}$ ) from phenformin (at $3.47 \mathrm{~min}$ ), $60 \mu \mathrm{g} / \mathrm{mL}$ each in aqueous sample. $20 \mathrm{mM} \mathrm{NH} \mathrm{NHA}_{4}+5 \%$ HOAc in acetonitrile as the running buffer; $C E$ under $15 \mathrm{kV}$; room temperature $=22^{\circ} \mathrm{C}$; electrokinetic injection at $15 \mathrm{kV}$ for $6 \mathrm{~s}$; $\mathrm{UV}$ detection at $240 \mathrm{~nm}$. 


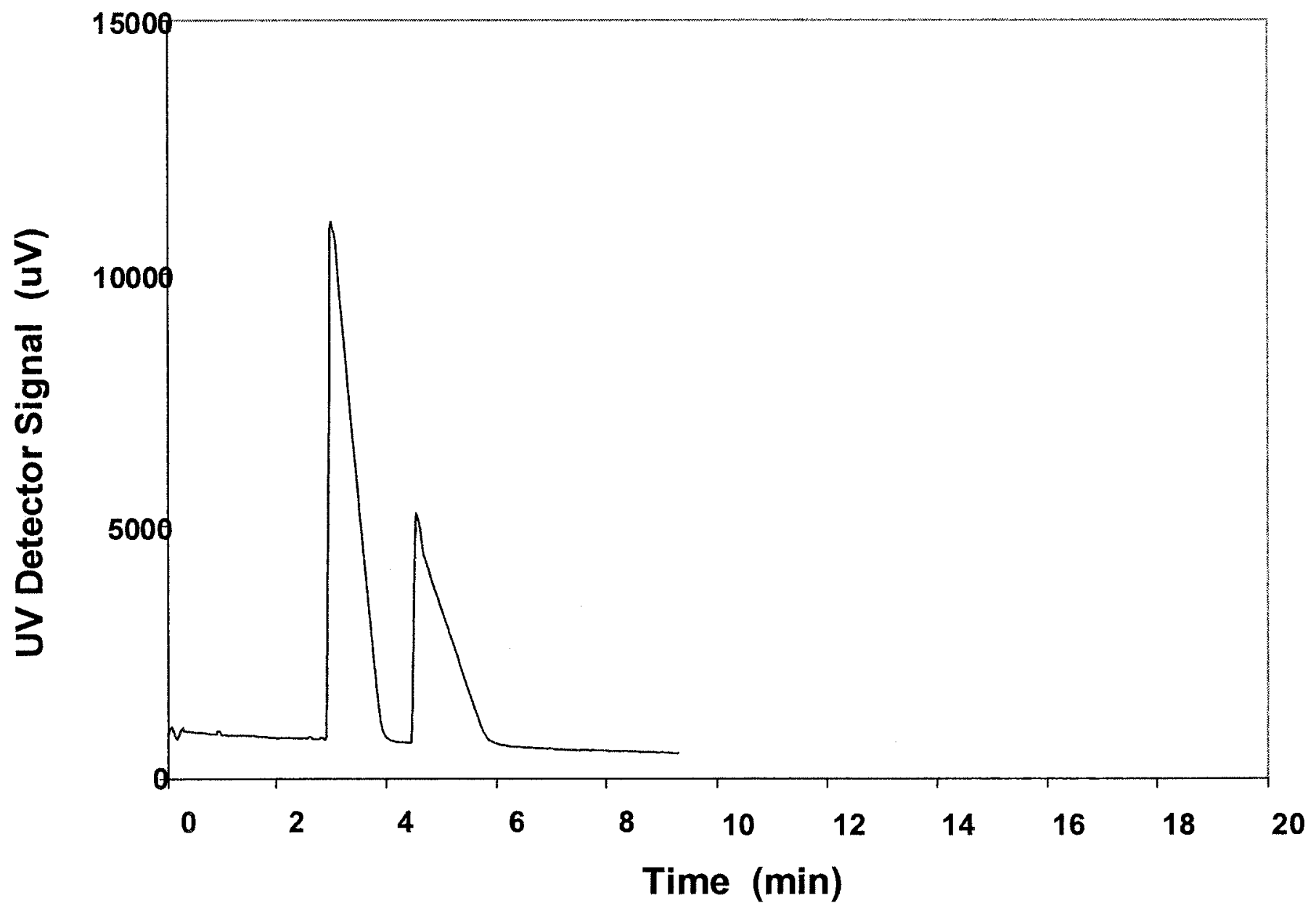

Figure 19 Separation of metformin (at $3.00 \mathrm{~min}$ ) from phenformin (at $4.55 \mathrm{~min}$ ), $60 \mu \mathrm{g} / \mathrm{mL}$ each in aqueous sample. $20 \mathrm{mM} \mathrm{NH} \mathrm{N}_{4} \mathrm{OAc}+5 \% \mathrm{HOAc}$ in water as the running buffer; $\mathrm{CE}$ under $15 \mathrm{kV}$; room temperature $=$ $22^{\circ} \mathrm{C}$; electrokinetic injection at $15 \mathrm{kV}$ for $6 \mathrm{~s}$; $\mathrm{UV}$ detection at 240 nm. 


\subsubsection{Effect on buffer composition}

Non-aqueous CE involves the separation of analytes in a medium composed of organic solvents. The viscosity and dielectric constants of organic solvents affect both sample ion mobility and the level of electroosmotic flow. The use of non-aqueous medium allows additional selectivity options in method development, and it is also valuable for the separation of water-insoluble compounds. Acetonitrile is one of the most commonly used solvents for background electrolytes in non-aqueous CE. It is inexpensive, is easily available at high purity, and has a low absorption at commonly used UV detection wavelengths. Furthermore, combined with other organic solvents or buffer electrolytes, the mobility and separation selectivity could be altered in different ways to greatly expand the range of $\mathrm{CE}$ applications. The lower currents present in nonaqueous solvents allow the use of high electric field strengths and wide bore capillaries, the latter in turn allowing larger sample load. In this way, the detection sensitivity can be further enhanced.

To investigate the effects of buffer solutions, the content of ammonium acetate was varied from 1 to $20 \mathrm{mM}$ in acetonitrile. In these solutions, the acetic acid concentration was maintained between 1 and 5\%. The sample solutions, which contained $60 \mu \mathrm{g} / \mathrm{mL}$ of metformin and phenformin in acetonitrile, were electrokinetically injected at $15 \mathrm{kV}$ for $6 \mathrm{~s}$. Finally, $20 \mathrm{mM}$ ammonium acetate and $5 \%$ acetic acid in acetonitrile were determined to be the non-aqueous medium giving the best separation for the two analytes in terms of resolution and total analysis time. 


\subsubsection{Sample Matrix Effects on CE-UV Peak Areas}

Since metformin and phenformin became protonated in the acidic sample matrix to form cations, high stacking efficiencies were afforded by the modest matrix conductivity during electrokinetic injection. Figure 20 correlates the CE-UV peak areas and conductivity in different sample matrices. These results indicate that methanol $+3 \%$ HOAc was an optimal sample matrix. A more acidic matrix like methanol $+3 \%$ TFA actually made it worse due to its increased conductivity, as illustrated in Figure 21. 


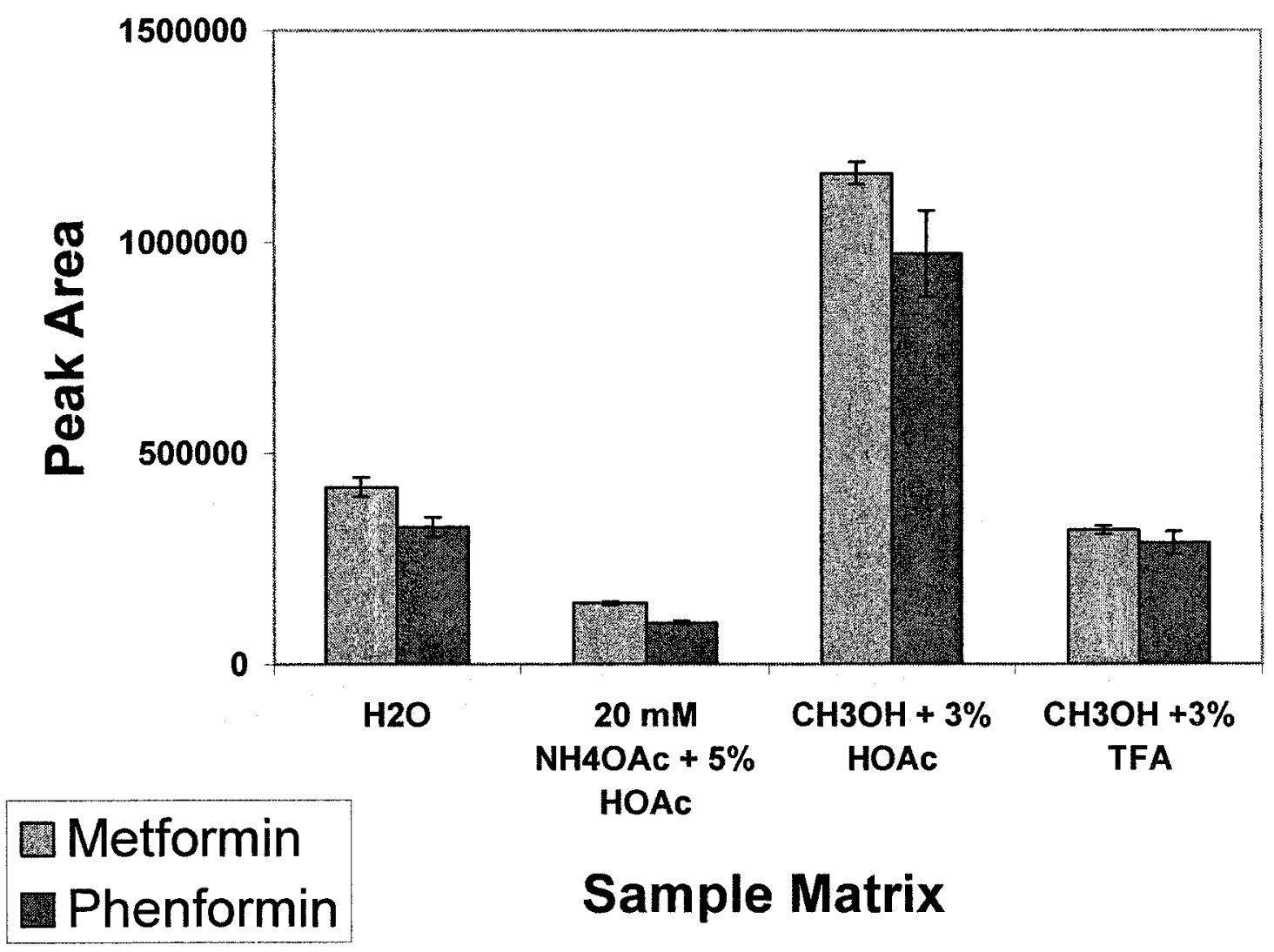

Figure 20. Effect of sample matrix on CE-UV peak area for $60 \mu \mathrm{g} / \mathrm{mL}$ metformin and $60 \mu \mathrm{g} / \mathrm{mL}$ of phenformin. $20 \mathrm{mM}$ ammonium acetate and $5 \%$ acetic acid in acetonitrile as running buffer; $\mathrm{CE}$ under $15 \mathrm{kV}$ at 13 $\mu \mathrm{A}$; room temperature $=22^{\circ} \mathrm{C}$; electrokinetic injection at $15 \mathrm{kV}$ for 6 s; UV detection at $240 \mathrm{~nm}$. 


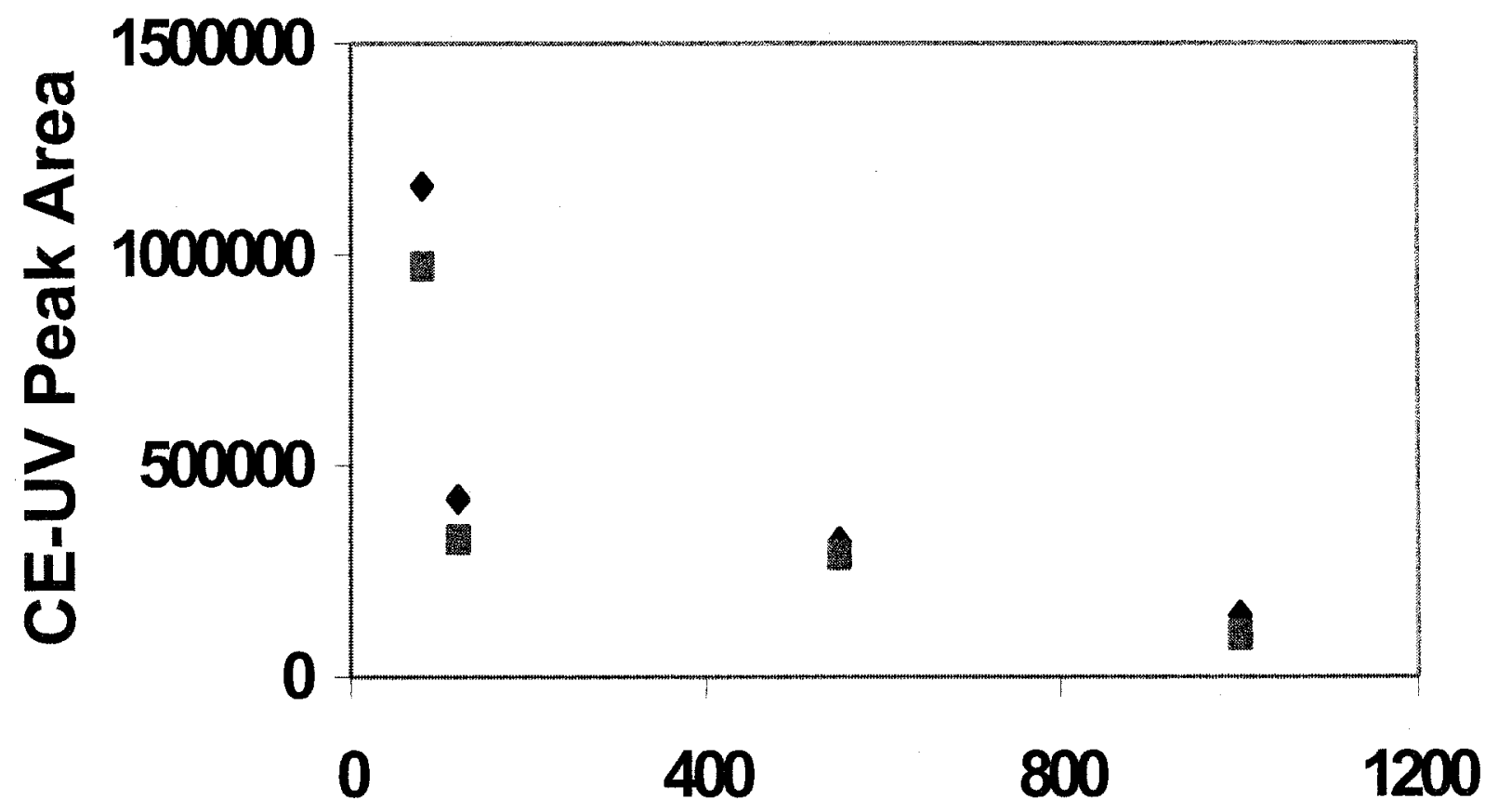

\section{- Metformin 60 ug/mL \\ in Phenformin $60 \mathrm{ug} / \mathrm{mL}$}

\section{Conductivity $(\mu \mathrm{S} / \mathrm{cm})$}

Figure 21. Dependence of CE-UV peak areas for $60 \mu \mathrm{g} / \mathrm{mL}$ metformin and 60 $\mu \mathrm{g} / \mathrm{mL}$ of phenformin on sample conductivity. $20 \mathrm{mM}$ ammonium acetate and $5 \%$ acetic acid in acetonitrile as running buffer; $\mathrm{CE}$ under $15 \mathrm{kV}$ at $13 \mu \mathrm{A}$; room temperature $=22^{\circ} \mathrm{C}$; electrokinetic injection at $15 \mathrm{kV}$ for $6 \mathrm{~s}$; UV detection at $240 \mathrm{~nm}$. 


\subsubsection{Human plasma analysis}

Metformin $\mathrm{HCl}$ tablets contain $500-850 \mathrm{mg}$ of metformin $\mathrm{HCl}$. In addition, each tablet contains the following inactive ingredients: povidone, magnesium stearate and hydroxypropyl methylcellulose (hypromellose) coating. There are a lot of ionic substances and proteins in human plasma. Ineffective stacking and unsatisfactory electropherograms would be obtained unless the plasma samples are deionized. For CE analysis of human plasma and serum, solid phase extraction (SPE) was considered to be a suitable sample preparation technique. The commercially-available C18 SPE cartridge was hence evaluated for binding metformin and phenformin in spiked plasma samples. When metformin and phenformin were next eluted from the cartridge with methanol + $3 \%$ HOAc, a high recovery and precision was achieved for both compounds.

A typical CE analysis of the methanol $+3 \%$ HOAc eluate from C18 SPE of human plasma is demonstrated in Figure 22. No endogenous peak was observed interfering with metformin $(1.75 \mathrm{~min})$ or phenformin $(2.70 \mathrm{~min})$. These results verified that metformin is negligibly bound to plasma proteins. No metabolites or conjugates of metformin could be identified. At the usual clinical doses and dosing schedules of metformin, steady state plasma concentrations of metformin are typically $\sim 1 \mu \mathrm{g} / \mathrm{mL}$. Peak metformin plasma levels would not exceed $5 \mu \mathrm{g} / \mathrm{mL}$, even at maximum therapeutic doses of 850-1500 mg during controlled clinical trials ${ }^{110}$. 


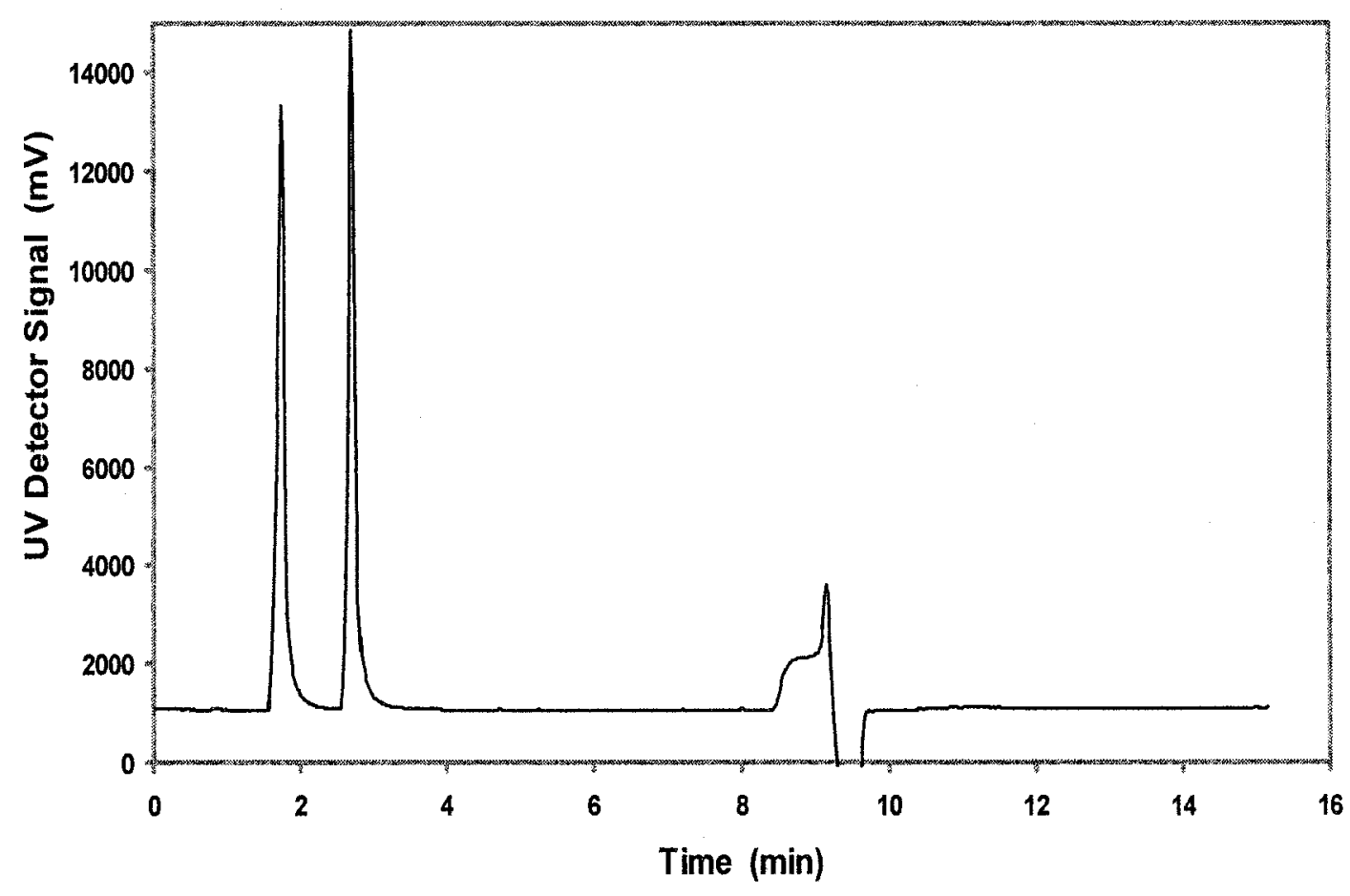

Figure 22. CE analysis of metformin and phenformin from the spiked human plasma

Furthermore, this SPE-CE-UV method was applied to analyze metformin, phenformin and glyburide simultaneously for human plasma. In clinical applications, glyburide is usually combined with metformin for improving glycemic control in patients with type 2 diabetes. As a potential interference, using 3\% acetic acid in methanol as the sample matrix, glyburide (at $6.43 \mathrm{~min}$ ) was totally separated from metformin (at 1.78 $\mathrm{min}$ ) and phenformin (at $2.25 \mathrm{~min}$ ) (Figure 23). These results demonstrated how easy it 
was to separate the neutral glyburide molecules from the positively charged metformin and phenformin cations by $\mathrm{CE}$.

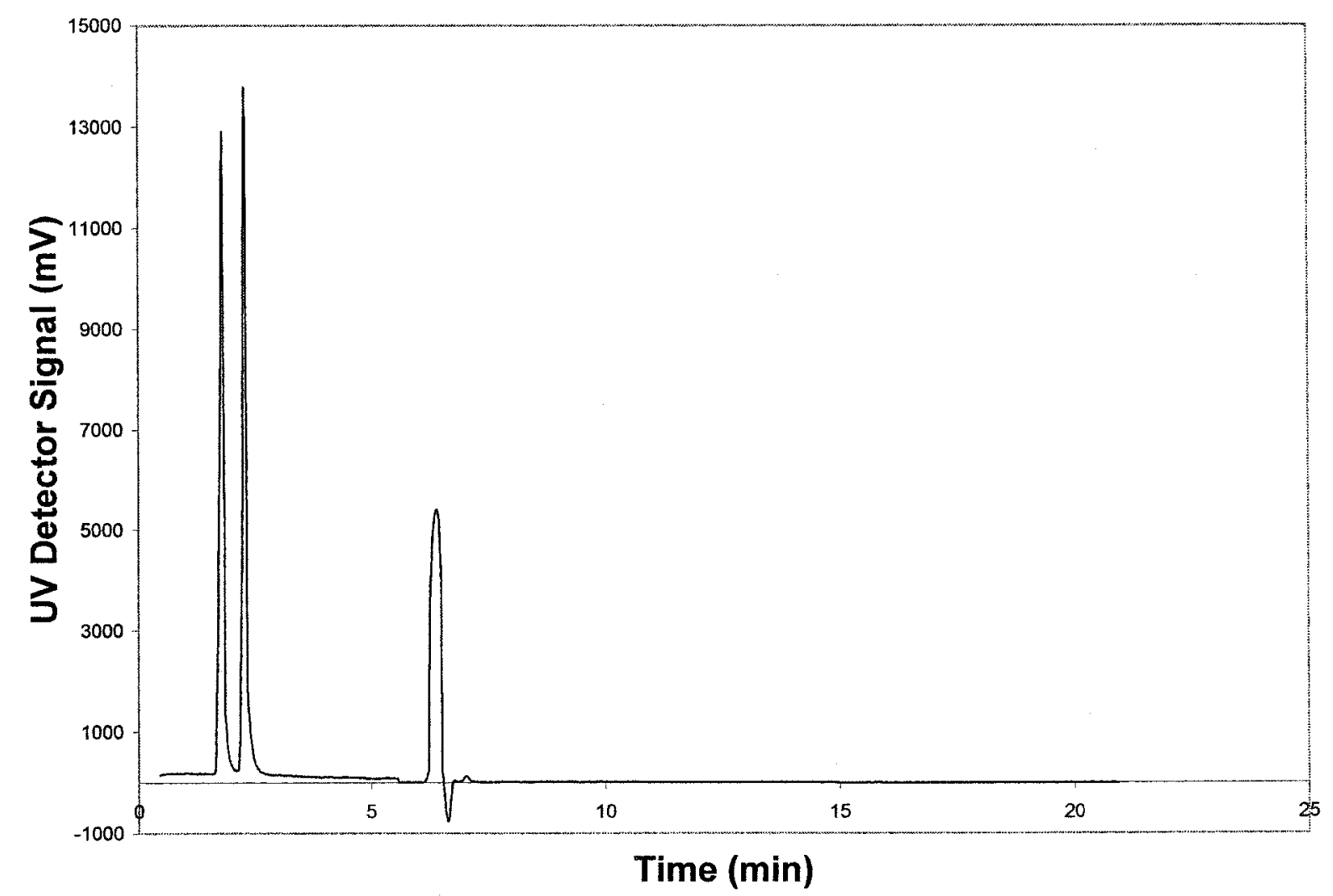

Figure 23. CE analysis of metformin, phenformin and glyburide from the spiked human plasma

\subsubsection{Linear dynamic range and detection limit}

When metformin hydrochloride capsules were administered in a previous study by Song et al. and blood samples were assayed at regular time intervals, the results showed that the concentration of metformin in plasma reached a maximum of $\mathrm{C}_{\max }=1.9$ $\mu \mathrm{g} / \mathrm{mL}$ at $\mathrm{t}_{\max }=3-4$ hours $^{108}$. A recent report by Tache et al. showed the variation of metformin concentration in plasma samples (from twelve healthy human volunteers) as a 
function of time after a single 500-mg oral dose administration. The maximum metformin concentration was $1.2-1.3 \mu \mathrm{g} / \mathrm{mL}$, as found at $2-3$ hours after dose administration ${ }^{111}$. In the present SPE-CE method development, standard calibration curves were constructed over a concentration range from $1 \mu \mathrm{g} / \mathrm{mL}$ to $30 \mu \mathrm{g} / \mathrm{mL}$ metformin and phenformin in plasma. As shown in Figure 23, with an electrokinetic injection time of $6 \mathrm{~s}$ and UV detection at $240 \mathrm{~nm}$, linearity was observed from $1 \mu \mathrm{g} / \mathrm{mL}$ to $15 \mu \mathrm{g} / \mathrm{mL}\left(\mathrm{R}^{2}=0.9600\right.$ and 0.9506 , and slopes $=7106$ and 12300 arbitrary units per $\mu \mathrm{g} / \mathrm{mL}$, for metformin and phenformin respectively). Significant scattering of data points appeared between $15 \mu \mathrm{g} / \mathrm{mL}$ to $30 \mu \mathrm{g} / \mathrm{mL}$. Hence the method would be best used for monitoring metformin and phenformin between $15 \mu \mathrm{g} / \mathrm{mL}$ to $1 \mu \mathrm{g} / \mathrm{mL}$ in human plasma. When the electrokinetic injection time was increased from $6 \mathrm{~s}$ to $36 \mathrm{~s}$, the metformin and phenformin peak areas increased linearly $\left(\mathrm{R}^{2}=0.9804\right.$ and 0.9650 , respectively). Further increase of injection time to $42 \mathrm{~s}$ began to cause splitting of the metformin peak. Using an optimal injection time of $36 \mathrm{~s}$, progressive dilution of the $1 \mu \mathrm{g} / \mathrm{mL}$ plasma sample with methanol $+3 \%$ HOAc for CE-UV analysis demonstrated improvement in detection limits down to $12 \mathrm{ng} / \mathrm{mL}$ for metformin and $6 \mathrm{ng} / \mathrm{mL}$ for phenformin. However, both precision and linearity were compromised. 

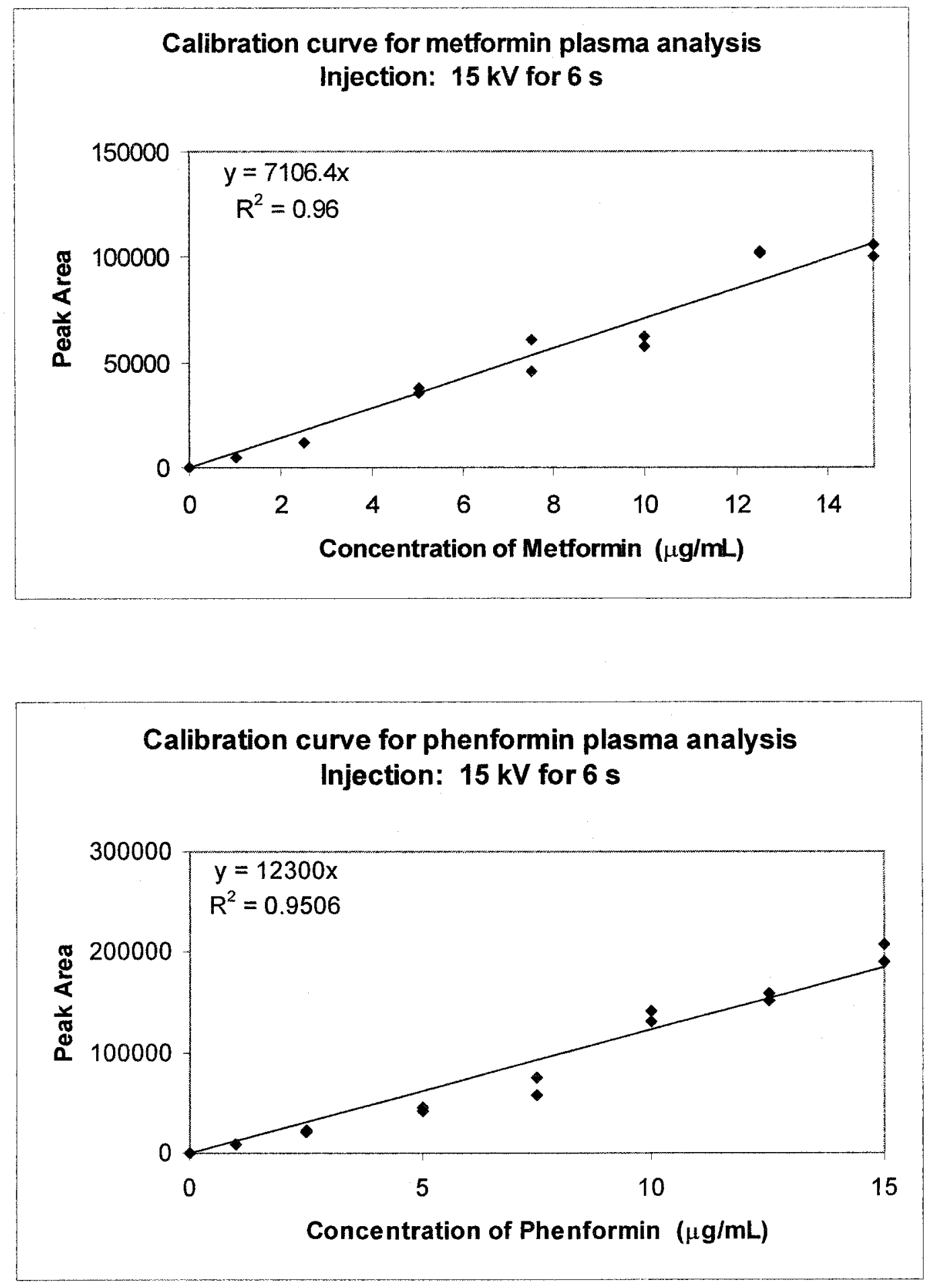

Figure 23. CE-SPE calibration curves for plasma analysis of metformin and phenformin 


\subsubsection{Internal standard method}

Alternatively, the internal standard method was evaluated with an electrokinetic injection time of $6 \mathrm{~s}$. By plotting the ratio of metformin and internal standard (phenformin) peak areas versus metformin concentration, a straight line was obtained in the concentration range of 0.2 to $3.5 \mu \mathrm{g} / \mathrm{mL}$. The limit of detection was $0.1 \mu \mathrm{g} / \mathrm{mL}(\mathrm{S} / \mathrm{N}$ $=3)$. At the limit of quantification, an acceptable RSD of $20 \%(n=5)$ was obtained. 


\section{CHAPTER IV}

\section{CONCLUSIONS}


MISPE has become widely used for analyte preconcentration and sample matrix cleanup. To date MISPE methods are available for the rapid screening of many drugs (including aminopyridine, bupivacaine, cephalexin, darifenacin, 7-hydroxycoumarin, nicotine, pentamidin, propranolol, sameridine, tamoxifen, and theophylline $)^{112}$. Metformin is more basic than all of these drugs previously reported, except for propranolol, which has a higher $\mathrm{pKa}$ of $13.8 \pm 0.2$ but a smaller number of three functional groups for binding interactions ${ }^{113}$. In the present study, metformin was chosen as a challenging molecule (with a high $\mathrm{pKa}$ of $13.1 \pm 0.5$ and a large number of five functional groups for binding interactions) to re-establish generic rules that would enable speedy development of MISPE-DPE-FPE methods. A new MIP with good binding and selectivity characteristics for metformin was synthesized. Specific recognition cavities allowed rebinding of metformin in $\mathrm{CH}_{3} \mathrm{CN}$ based on molecular shape, hydrogen bonding, ionic attraction and hydrophobic interactions. A working range was mapped with respect to sample solvent and buffer compositions. These results highlighted the importance of optimization, in the breadth of potential assay conditions that could be employed for MISPE, without any modification of the mobile phase. A robust MISPE--DPE-FPE method was successfully developed for the determination of metformin by UV detection. A special reagent, 5\% picric acid in acetonitrile, has demonstrated great success in DPE to eliminate phenformin. This MISPE-DPE-FPE method merits consideration for applications in pharmaceutical and biomedical analysis. Currently, the MISPE-DPE-FPE method is being applied in our research laboratory for the direct screening of metformin in human plasma samples. Modern applications in pharmaceutical and biomedical analysis could study the effects of metformin on fatal and nonfatal lactic acidosis in type 
2 diabetes mellitus ${ }^{114}$, the reproductive system in patients with polycystic ovary syndrome ${ }^{115}$, human ovarian steroidogenesis ${ }^{116}$, as well as body mass index, menstrual cyclicity, and ovulation induction in women with polycystic ovary syndrome ${ }^{117}$.

Furthermore, the simultaneous determination of metformin, phenformin and other drug compounds in human plasma has been demonstrated by capillary electrophoresis with solid phase extraction. The present SPE-CE method is unique in that rapid separation of metformin and phenformin from other drug compounds is the merit of judicious optimization based on the basic and acidic functionalities of various SPE and CE steps. CE analysis was best performed using a non-aqueous buffer, acetonitrile +25 $\mathrm{mM}$ ammonium acetate $+5 \%$ acetic acid. This buffer afforded rapid separation of metformin from phenformin within $3 \mathrm{~min}$, depending on the sample matrix composition. Potential applications of this newly developed SPE-CE methodology may fall into two pharmaceutical and biomedical analysis areas. First, the absolute bioavailability of a 500-mg metformin hydrochloride tablet given under fasting conditions is approximately $50-60 \%$. Studies using single oral doses of metformin tablets, from $500 \mathrm{mg}$ to $2550 \mathrm{mg}$, have indicated that there is a lack of dose proportionality with increasing doses, which is due to decreased absorption rather than an alteration in elimination. Food decreases the extent of and slightly delays the absorption of metformin, compared to the same tablet strength administered fasting. Second, intravenous single-dose studies in normal subjects demonstrate that metformin is excreted unchanged in the urine and does not undergo hepatic metabolism (i.e., no metabolites have been identified in humans) nor biliary excretion. The clinical relevance of these two related areas is important, and further investigation would be greatly facilitated by the present SPE-CE methodology. 
1 G. Wulff, A. Sarhan, Angew. Chem., 1972, 84, 364.

2 K. Mosbach, et al., ACS Symp. Ser., 1998, 7.3, 29-48.

3 S.A. Piletsky, et al., J. Membr. Sci., 1999, 157, 263.

$4 \quad$ M.W. polyakov, Zh. Fiz. Khimill., 1931, 2, 799.

$5 \quad$ F.H. Dickey, Proc. Nat. Acad. Sci., 1949, 35, 227.

6 F.H. Dickey, J. Phys. Chem., 1955, 59, 695.

7 T. Takagishi, I.M. Klotz, Biopolymers, 1972, 11, 483.

8 R. Arshady, K. Mosbach, Macromol. Chme., 1981, 182, 687.

9 P.K. Dhal, F.H. Arnold, J. Am. Chem. Soc., 1991, 113, 7417.

10 M. Kempe, K. Mosbach, J. chromatogr. A, 1995, 694, 3.

11 O. Ramstrom, R. J. Ansell, Chirality, 1998, 10, 195.

12 J. Olsen, P. Martin, I.D. Wilson, Anal. Commun., 1998, 35, 13H-14H.

13 L.I. Andersson, K. Mosbach, in: C.P. Price, D.J. Newman (Eds.), Principles and Practice of Immunoassay, $2^{\text {nd }}$ Ed, Macmillan Reference Ltd, London, UK, 1997, pp. 139.

14 L. Schweitz, L.I. Andersson, S. Nilsson, J. Chromatogr. A, 1998, 817, 5.

15 B. Sellergren, K.J. Shea, J. Chromatogr., 1993, 635, 31.

16 Y. Chen, M. Kele, P. Sajonz, B. Sellergren, G. Guiochon, Anal. Chem., 1999, 71, 928.

17 L.I. Andersson, J. Chromatogr. B Biomed. App1., 2000, 739, 163.

18 D. Kriz, K. Mosbach, Anal. Chim. Acta, 1995, 300, 71.

19 D. Kriz, O. Ramstrom, K. Mosbach, Anal. Chem., 1997, 69, 345A.

20 S. Kroger, A.P.F. Truner, K. Mosbach, K. Haupt, Anal. Chem., 1999, 71, 3698. 
21 G. Wulff, T. Gross, R. Schonfeld, Angew. Chem. Int. Ed. Engl., 1997, 36, 1961.

22 C.F. Poole, S.K. Poole, Chromatography today, Elsevier, Amsterdam, 1991.

23 M. Vanderlaan, L.H. Stanker, B.E. Watkins, D.W. Roberts, Immunoassays for Trace Chemical Analysis; Monitoring Toxic Chemicals in Humans, Food, and the Environment, American Chemical Society, Washington D.C., 1991.

24 J.O. Nelson, S.E. Karu, R.B. Wong, Immunoanalysis of Agrochemicals, ACS Symposium Series, 586, American Chemical Society, Washington, 1995.

25 T.E. Mallouk, K.J. Harrison, Interfacial design and chemical sensing, ACS Symposium Series 561, American Chemical Society, Washington D.C., 1994.

26 B. Sellergren, Anal. Chem., 1994, 66, 1578.

27 W.M. Mullett, E.P.C. Lai, Anal. Chem., 1998, 70, 3636.

28 M.T. Muldoon, L.H. Stanker, Anal. Chem. 1997, 69, 803.

29 M. Walshe, J. Howarth, M.T. Kelly, R O'Kennedy, M.R. Smyth, J. Pharm. Biomed. Anal., 1997, 16, 319.

30 A. Aander, P. Findlay, T. Renner, Bl Sellergren, A. Swietlow, Anal. Chem., 1998, $70,3303$.

31 L.I. Andersson, A. Paprica, T. Arvidsson, Chromatographia, 1997, 46, 57.

32 W.M. Mullett, E.P.C. Lai, Microchem. J., 1999, 61, 143.

$33 \mathrm{http}: / /$ www.rxlist.com/cgi/generic/metformi.htm

34 C.J. Glueck, P. Wang, R. Fontaine, T. Tracy, L. Sieve-Smith, J. Adolescent Health, 29 (2001) 160.

$35 \mathrm{http}: / /$ www.aegis.com/pubs/drugs/267.html

36 http://www.rxlist.com/cgi/generic2/glucovance_cp.htm 
37 D.J. Chisholm, L.V. Campbell, E.W. Kraegen, Clinical and Experimental Pharmacology and Physiology, 1997, 24, 782.

$38 \mathrm{http} / /$ www.fda.gov/cder/foi/label/2001/20357s22lbl.pdf.

39 K.H. Yuen, K. K. Peh, J. Chromatogr. B, 1998, 710, 243.

40 O. Vesterqvist, F. Nabbie, B. Swanson, J. Chromatogr. B, 1998, 716, 299.

41 C.L. Cheng, C.H. Chou, J. Chromatogr. B, 2001, 762, 51.

42 A.R. Bonfigli, S. Manfrini, F. Gregorio, R. Testa, I. Testa, G. De Sio, G. Coppa, Therapeutic Drug Monitoring, 1999, 21, 330.

43 F. Tache, V. David, A. Farca, A. Medvedovici, Microchem. J., 2001, 68, 13.

44 M. Zhang, G.A. Moore, M. Lever, S.J. Gardiner, C.M.J. Kirkpatrick, E.J. Begg, J. Chromatogr. B , 2002, 766, 175.

45 J.Z. Song, H.F. Chen, S.J. Tian, Z.P. Sun, J. Chromatogr. B, 2002, 708, 277.

46 Y.G. Liu, G.Z. Li, Chinese J. Anal. Chem., 2001, 29, 1027.

47 S.S.M. Hassan, W.H. Mahmoud, M.A.F. Elmosallamy, A.H.M. Othman, Anal. Chim. Acta, 1999, 378, 299.

48 Calculated using Advanced Chemistry Development (ACD) Software Solaris V4.67.

49 G. De Groot, R.A.A. Maes, B. Sangster, A.N.P. Van Heijst, L.F. Verdonck, J. Anal. Toxicol., 1980, 4, 281.

$50 \quad$ K.H. Yuen, K.K. Peh, J. Chromatogr. B, 1998, 710, 243.

51 O. Vesterqvist, F. Nabbie, B. Swanson, J. Chromatogr. B, 1998, 716, 299.

52 C.L. Cheng, C.H. Chou, J. Chromatogr. B, 2001, 762, 51.

53 A. Zarghi, S.M. Foroutan, A. Shafaati, A. Khoddam, J. Pharmaceut. Biomed. 
Anal., 2003, 31, 197.

54 S. Hjerten, Chromatogr. Reviews, 1967, 9, 122.

55 R.P. Oda, V.J. Bush, V.J. Landers, Handbook of Capillary Electrophoresis, CRC

Press, Boca Raton, FL, 1996, 639.

56 H.H. Lauer, D. McManigill, Anal. Chem., 1986, 58, 166.

57 K.C. Chan, G.M. Janini, G.M. Muschik, H.J. Issaq, J. Chromatogr., 1993, 622, 269.

58 G.M. Janini, G.M. Muschik, H.J. Issaq, Electrophoresis, 1996, 17, 1575.

59 W.R. Jones, P. Jandik, J. Chromatrogr., 1992, 608, 385.

60 G.M. Janini, G.M. Muschik, H.J. Issaq, J. Capil. Elecrophor., 1994, 1, 116.

61 R. K. Gilpin, L. A. Pachla, Anal.Chem., 1999, 71, 217 R.

62 J. Caslavska, S. Licnhard, W. Thormann, J. Chromatogr., 1993, 638, 335.

63 (a) E.P.C.Lai, S.G.Wu, Anal.Chim.Acta, 2003, 481, 65.

(b) E.P.C. Lai, S.G. Wu, Anal. Chim. Acta, 2003, 481, 177.

64 J.Z. Song, H.F. Chen, S.J. Tian, Z.P. Sun, J. Chromatogr. B, 1998, 708, 277.

65 H. Siren, T. Hiissa, Y. Min, Analyst, 2003, 25, 1561.

66 R. Huupponen, P. Ojala-Karlsson, J. Rouru, M. Koulu, J. Chromatogr., 1992, $583,270$.

67 M. H. Sbraham, P.P. Duce, D.V. Prior, D. G. Barrat, J.J. Morris, P.J. Taylor, J. Chem. Soc. Perkin Trans. II, 1989, 1355.

68 G. Albrecht, G. Zundel, Z. Naturforsch., 1984, 39a, 986.

69 S.H. Cheong, S. McNiven, A. Rachkov, R. Levi, K. Yano, I. Karube, Macromolecules, 1997, 30, 1317. 
70 J. Matsui, Y. Miyoshi, T. Takeuchi, Chem. Lett., 1995, 11, 1007.

71 R. Kataky, P.M. Kelly, D. Parker, A.F. Patti, J. Chem. Soc. Perkin Trans., 1994, 2,2381 .

72 C. Dauwe, B. Sellergren, J. Chromatogr. A, 1996, 753, 191.

73 D. Spivak, M. A. Gilmore and K. J. Shea, J. Am. Chem. Soc., 1997, 119, 4388.

74 K. Hosoya, K. Yoshizako, K. Kimata, N. Tanaka and J. Haginaka, J. Chromatogr., $1997,18,232$.

75 C. Yu and K. Mosbach, J. Org. Chem., 1997, 62, 4057.

76 D. Spivak, M.A. Gilmore, K.J. Shea, J. A. Chem. Soc., 197, 119, 4388.

77 B. Sellergren, K.J. Shea, J. Chromatogr., 1993, 635,31.

78 J. Bandrup, E.H. Immergut, Polymer handbook, Wiley, New York, 1989.

79 G.Wulff, Angew. Chem., Int. Ed. Engl., 1995, 34, 1812.

80 M. Kempe, Anal. Chem., 1996, 68, 1948.

81 L. I. Andersson, A. Paprica and T. Arvidsson, Chromatographia, 1997, 46, 57.

82 D. Stevenson, Trends Anal. Chem., 1999, 18, 154

83 R. F. Venn and R. J. Goody, Chromatographia, 1999, 50, 407.

84 P. Martin, I. D. Wilson, D. E. Morgan, G. R. Jones and K. Jones, Anal. Commun., $1997,34,45$.

85 E.P.C. Lai, S.G. Wu, Anal. Chim. Acta, 2003, 481, 165.

86 F. Dickert and O. Hayden, "Molecularly Imprinted Polymers", B. Sellergren (ed.), Elsevier, Amsterdam, Netherlands, 2001, Chapter 21, p. 521.

87 C. Baggiani, F. Trotta, G. Giraudi, C. Glovannoli, A. Vanni, Anal. Commun., $1999,36,263$. 
88 J.G. Karlsson, L.I. Andersson, I.A. Nicholls, Anal. Chim. Acta, 2001, 435, 57.

89 B. Sellergren, Anal.Chem., 1994, 66, 1578.

90 M.T. Muldoon, L.H. Stanker, Anal. Chme., 1997, 69, 803.

91 J. Matsui, M. Okada, M. Tsuruoka, T. Takeuchi, Anal. Commun., 1997, 34, 85.

92 Calculated using Advanced Chemistry Development (ACD) Software Solaris V4.67, http://www.cas.org/SCIFINDER/SC

93 L.I. Andersson, M. Abdel-Rehim, L. Nicklasson, L. Schweitz, S. Nilsson. Chromatogr. Suppl. 2003, 55, p. S65.

94 L.I. Andersson, M. Abdel-Rehim, L. Nicklasson, L. Schweitz, S. Nilsson, Chromatogr., 2002, Supp1. 55, S65.

95 W.M. Mullett, E.P.C. Lai, J. Pharm. Biochem. Anal., 1999, 21, 835.

96 W.M. Mullett, E.P.C. Lai, Microchem. J., 1999, 61, 143.

97 W.M. Mullett, E.P.C. Lai, B. Sellergren, Anal. Comm., 1999, 36, 217.

98 W.M. Mullett, M.F. Dirie, E.P.C. Lai, H. Guo, X. He, Anal. Chim. Acta, 2000, 414, 123.

99 A.K. Jana, S.K. Mukhopadhyayb, B.B. Bhowmik, Spectrochim. Acta A, 2002, 8, 1697.

100 http://www.stanford.edu/ -travisw/pKas.pdf, 2003.

101 http://www.cem.msu.edu/ reusch/VirtualText/acidity2.htm, 2003.

$102 \mathrm{http} / /$ www.cas.org/SCIFINDER/SCHOLAR, 2003.

103 S.H. el-Mossalamy, A.S. Amin, A.A. Khalil, Ann. Chim., 2002, 92, 749.

104 http://www.lwc.edu/staff/pbarber/C121/c121lec5.htm , 1999.

105 E.P.C. Lai, S.Y. Feng, Microchem. J., 2003, 75, 159. 
106 K.H. Yuen, K.K. Peh, J. Chromatogr. B, 1998, 710, 243.

107 M. Zhang, G.A. Moore, M. Lever, S.J. Gardiner, C.M.J. Kirkpatrick, E.J. Begg, J. Chromatogr. B, 2001, 766, 175.

108 J.Z. Song, H.F. Chen, S.J. Tian, Z.P. Sun, J. Chromatogr. B, 1998, 708, 277.

109 H. Siren, T. Hiissa, Y. Min, Analyst, 2000, 125, 1561.

110 A.J. Scheen, Clinical Pharmacokinetics, 1996, 30, 359.

111 F. Tache, V. David, A. Farca, A. Medvedovici, Michrochem. J., 2001, 68, 13.

112 N. Masque, R.M. Marce, F. Borrull, TrAC, 2001, 20, 477.

113 P. Martin, I.D. Wilson, G.R. Jones, J. Chromatogr. A, 2000, 889, 143.

114 http://www.cochrane.org/Cochrane/revabstr/ab002967.htm, 2003.

115 M.F. Costello, J.A. Eden, Fertil. Steril., 2003, 79, 1.

116 R. Mansfield, R. Galea, M. Brincat, D. Hole, H. Mason, Fertil. Steril., 2003, 79, 956.

117 A. Derek, M.D. Haas, R. Bruce, M.D. Carr, R. George, M.D. Attia, Fertil. Steri1., $2003,79,469$. 